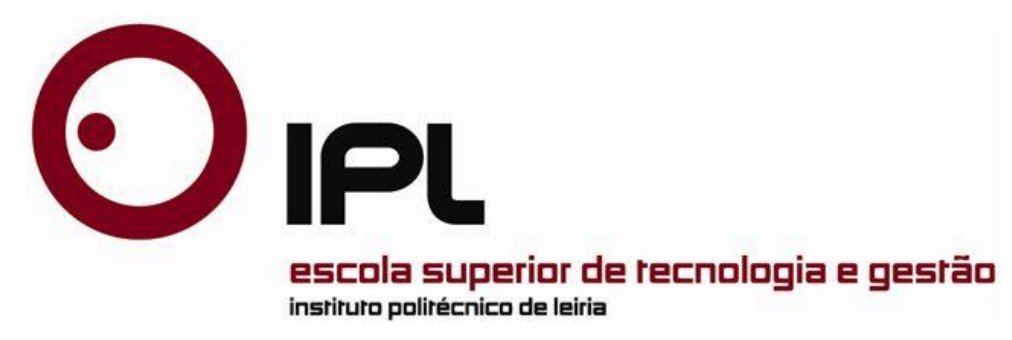

Master thesis in

Product Design Engineering

\title{
Optimization of a Perfusion Bioreactor for Tissue
}

Engineering

Dino Miguel Fernandes Freitas 


\title{
Oipt \\ escala superiar de recnologia e gestäa \\ instiruro polirécnico de leiria
}

\author{
Master thesis in
}

Product Design Engineering

\section{Optimization of a Perfusion Bioreactor for Tissue Engineering}

\section{Dino Miguel Fernandes Freitas}

Master thesis realized under the supervision of Doctor Henrique Amorim Almeida Professor at the School of Technology and Management of the Polytechnic Institute of Leiria. 


\section{To my Family and Ritinha}


"Que me pode o Destino conceder

Melhor que o lapso sensual da vida

Entre ignorâncias destas?

Sábio deveras o que não procura, Que, procurando, achara o abismo em tudo E a dúvida em si mesmo. Pomos a dúvida onde há rosas. Damos

Quase tudo do sentido a entendê-lo E ignoramos, pensantes.

Terei razão, se a alguém razão é dada” Ricardo Reis “Razão” (Fernando Pessoa) 


\section{Agradecimentos}

Ao Professor Doutor Henrique Almeida, meu orientador e grande amigo, a quem agradeço a sua generosa paciência, exigência e ambição. Os contínuos estímulos para prosseguir este trabalho e o contínuo apoio moral e cientifico foram sempre determinantes para que continuasse a desenvolver esta dissertação. Agradeço profundamente a amizade com que me prendou durante todos estes anos do meu percurso académico e profissional, que revelam uma pessoa dedicada, competente e honesta.

Ao Professor Doutor Paulo Bártolo, meu co-orientador, meu amigo, meu chefe e meu exemplo pessoal e profissional. Palavras são parcas para descrever o meu profundo agradecimento não só pelo constante apoio profissional e académico bem como pessoal. Agradeço todas as orientações científicas que me deu na realização deste trabalho bem como todo o rigor e contributo crítico ao longo de toda a minha vida profissional e académica. A sua constante disponibilidade para me auxiliar tornam todas as minhas etapas sempre mais fáceis de superar. Agradeço a todos os meus familiares e amigos por todo o apoio, contributo e incentivo prestado e por estarem sempre presentes quando mais preciso e principalmente por compreenderem os meus momentos de constante ausência. Agradeço especialmente ao André Vieira, Joana Maia, João Pascoal, Carolina Luís, Paulo Carvalho, Tânia Luís, Sérgio Santos, Vítor Hugo, Jair Cruz e Ruben Santos por estarem sempre presentes, mesmo sem pedir nada em troca (às vezes).

À Ana Rita por todo o apoio e motivação em todo o meu percurso académico e profissional. Foi graças à sua extrema paciência e compreensão, especialmente quando mais tive ausente, e também do seu contínuo apoio ao longo de todos estes anos que foi possível chegar até aqui. Acreditou sempre no meu valor e deu-me sempre a força necessária para ir superando os meus obstáculos. Obrigado.

Ao Alexandre, meu irmão e meu melhor amigo. Por me apoiar incondicionalmente e perdoar todos os meus momentos de ausência. Por me apoiar mesmo sem palavras. Agradeço a boa disposição e acima de tudo o amor de “maninho” com que me presenteia diariamente. 
Por último, aos meus Pais, principalmente por estarem presentes. Por me apoiarem incondicionalmente e darem-me a força necessária para continuar a lutar pelo que quero. Por me alegrarem e animarem nos momentos mais difíceis e por nunca me deixarem baixar os braços acreditando sempre em mim e principalmente por me apoiarem no percurso que escolhi. Agradeço há minha mãe pela amizade de uma amiga e o amor de uma mãe. Agradeço ao meu pai pelos sacrifícios e determinação nas vitórias por quem ama.

A todos, o meu mais sincero agradecimento. 


\section{Resumo}

A regeneração de tecidos e/ou de órgãos é a solução para colmatar a falta de órgãos e tecidos, tanto actualmente como num futuro próximo. Este domínio da medicina tem crescido bastante e tem substituído algumas terapias convencionais. Os seus principais objectivos são restaurar, manter ou melhorar as funções dos tecidos. A Engenharia de Tecidos utiliza um dador para a recolha de tecido que é depois desassociado em células individuais. Estas células podem ser directamente implantadas, ou influenciadas a proliferar para um tecido organizado. Esta última situação pode ocorrer dentro de uma estrutura 3D vascularizada, conhecida como scaffold. Depois da implementação das células, esta estrutura pode ser inserida num bioreactor de perfusão permitindo a proliferação e diferenciação celular antes da implementação. Por forma a optimizar o processo de cultura in vitro, está em curso o desenvolvimento de um bioreactor de perfusão, sendo que uns dos pontos críticos assentam nas entradas e saídas do fluido na câmara de cultura.

O presente trabalho tem por objectivo avaliar por meio de métodos numéricos o fluxo do fluido obtido no interior da câmara de cultura por forma a optimizar o processo de proliferação celular.

Palavras-chave: Scaffolds, Bioreactor de Perfusão, Simulação Numérica, Optimização Computacional, Comportamento Vascular, Cultura Celular, Engenharia de Tecidos. 


\section{Abstract}

Tissue engineering aims to repair and regenerate damaged tissues by developing biological substitutes mimicking the natural extracellular matrix. It is evident that scaffolds, being a tridimensional matrix, are of extreme importance providing the necessary support for the new tissue. This new tissue is cultivated in vivo or in vitro in a bioreactor in which is placed the scaffold with cells. In order to control the cell culture process inside of a bioreactor it is essential to know the fluid flow inside and around the scaffold in order to know witch parameters must be controlled in order to obtain optimum conditions to cell culture. The wall shear stress must be adequate to the tissue to be cultivated, i.e., bone, muscle, cartilage and it is known that a proper stimulus is necessary to improve the cell proliferation inside the scaffold.

This work considers a novel perfusion bioreactor and it is intended to optimize the fluid flow within the chamber and the scaffold by assessing the turbulence kinetic energy, the velocity and the wall shear stress.

Keywords: Scaffolds, Perfusion Bioreactor, Numerical Simulation, Computational Optimization, Vascular Behaviour, Cell Culture, Tissue Engineering. 


\section{Index of Figures}

Figure 1 Multidisciplinary nature of the tissue engineering field.

Figure 2 Scaffold-based strategies for engineering personalized bone grafts (adapted from Bhumiratana and Vunjak-Novakovic, 2012).

Figure 3 Tissue engineering process involving the cell seeding on scaffolds, in vitro culturing and patient implantation, adapted from Bartolo et al., (2012) and Liu and Czernuszka (2006)..................5

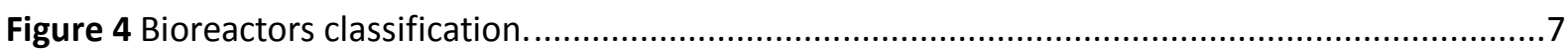

Figure 5 Flowchart of the topics and objectives that are addressed in the thesis...............................9

Figure 6 Mesenchymal stem cells differentiation (Caplan and Bruder, 2001).................................15

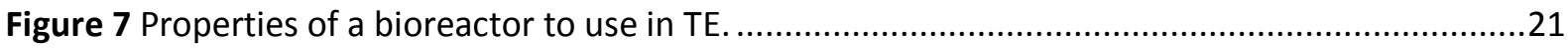

Figure 8 Example of static culture systems a) T-flasks, b) Well plates and c) Petri dishes...................23

Figure 9 Examples of Spinner flasks from Chemglass ${ }^{\circledR}$ (left) and Capitol Scientific ${ }^{\circledR}$ (right)................25

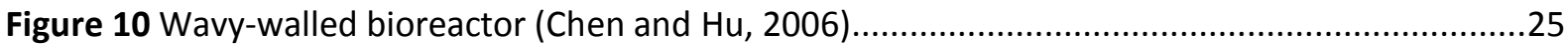

Figure 11 Schematic of a stirred vessel (left) (Redondo, 2014) and a stirred bioreactor from

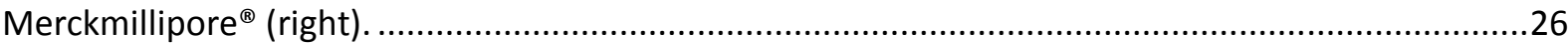

Figure 12 Rotating wall vessel (RWV) bioreactor from Synthecon ${ }^{\circledR}$............................................28

Figure 13 Illustration of a STLV and HARV bioreactor (Ghosh and Kaplan, 2008) ............................29

Figure 14 Schematic of a Rotating Shaft Bioreactor (Chen et al., 2004)..........................................30

Figure 15 Biaxial Rotating Bioreactor (Singh et al., 2005) ........................................................30

Figure 16 Schematic of a bioreactor that apply controlled mechanical forces (Martin et al., 2004)....32

Figure 17 Schematic illustration of a bioreactor assembly that demonstrates (a) perfusion flow and (b) hydrostatic compression (Orr and Burg, 2008)

Figure 18 Illustration of a (a) perfusion bioreactor and (b) an example of a perfusion bioreactor (Chen and $\mathrm{Hu}, 2006$; C.I.T., 2014).

Figure 19 Bidirectional perfusion bioreactor in a U tube design (Wendt et al., 2003)

Figure 20 Basic hollow fibre bioreactor design and the HF Primer ${ }^{\mathrm{TM}}$ small-scale bioreactor (Hirschel et al., 2011). ..36

Figure 21 Schematic of the fluidized bed or packed bed bioreactor (Cabrita et al., 2003)..................37

Figure 22 Schematic diagram of the pulsatile flow bioreactor system (Cooper et al., 2007).............37

Figure 23 Classification of the rheological behavior of fluids (adapted from Nguyen and Choi, 2012).

Figure 24 Model and measures of the perfusion bioreactor.................................................46

Figure 25 Model of the perfusion bioreactor demonstrating the four pistons configurations, a) OpenOpen, b) Open-Close, c) Close-Open and d) Close-Close positions.

Figure 26 Membrane configuration to redirect the fluid flow where a) is the Parallel Flow configuration, b) the Inwards Flow configuration and c) the Outward Flow configuration. 
Figure 27 Design of the scaffold used in this work, a) detail of the filament pattern; b) lateral view of the scaffold

Figure 28 Computational simulation schematic. ..................................................................49

Figure 29 Velocity results for the three input velocities without scaffold.......................................52

Figure 30 V1 velocity streamlines without scaffold for a) the OF-OC and b) the IF-OC.....................52

Figure $31 \mathrm{~V} 2$ velocity streamlines without scaffold for a) the OF-OC and b) the PF-CC. ...................53

Figure 32 V3 velocity streamlines without scaffold for a) the OF-OC and b) the PF-CC. ..................53

Figure 33 Velocity results for the three input velocities with scaffold. .........................................5.

Figure $34 \mathrm{~V} 1$ velocity streamlines with scaffold for $\mathrm{a}$ ) the OF-CC and $\mathrm{b}$ ) the PF-OO. ......................54

Figure 35 V2 velocity streamlines with scaffold for a) the OF-CC and b) the IF-OC.........................55

Figure 36 V3 velocity streamlines with scaffold for $a)$ the OF-CO and $b$ ) the IF-OC. .......................56

Figure 37 Turbulence results for the three input velocities without scaffold..................................56

Figure 38 V1 turbulence results without scaffold for $a)$ the IF-CC and b) the PF-CC. ......................57

Figure 39 V2 turbulence results without scaffold for a) the IF-OO and b) the PF-CC. .....................57

Figure 40 V3 turbulence results without scaffold for a) the IF-OC and b) the PF-CC.......................58

Figure 41 Turbulence results for the three input velocities with scaffold.......................................58

Figure 42 V1 turbulence results with scaffold for a) the IF-CC and b) the PF-CC.........................59

Figure 43 V2 turbulence results with scaffold for a) the IF-OO and b) the PF-CC...........................59

Figure $44 \mathrm{~V} 3$ turbulence results with scaffold for a) the IF-CO and b) the PF-OO. .........................60

Figure 45 Pressure results for the three input velocities without scaffold......................................60

Figure $46 \mathrm{~V} 2$ pressure results without scaffold for $\mathrm{a})$ the OF-CO and $\mathrm{b}$ ) the PF-OO.........................61

Figure 47 Pressure results for the three input velocities with scaffold. ........................................62

Figure 48 V2 pressure results with scaffold for a) the IF-CO and b) the PF-OC. .............................62

Figure 49 Scaffold velocity results for the three input velocities. ..................................................63

Figure 50 V2 scaffold velocity results for a) the IF-CO, b) the PF-OC and c) the OF-CO....................63

Figure $\mathbf{5 1}$ Scaffold velocity results for the three input velocities. ............................................64

Figure 52 V2 wall shear stress results for a) the IF-CO, b) the PF-OC and c) the OF-CO..................65

Figure 53 Velocity comparison in percentage between the different combinations with scaffold......67

Figure 54 Turbulence comparison in percentage between the different combinations with scaffold. 68

Figure 55 Pressure comparison in percentage between the different combinations with scaffold. ....68

Figure 56 Scaffold velocity comparison in percentage between the different combinations. ............69

Figure $\mathbf{5 7}$ Wall shear stress comparison in percentage between the different combinations. ...........69

Figure 58 Shear stress results comparison with optimal/normal stress of the cells..........................70 


\section{Index of Tables}

Table 1 Core areas within Tissue Engineering, adapted from Kuppan et al., (2012), Jeong et al., (2007) and Tabata (2001).

Table 2 Most relevant growth factors for tissue engineering applications, adapted from Tessmar and Gopferich (2007), Boontheekul and Mooney (2003) and Rose and Oreffo (2002).

Table 3 Relationship between scaffold characteristics and the corresponding biological effect (Mahajan, 2005).

Table 4 Most common culture mediums (Butler, 2004)

Table 5 Example of limit and optimal stresses of several types of cells. 20

Table 6 Main requirements of a bioreactor for the use in TE (Chen and Hu, 2006; Lyons and Pandit, 2005; Pörtner et al., 2005; Korossis et al., 2005; Martin et al., 2004).

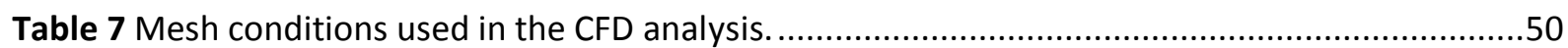

Table 8 Fluid characteristics and chamber properties used in the CFD analysis. ...............................50 


\section{List of acronyms}

\begin{tabular}{ll}
$\mathbf{0 - 9}$ & \\
\hline 2D & Two-dimensional \\
3D & Three-dimensional
\end{tabular}

B

\begin{tabular}{ll}
\hline BME & Basal Medium Eagle \\
BMP & Bone morphogenetic protein \\
C & \\
\hline CAD & Computer-aided Design \\
CFD & Computational Fluid Dynamics \\
Cm & centimetres
\end{tabular}

\section{D}

DMEM Dulbecco's Modified Eagle's Medium

DNA Deoxyribonucleic acid

dyn Dyne (unit)

\begin{tabular}{ll}
\multicolumn{1}{c}{ E } & \\
\hline ECM & Extracellular Matrix \\
EMEM & Eagle's Minimal Essential Medium \\
EGF & Epidermal growth factor
\end{tabular}

\begin{tabular}{ll}
$\mathbf{F}$ & \\
\hline FGF & Fibroblast growth factor
\end{tabular}

G

\begin{tabular}{ll}
\hline GAG & Glycosaminoglycans \\
GMEM & Glasgow Minimum Essential Medium
\end{tabular}

\section{H}

\begin{tabular}{ll}
\hline HARV & High Aspect Ratio Vessel \\
HEPES & 4-(2-hydroxyethyl)-1-piperazineethanesulfonic acid \\
HFB & Hollow Fibre Bioreactor \\
Hz & Hertz
\end{tabular}




\begin{tabular}{ll}
\multicolumn{1}{c}{ I } \\
\hline IGF & Insulin-like growth factor \\
\hline $\mathrm{KPa}$ & kilopascal \\
$\mathrm{L}$ & \\
\hline $\mathrm{L}-15$ & Leibovitz Medium
\end{tabular}

\begin{tabular}{ll}
$\mathbf{M}$ & \\
\hline $\min$ & minute \\
$\mathrm{ml}$ & millilitre \\
$\mathrm{mm}$ & millimetre
\end{tabular}

$\frac{\mathbf{N}}{\text { NASA } \quad \text { National Aeronautics and Space Administration }}$

\begin{tabular}{ll}
\multicolumn{1}{c}{$\mathbf{P}$} & \\
\hline $\mathrm{Pa}$ & Pascal (unit) \\
$\mathrm{PCL}$ & Poly( -caprolactone) \\
PDGF & Platelet-derived growth factor
\end{tabular}

\begin{tabular}{ll}
\multicolumn{1}{c}{$\mathbf{R}$} & \\
\hline rpm & Revolutions per minute \\
RPMI & Roswell Park Memorial Institute Medium \\
RSB & Rotating Shaft Bioreactor \\
RWPV & Rotating-wall Perfusion Vessel \\
RWV & Rotating-wall Vessel
\end{tabular}

\begin{tabular}{|c|c|}
\hline SMC & Smooth Muscle Cells \\
\hline $\begin{array}{r}\text { STLV } \\
\qquad \mathbf{T}\end{array}$ & Slow Turning Lateral Vessel \\
\hline TCP & Tricalcium Phosphate \\
\hline TE & Tissue Engineering \\
\hline TKE & Turbulence Kinetic Turbulence \\
\hline TGF- $\beta$ & Transforming growth factor $-\beta$ \\
\hline \multicolumn{2}{|l|}{$\mathbf{U}$} \\
\hline USA & United States of America \\
\hline $\mathbf{w}$ & \\
\hline
\end{tabular}




\section{Index}

AGRADECIMENTOS

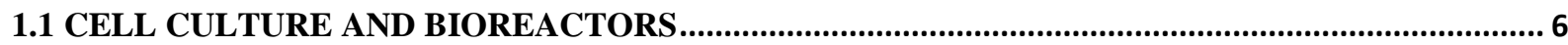

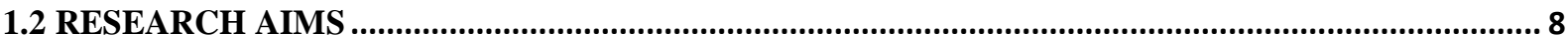

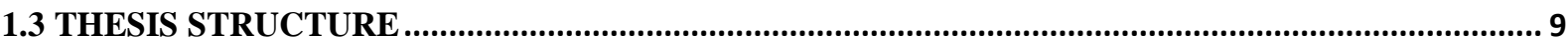

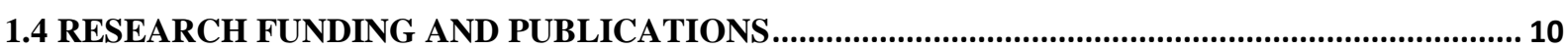

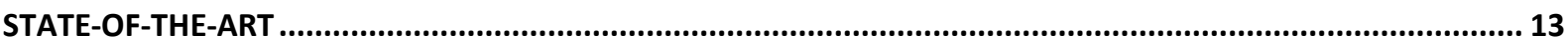

2.1 CELL CULTURE IN TISSUE ENGINEERING ............................................................................... 13

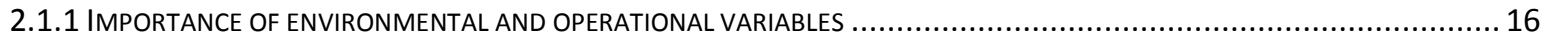

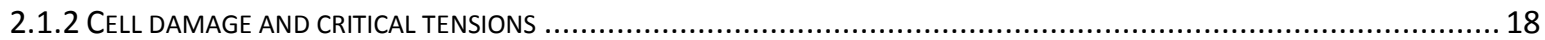

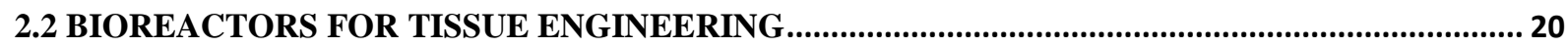

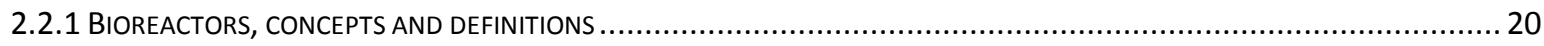

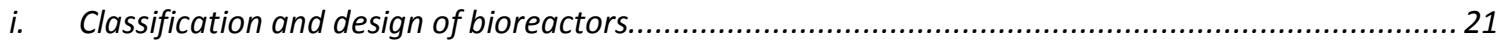

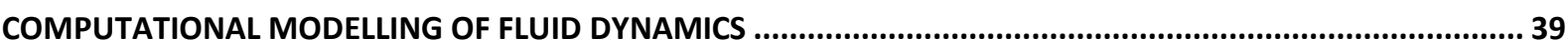

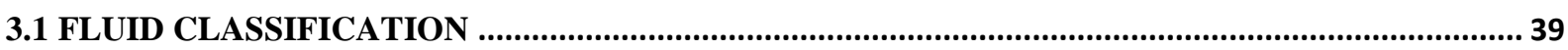

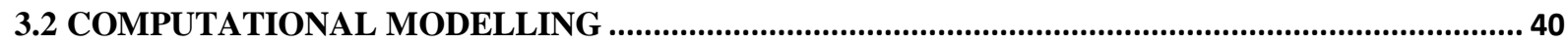

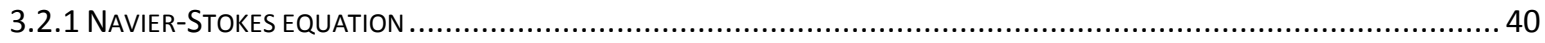

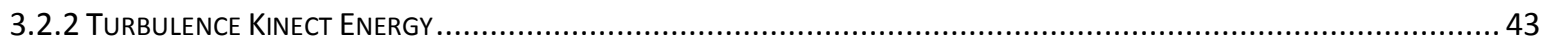

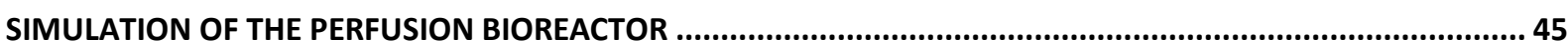

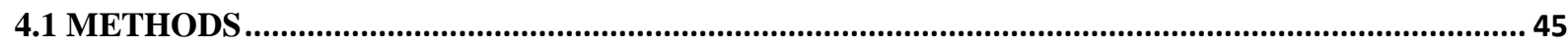

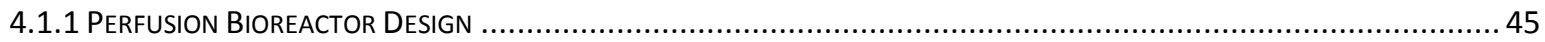

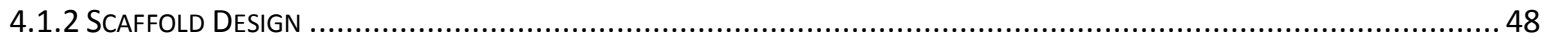

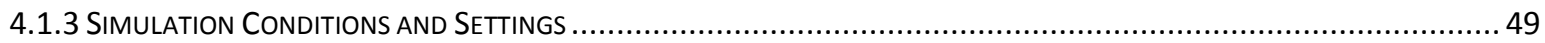

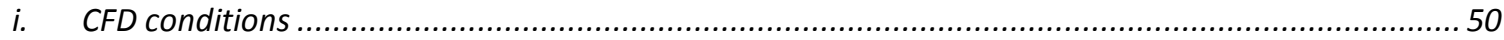




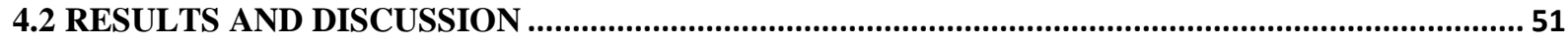

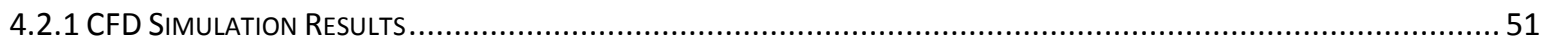

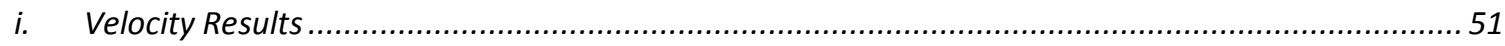

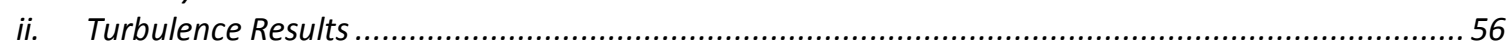

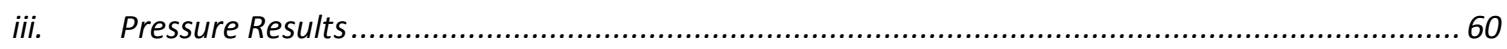

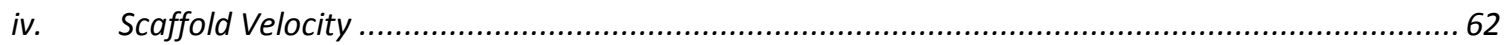

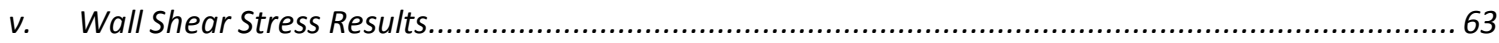

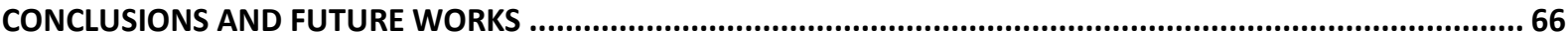

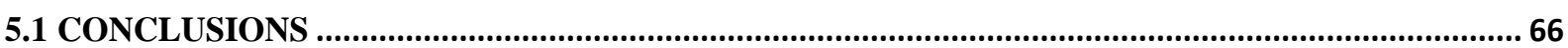

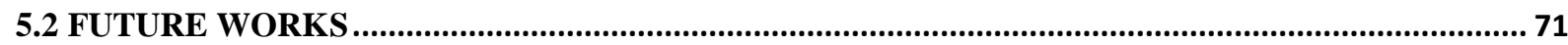

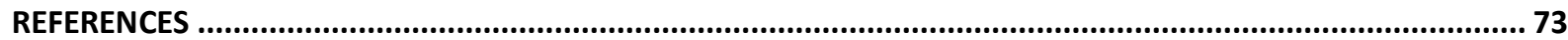




\section{Introduction}

Tissue Engineering is an emerging field that complies different areas of science focusing essentially on the use of cells, biomaterials, computational methods and fabrication processes (Figure 1) merging principles of areas such as biology, engineering and medicine in order to create biological tissues that are functionally defective or damaged (Eshraghi and Das, 2010; Bártolo et al., 2009a; 2009b; 2008; Gibson, 2005; Tan et al., 2005; Vozzi et al., 2003; Risbud, 2001). Skalak and Fox (1988), defined Tissue Engineering as the "application of the principles and methods of engineering and life sciences toward the fundamental understanding of structure-function relationships in normal and pathological mammalian tissues and the development of biological substitutes to restore, maintain, or improve tissue and organ functions” (Bártolo et al., 2008).

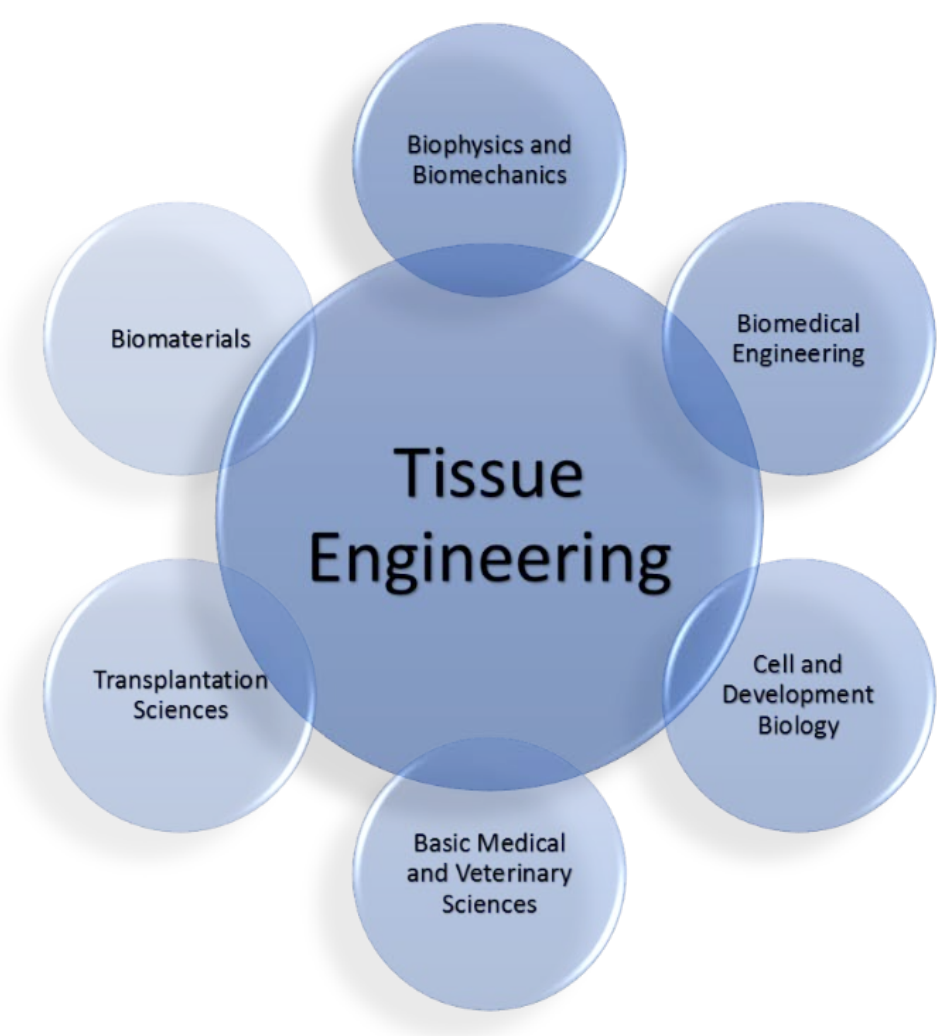

Figure 1 Multidisciplinary nature of the tissue engineering field. 
The main reason for the appearance of this new research domain that rapidly expanded was to address the organ shortage problem that comprises not only full organs to be substituted by the damaged ones, as well as to regenerate tissues and gene therapy (Table 1). In the near future, diseases such as Parkinson, Alzheimer, osteoporosis, cancer and many others can be treated through the regeneration of the damaged or diseased tissues.

The National Science Foundation (2003) of the United States of America (USA) published an historical overview of this emerging field and also, more recently, Bártolo et al. (2012) presented the perspectives till 2030 for this specific domain of research.

Table 1 Core areas within Tissue Engineering, adapted from Kuppan et al., (2012), Jeong et al., (2007) and Tabata (2001).

\begin{tabular}{|c|c|c|}
\hline & Purpose & Techniques/Methodology \\
\hline \multirow{3}{*}{$\begin{array}{l}\text { Tissue } \\
\text { Regeneration }\end{array}$} & In vitro production of tissue constructs & Cell scaffolding, bioreactor , microgravity \\
\hline & In vivo natural healing process & $\begin{array}{l}\text { Cell scaffolding, controlled release, physical } \\
\text { barrier }\end{array}$ \\
\hline & Ischemia therapy & Angionesis \\
\hline \multirow{3}{*}{$\begin{array}{l}\text { Organ } \\
\text { Substitution }\end{array}$} & Immunoisolation & Biological Barrier \\
\hline & Nutrition and oxygen supply & Angionesis \\
\hline & Temporary assistance for organ function & Extracorporeal system \\
\hline $\begin{array}{l}\text { Gene } \\
\text { therapy }\end{array}$ & $\begin{array}{l}\text { Inhibiting induction of a specific gene, or by } \\
\text { editing undesirable genomic mutations }\end{array}$ & $\begin{array}{l}\text { Intracellular transfer of nucleic acid drugs to } \\
\text { modulate cellular functions and responses } \\
\text { by expressing exogenous proteins }\end{array}$ \\
\hline
\end{tabular}

In order to create new tissues there are three general strategies: Cell-based strategies; Growthfactor-based strategies; and Scaffold-based strategies as is illustrated in Figure 2. The scaffoldbased strategies is one of the most common and has been adopted by several authors, such as: Bhumiratana and Vunjak-Novakovic (2012), Norotte et al. (2009), Bártolo et al. (2008), Matsumoto and Mooney (2006), Mistry and Mikos, (2005), Fuchs et al. (2001), Langer (1997) and Langer and Vacanti (1993). 


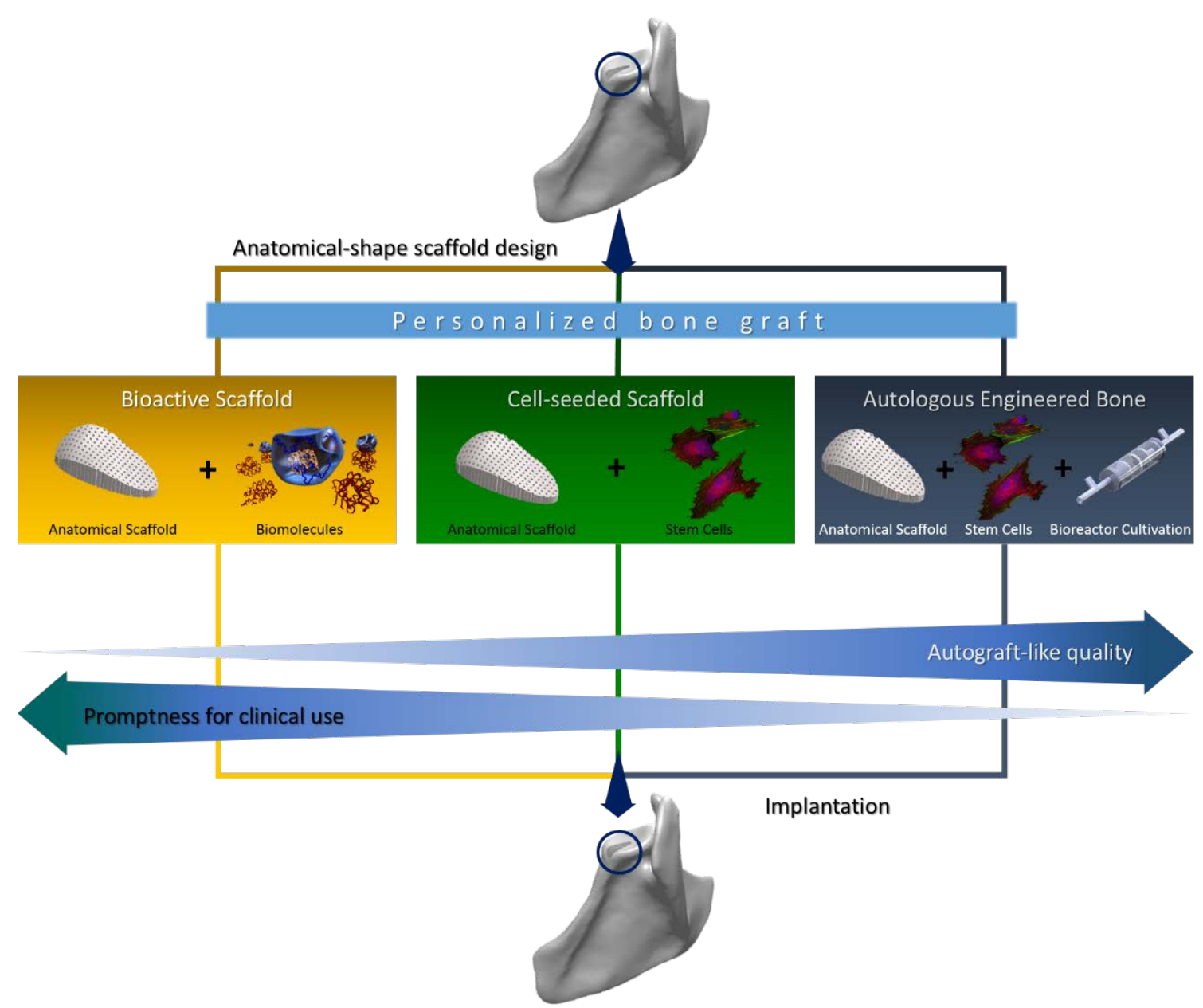

Figure 2 Scaffold-based strategies for engineering personalized bone grafts (adapted from Bhumiratana and Vunjak-Novakovic, 2012).

i. Cell-based strategies, consists in the implantation, in vivo, of isolated cells or cells substitutes so that they may synthesize their own Extracellular Matrix (ECM). Using this method is intended to limit surgery complications by only allowing the replacement of the damaged cells. The main limitations of this strategy is the immunological rejection and failure of the encapsulated cells.

ii. Growth-factor-based strategies uses growth factors and controlled-released systems to create new tissues. Growth factors are basically proteins that are produced by cells that are functioning as signalling molecules. With these proteins, it is possible to promote cell adhesion, proliferation, migration and differentiation of the cultured cells (Tessmar and Gopferich, 2007; Boontheekul and Mooney, 2003; Rose and Oreffo, 2002). Table 2 indicates the most relevant growth factors for bone regeneration and wound healing applications. 
Table 2 Most relevant growth factors for tissue engineering applications, adapted from Tessmar and Gopferich (2007), Boontheekul and Mooney (2003) and Rose and Oreffo (2002).

\section{Bone Regeneration}

\begin{tabular}{ll}
\hline \multicolumn{1}{c}{ Growth factor } & \multicolumn{1}{c}{ Relevant activities } \\
\hline Transforming growth factor- $\beta$ (TGF- $\beta$ ) & Proliferation and differentiation of bone \\
\hline Bone morphogenetic protein (BMP) & Differentiation of bone forming cells \\
\hline Insulin-like growth factor (IGF) & $\begin{array}{l}\text { Stimulates proliferation of osteoblasts and } \\
\text { synthesis of bone matrix }\end{array}$ \\
\hline Fibroblast growth factor (FGF) & Proliferation of osteoblasts \\
\hline Platelet-derived growth factor (PDGF) & Proliferation of osteoblasts \\
\hline Growth factor & Wound Healing \\
\hline Platelet-derived growth factor (PDGF) & \begin{tabular}{l} 
Active in all stages of healing process \\
\hline Epidermal growth factor (EGF)
\end{tabular} \\
\hline Transforming growth factor- $\beta$ (TGF- $\beta$ ) & $\begin{array}{l}\text { Mitogenic for keratinocytes } \\
\text { Promotes keratinocyte migration, ECM synthesis and } \\
\text { remodelling, and differentiation of epithelial cells }\end{array}$ \\
\hline
\end{tabular}

iii. Scaffold-based methods provides a substrate for the implanted cells, $i$. e., scaffolds provide an initial biochemical and biophysical substrate in order to support the cells until they start producing their own ECM and stimulate new tissue formation (Bartolo et al., 2012). There are two main methods within this strategy, which can be used in an open or closed culture system. The first one starts with an in vitro culture of cells and then they are seeded inside the scaffold pores, whereas the second method consists on isolating the cells from the body by a permeable membrane allowing the exchange of nutrients and wastes, protecting cells from the immune response of the body. The last step of this culture strategy regards the implantation of the cell-matrix in the body.

Using scaffolds as a temporary support matrix for cells is the most commonly used strategy for tissue engineering (Fuchs et al., 2001). With this approach, the cells are harvested from living tissue, from the patient (autograph) or from a different individual (allograph) and then they will be cultured in vitro on a scaffold in order to obtain the tissue-scaffold construct for 
transplantation (Liu and Czernuszka, 2006). Besides providing the initial biochemical and biophysical substrate to improve the cell growth, scaffolds also serve as a temporary template to accommodate and aid in the definition, formation and orientation of the new tissue throughout the 3D space (Bártolo et al., 2012). In Figure 3 is illustrated this strategy taking into account all the essential factors.

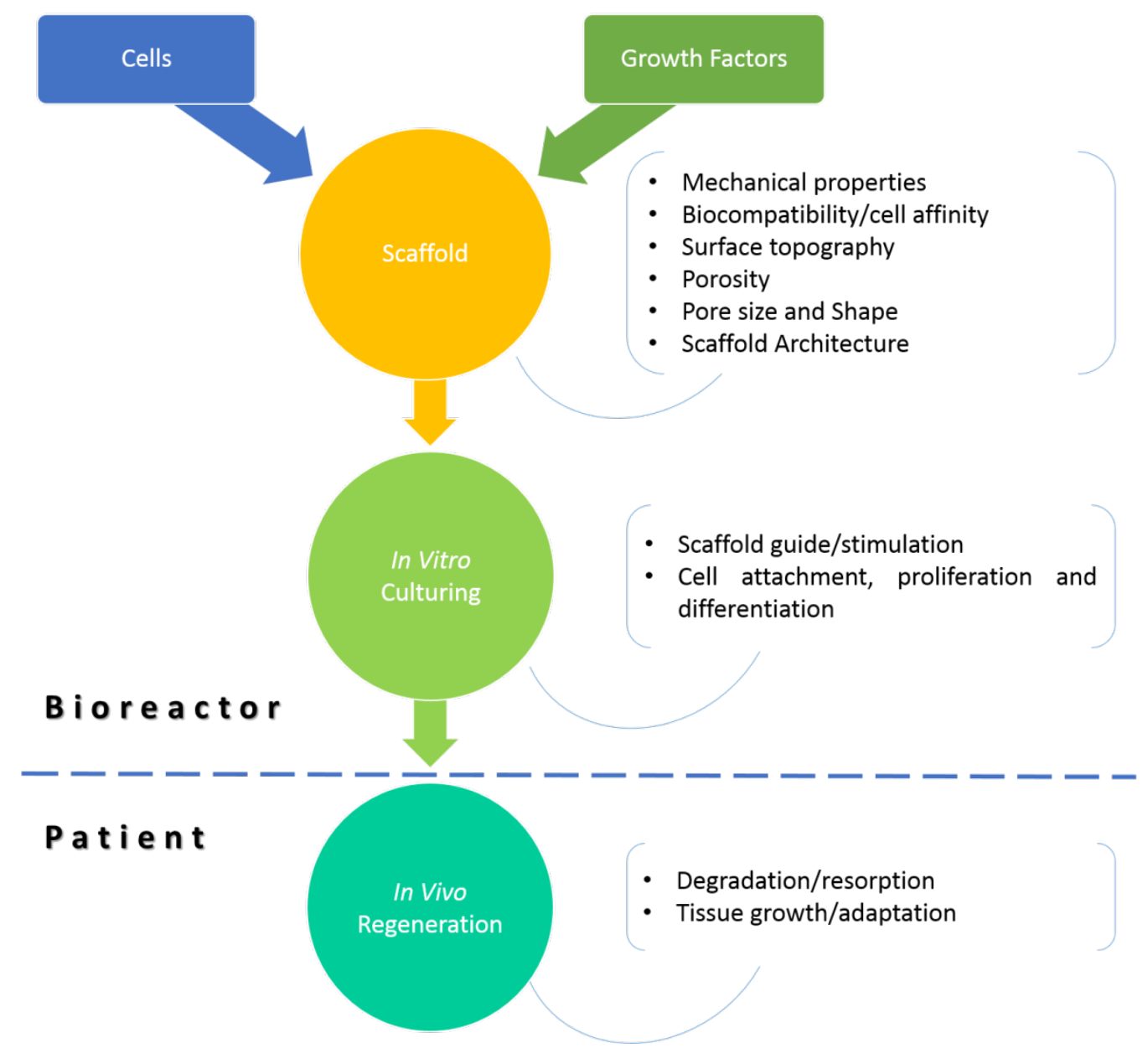

Figure 3 Tissue engineering process involving the cell seeding on scaffolds, in vitro culturing and patient implantation, adapted from Bartolo et al., (2012) and Liu and Czernuszka (2006).

There are several main purposes that a scaffold must achieve. It must serve as an adhesion substrate for cells, allowing cell attachment, proliferation and differentiation; it must deliver and retain cells and growth factors; it has to enable diffusion of cell nutrients and oxygen; and must provide temporary mechanical and biological environment to the newly grown tissue enabling tissue regeneration in an organized way (Billiet et al., 2012; Truscello et al., 2012; Guillotin and Guillemot, 2011; Bártolo et al., 2009a; 2009b; 2008; Tan and Teoh, 2007; Liu 
and Czernuszka, 2006; Kreke et al., 2005; Gomes and Reis, 2004; Gross and RodriguezLorenzo, 2004; Leong et al., 2003; Kreeger and Shea, 2002; Hutmacher, 2001; Kim and Mooney, 2001; Langer and Vacanti, 1993). In order to accomplish all this goals, the scaffolds must fulfil several biological and physical requirements (Table 3) that will affect cell survival, signalling, growth, propagation and reorganization and also cell shape modelling and gene expression (Bártolo et al., 2012; Billiet et al., 2012; Reverchon and Cardea, 2012; Vasanthan et al., 2012; Bártolo et al., 2009a; 2009b; 2008; Sanz-Herrera et al., 2009; Leong et al., 2008; Chen et al., 1997; Mooney et al., 1992).

Table 3 Relationship between scaffold characteristics and the corresponding biological effect (Mahajan, 2005).

\begin{tabular}{ll}
\multicolumn{1}{c}{ Scaffold Characteristics } & \multicolumn{1}{c}{ Biological Effects } \\
\hline Biocompatibility & Cell viability and tissue response \\
\hline Biodegradability & Aids tissue remodelling \\
\hline Porosity & Cell migration inside the scaffold - Vascularisation \\
\hline Chemical properties of the material & Aids in cell attachment and signalling in cell environment. \\
\hline Mechanical properties & Allows release of bioactive substances \\
\hline
\end{tabular}

\subsection{Cell Culture and Bioreactors}

In Tissue Engineering, cell culture plays a major role in the construction of tissue replacement. Normally cells are harvested from embryonic tissue being these type of cells used in primary cultures because they have an enormous potential to differentiate and grow into different types of tissues.

There is several types of cells ideal for processing new tissues ex situ like mesenchymal stem cells; permanent or established cell strains; and hybridomas. Considering the primary cells, there are a vast diversity of cell lines that are used in cell culture such as epithelial cells; connective tissue cells; muscle cells; nerve cells; and blood and lymphatic cells.

For a successful tissue construct, there are some requirements that most provide a stable and propitious environment for culturing the cells. In order to accomplish a successful cell culture, one has to consider the operational and environmental variables such as $\mathrm{pH}$, temperature, medium control and oxygenation. All these conditions must be considered in order to have an 
excellent cell growth within the scaffold and to control all these variables in tissue engineering, bioreactors are often used because one may control and visualize the progress of the undergoing cell culture.

A bioreactor is usually defined as an equipment in which occurs biological and/or biochemical processes in a controlled environment. There are several types of bioreactors and they are classified accordingly to the environment which unfolds the tissue culture depending in the type of stimulus involved and they can also be classified regarding the type of tissue that will be cultured.

Due to the specificity of each type of cell and the tissue that will be created, there was a need to develop various types of bioreactors with more focus on its operational and ability to apply stimulus. Essentially the bioreactors are divided in two groups, the static culture group and the dynamic culture bioreactors (Figure 4).

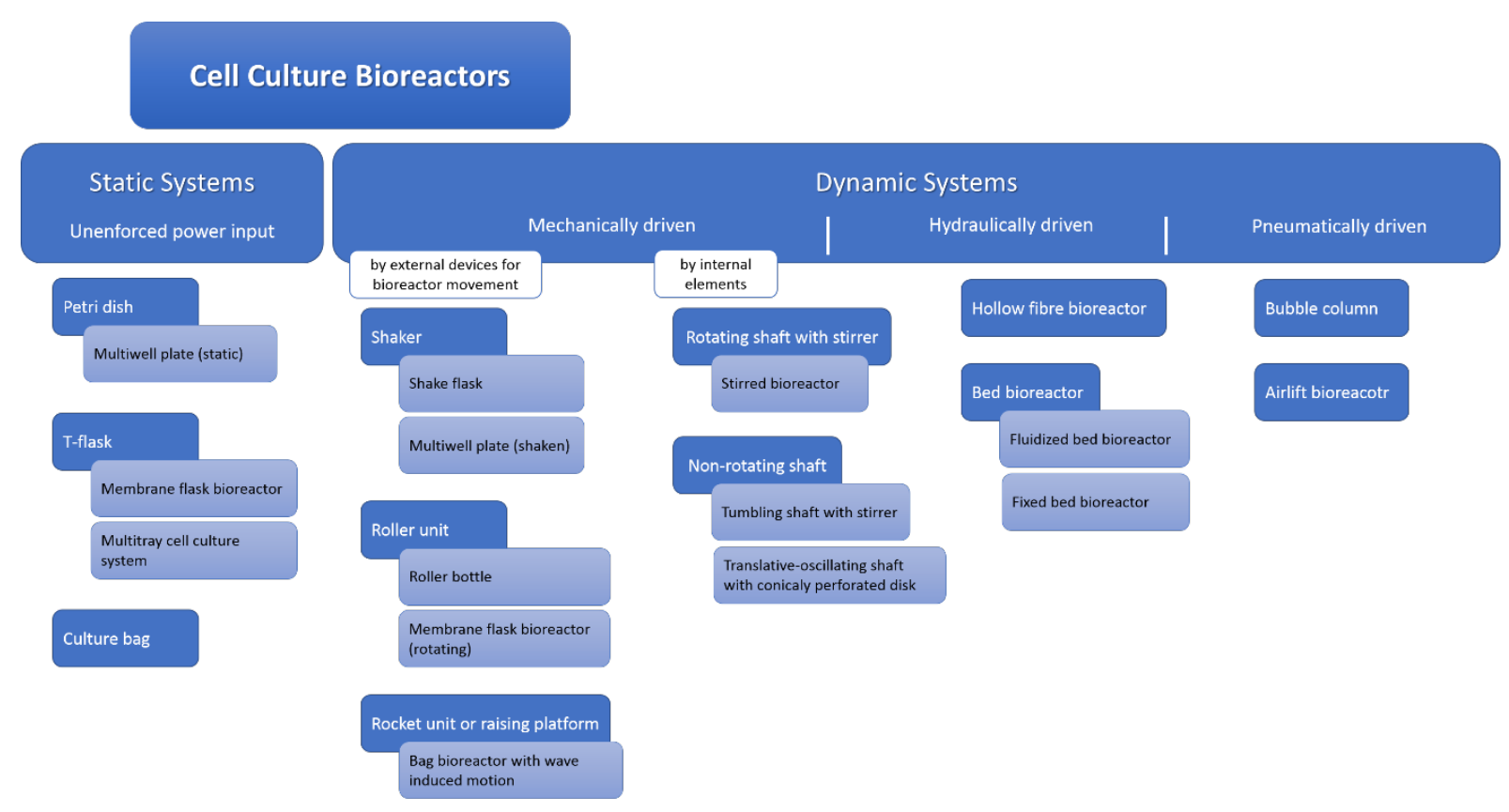

Figure 4 Bioreactors classification.

Static culture systems are the most simple to operate and manage because one just needs to considerer the environmental conditions in order to occur cell growth within the scaffold (e.g. petri dish, t-flask, culture bag) while dynamic systems apply stronger stimulus to the cells, either directly or indirectly.

In dynamic cultures, there are agitation systems that provide a homogeneous environment and such systems like spinnerflask, Wavywalled Bioreactor (WWB) or stirred vessel bioreactor have the main purpose of increasing mass transfer during the cell culture. Another type of 
dynamic bioreactors are the rotational bioreactors that uses movement about one or more axes to create agitation in the culture medium and therefore increasing the mass transfer.

Mechanical stimulation systems have the advantage of direct stimulation of the cells, not only aiding the increase of cell proliferation as also will improve the differentiation and alignment of the cells within the scaffolds. Depending on the type of cells that will are to be cultured, and more intrinsically, the different tissues that will be constructed, there are different types of stimulus that can be applied using these systems.

One of the main purposes of the perfusion bioreactors is to solve the problems of the nonuniformity of the cell proliferation within the scaffold. This can be accomplished by controlling the medium flow velocity through the scaffold and cells while continuously renewing the culture medium and cell retention.

Optimised cell culturing can be accomplished in vitro with the aid of equipment's such as bioreactors by taking into account all these factors since operational to the environmental variables.

\subsection{Research Aims}

The design of a perfusion bioreactor for tissue engineering applications is the key topic of this research, where problems as diffusion of the flow within the scaffolds, cell damage and critical tensions, homogenization of the cell distribution throughout the scaffold and optimization and prediction of fluid behaviour around and within the scaffold, allowing further improvement of scaffolds design, present a critical challenge in this research topic.

Taking into account the different problems that are inherent to cell culturing in tissue engineering, this research work must consider the following main objectives:

- The design optimization of a perfusion bioreactor;

- The evaluation of the inlet and outlet fluid flow within the chamber and scaffold;

- Analysis of the critical tensions that are admissible in cell culturing. 


\subsection{Thesis Structure}

This thesis is structured into 5 chapters as illustrated in Figure 5.
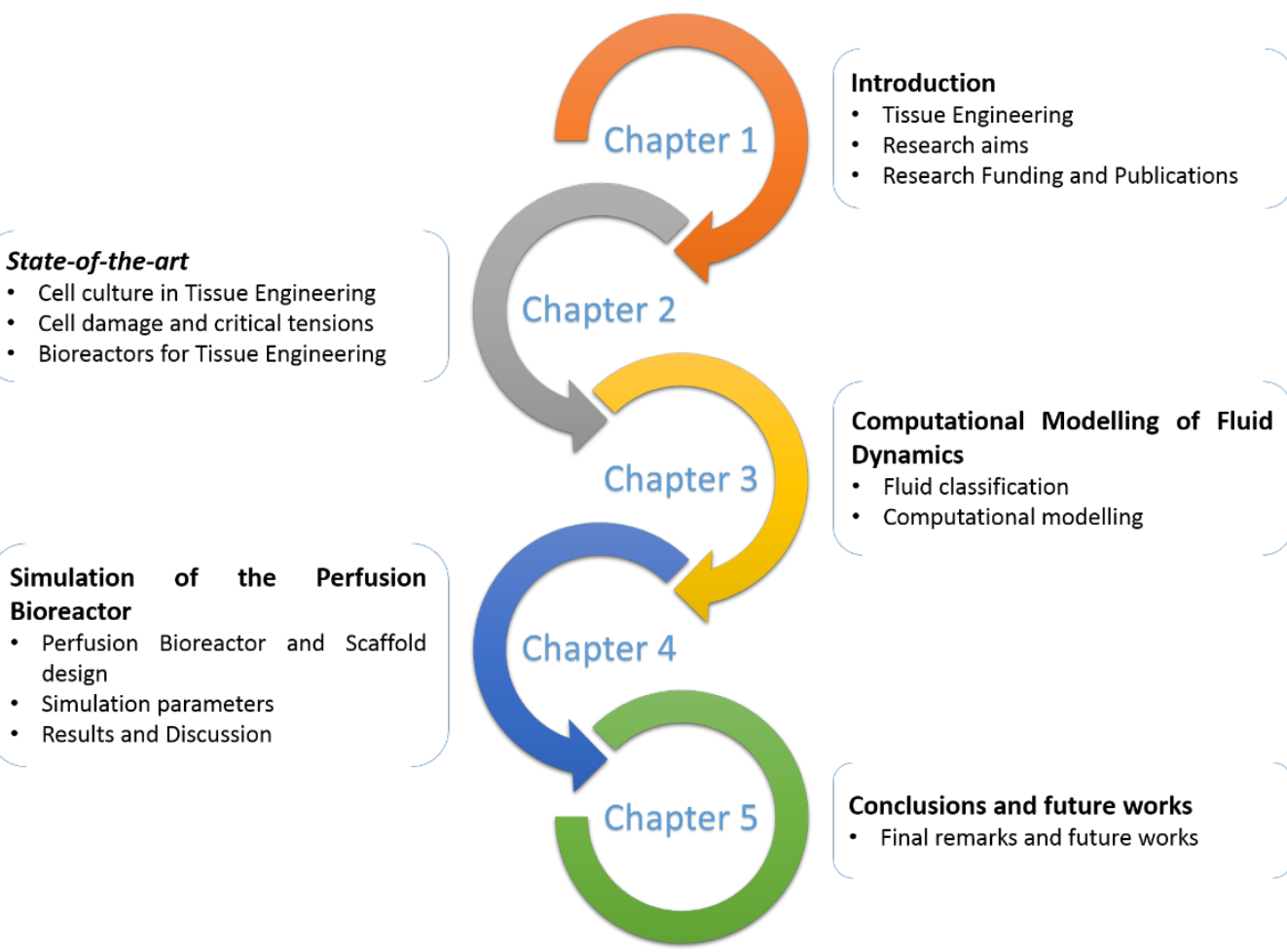

Figure 5 Flowchart of the topics and objectives that are addressed in the thesis.

The first chapter presents an overview of the tissue engineering field and more specifically the use of scaffolds. An in depth description of scaffolds, regarding its purpose, functionality, biological and physical requirements and characteristics.

The second chapter comprises the state-of-the-art related with Cell Culture and Bioreactors in Tissue Engineering. It is comprehensively described the process of tissue culture using several types of cells along with their differentiation process into a specific tissue. It is also described the several bioreactors and their properties according to the tissue needed to be cultured.

The third chapter describes the properties of fluids and how to characterize it computationally using several mathematical models in the computational calculations in order to determine the fluid behaviour across the bioreactor.

The fourth chapter of this work describe the methods used in this work since the design of the perfusion bioreactor and the scaffold as also the simulation parameters. It will also be exposed and discussed the results obtained from the simulations. 
The fifth and last chapter presents the conclusions as also the pros and cons of the work carried out under the perfusion bioreactor and future works in order to continue improving the tissue culture in bioreactors.

\subsection{Research Funding and Publications}

The research work undertaken in this thesis was supported by the following research projects:

1. Internacional Research Exchange for Biomedical Devices Design and Prototyping “IREBID”, funded by the People Marie Curie Actions, International Research Staff Exchange Scheme.

2. Development of Scaffolds with Controlled Microstructure for Bone Tissue Engineering (PTDC/EME-PME/104498/2008), funded by the Portuguese Foundation for Science and Technology.

3. Strategic Project UI 4044 (Pest-OE/EME/UI4044/2011), funded by the Portuguese Foundation for Science and Technology.

4. Rede IberoAmericana de Biofabricação: Materiais, Processos e Simulação, funded by the CYTED - Ciencia Y Tecnologia Para El Desarrollo.

5. BIOMAS - Biomanufacturing and Engineering Scaffolds, funded by the Portuguese Agency for Innovation.

6. BIOMAS II - Biomanufacturing and Engineering Scaffolds, funded by the Portuguese Agency for Innovation.

The following publications and patents also emerged from the research work carried out:

Articles in proceedings edited as book:

1. D. Freitas, H.A. Almeida \& P.J. Bártolo (2014) "Perfusion bioreactor fluid flow optimization”, CENTERIS/ProjMAN/HCist 2014 Book of industry papers, poster papers and abstracts, J. Varajão et al. (Eds.), SciKA (ISBN: 978-989-97433-4-2), 159 (CENTERIS/ProjMAN/HCist 2014, 15/10/2014-17/10/2014). 
2. D. Freitas, H. Almeida \& P. Bártolo (2014) "Permeability evaluation of flow behaviors within perfusion bioreactors”, New Trends in Mechanism and Machine Science - From Fundamentals to Industrial Applications, P. Flores \& F. Viadero (Eds.), Springer (ISBN: 978-3-319-09410-6), 761-768 (5th European Conference on Mechanism Science - EUCOMES 2014, Guimarães, Portugal, 16/09/201420/09/2014).

3. D. Freitas, H. Almeida \& P. Bártolo (2014) “Optimization of a Perfusion Bioreactor for Tissue Engineering”, Biodental Engineering III, R.N. Jorge et al (Eds.), CRC Press (ISBN: 978-1-138-02671-1), 145-149 (Porto, Portugal, 22/06/2014-23/06/2014).

4. R.F.B. Pereira, D.M.F. Freitas, A.P.O. Tojeira, H.A. Almeida, N. Alves \& P.J. Bártolo (2012), Computational optimization of a novel bioreactor for tissue engineering applications, Proceedings of the 1st International Conference on Design and Processes for Medical Devices (PROMED), E. Cerretti et al (Eds.), Neos Edizioni (ISBN:978-886608-058-9):217-221 (Brescia, Italy, 02/05/2012-04/05/2012).

5. D.M. Freitas, R. Pereira, A. Tojeira, P.J. Bártolo, N.M. Alves, C. Capela, A. Mendes \& H.A. Almeida (2011), Influência das Variáveis Dimensionais e de Rotação das Câmaras de Cultura de Bioreactores no Crescimento Celular, $4^{\circ}$ Congresso Nacional de Biomecânica, L. Roseiro \& A. Neto (Eds.), Sociedade Portuguesa de Biomecânica (ISBN:978-989-97161-0-0):407-412 (Coimbra, Portugal, 04/02/201105/02/2011).

Articles in international journals edited with review:

1. D. Freitas, H.A. Almeida \& P.J. Bártolo (2014) "Perfusion bioreactor fluid flow optimization”, Procedia Technology (ISSN: 2212-0173), 16: 1238-1247.

2. R. Pereira, D. Freitas, A. Tojeira, H.A. Almeida, N. Alves \& P.J. Bártolo (2014), Computer modelling and simulation of a bioreactor for tissue engineering, International Journal of Computer Integrated Manufacturing (ISSN: 0951-192X (Print) 1362-3052 (Online)), 27(10): 946-959. 
Articles in proceedings:

1. D. Freitas, P.J. Bártolo, H.A. Almeida, "Análise Computacional De Diferentes Tipos De Entradas De Fluxo Em Bioreactores De Perfusão", $6^{\circ}$ Congresso Nacional de Biomecânica (CNB2015), Monte Real, Portugal, 06/02/2015-07/02/2015.

2. D. Freitas, H.A. Almeida \& P.J. Bártolo (2014) "Fluid Flow Optimization of a Perfusion Bioreactor", International Conference on Biofabrication (ICB 2014), Pohang, Korea, 28/09/2014-01/10/2014.

3. A.P. Tojeira, D.M. Freitas, R.F. Pereira, P.J. Bártolo, N. Alves, C. Capela, A. Mendes \& H.A. Almeida (2010), Computational analysis of bioreactor chamber for tissue engineering applications, Rapid Product Development (RPD 2010), Marinha Grande, Portugal, 20/09/2010-21/09/2010.

4. R. Pereira, A. Tojeira, D.M. Freitas, P.J. Bártolo, N. Alves, C. Capela, A. Mendes \& H.A. Almeida (2009), Bioreactores em Engenharia de Tecidos, 1as Jornadas do Curso de Mestrado em Concepção e Desenvolvimento de Produto, Leiria, Portugal, 19/12/2009.

Intellectual Property - Patents:

1. Bioreactor Multifuncional para a Engenharia de Tecidos, D.M. Freitas, A.P. Tojeira, R.F. Pereira, P.J. Bártolo, N.M. Alves, A.L. Mendes, C.A. Capela \& H.A. Almeida, Patente de Invenção Nacional No 105176, 21/03/2013. 


\section{State-of-the-art}

In this chapter it is presented the state-of-the-art related with Cell Culture and Bioreactors in Tissue Engineering. It is thoroughly descript the several cells used for tissue construct along with the different differentiation of each kind of cell in the specific tissue. It is also described the several bioreactors and their properties according to the tissue needed to be cultured.

\subsection{Cell Culture in Tissue Engineering}

In the broad scope of Tissue Engineering, cell culture has been a carrier for the advances in the construction of tissue replacement for tissue/organ damage. The cell culture process is characterized by two phases, the acquisition of cells from a donor; and the cell growth in nutrient-rich media and specific growth factors for each cell type.

The stem cells primary culture, i.e., the first cell culture established from cells obtained directly from animal tissues, is generally established from embryonic tissue since in this type of tissue the cells are easily dispersed and have a high potential for growth and high differentiation. After the completion of the primary culture it is selected one type of cell (Butler, 2004).

Recent studies have demonstrated that there is some type of cells ideal for process future tissues ex situ being the following ones the most common:

- Mesenchymal stem cells: cells originating from the embryonic tissue and from multipotent cells that by differentiation processes origin specific cells type. Their use in tissue engineering is primarily explained by the versatility of becoming any kind of cell lineage.

- Permanent or established cells strains: cells that derived from a primary culture, but due to some changes are able to divide and proliferate indefinitely (primary culture); 
- Hybridomas: Cells that are obtained by fusing lymphocytes with tumor cells and are capable of expressing monoclonal antibodies.

From the primary cells (primary culture) it can be selected the following types of cell lines (Figure 6):

- Epithelial cells: cells disposed in layered formation coating organs or cavities which easily proliferate in a cell culture;

- Fibroblasts: cells that make up the majority of human tissues and are characterized by having a fibrous matrix, as a good example of this type of cells is the fibroblasts. The growth in culture is fast and efficient (doubling time 18-24 hours), becoming the most studied cell type under Tissue Engineering.

- $\quad$ Muscle cells: muscle tubules are formed from precursor cells which form a complex and multinucleated containing structural proteins (actin and myosin). The precursor cells, i.e., myoblasts may undergo differentiation forming aligned myotubes.

- $\quad$ Nerve cells: this cell type is responsible for transmitting electrical impulses. Neurons are highly differentiated cells and therefore difficult to grow in culture media. However, the addition of growth factors can lead to the formation of neurites (cytoplasmatic growth external to the neuron);

- Blood and lymphatic cells: cells growing in culture medium in the form of suspension. An example of this type of cells are the lymphocytes (white blood cells). These cells have high importance for the culture of cells, since they secrete immunoregulatory compounds. 


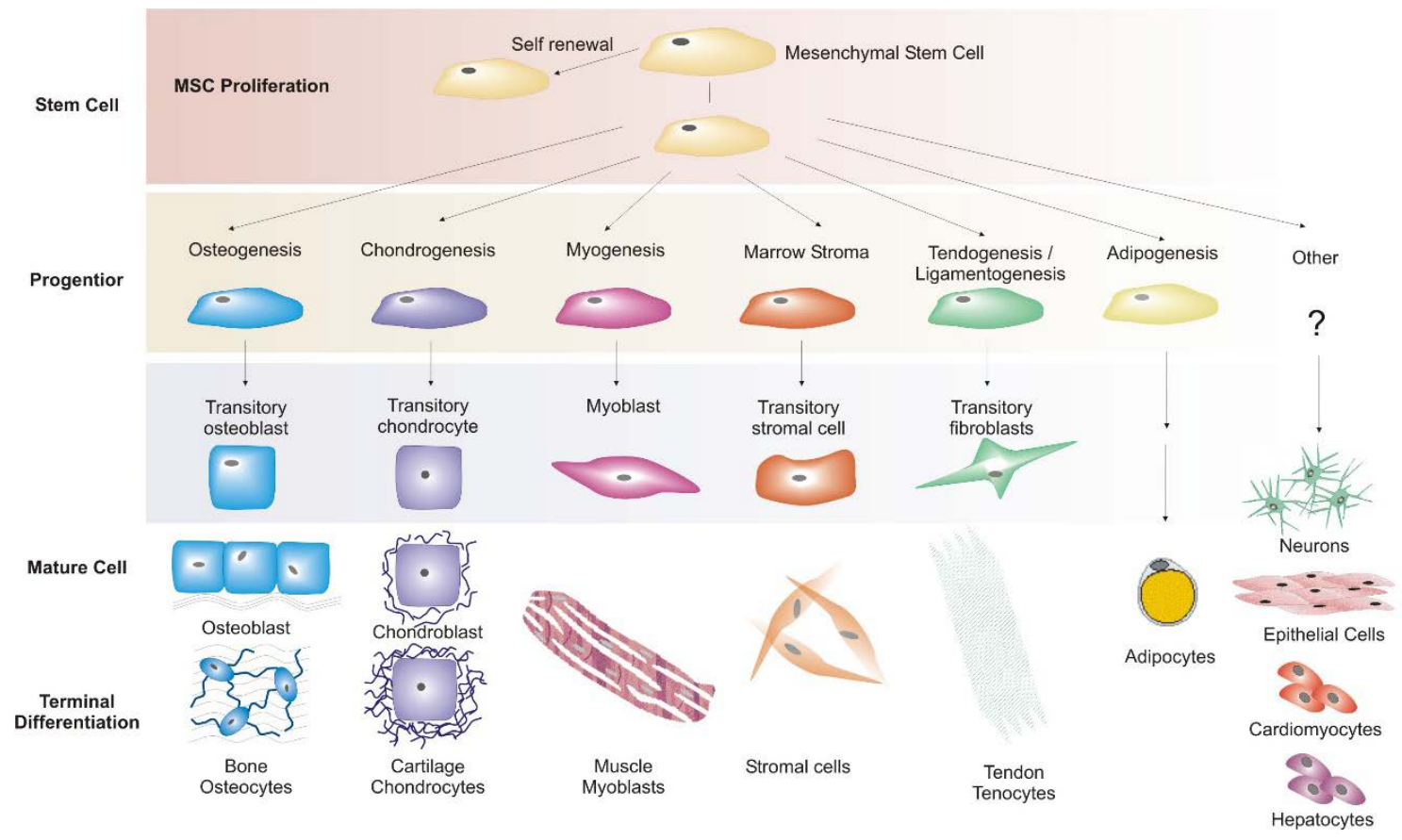

Figure 6 Mesenchymal stem cells differentiation (Caplan and Bruder, 2001).

In order to provide an environment conducive to the growth of cells in a three-dimensional structure or scaffold it is necessary to pay special attention to the culture medium, which can be defined chemically as a complex liquid medium capable of supporting cell growth over several generations. The composition of the culture medium varies depending on the cell type (Table 4) (Butler, 2004).

Table 4 Most common culture mediums (Butler, 2004)

\begin{tabular}{|c|c|}
\hline Culture Medium & Observations \\
\hline BME & Basal Medium Eagle, originally conceived for L mice and HeLa cell. \\
\hline EMEM & Eagle’s Minimal Essential Medium, is used in a variety of cells. \\
\hline DMEM & $\begin{array}{l}\text { Dulbecco's Modified Eagle's Medium, possess four times more amino acids and vitamins } \\
\text { concentration that the BME. }\end{array}$ \\
\hline GMEM & $\begin{array}{l}\text { Glasgow Minimum Essential Medium, possess two times more amino acids and vitamins } \\
\text { concentration that the BME. }\end{array}$ \\
\hline RPMI 1640 & $\begin{array}{l}\text { Roswell Park Memorial Institute Medium is often used for the culture of lymphocytes and } \\
\text { hybridomas. }\end{array}$ \\
\hline L-15 & Leibovitz Medium, used in environments with absence of $\mathrm{CO}_{2}$ for the culture of fibroblasts. \\
\hline Ham’s F-12 & It's a medium with a complex composition used for the culture of several cell lines. \\
\hline 199 & $\begin{array}{l}\text { Medium } 199 \text { has broad species applicability, particularly for cultivation of non-transformed } \\
\text { cells. }\end{array}$ \\
\hline
\end{tabular}




\subsubsection{Importance of environmental and operational variables}

Generically primary cells, which subsequently gives origin to a tissue, require a ribbed nutrient medium for the correct growth and proliferation. However, in certain environments human cells require external control of conditions such as temperature, $\mathrm{pH}$, product concentration of cell growth, among other parameters.

\section{Temperature}

The cell growth and development take place in vivo at a temperature of $37^{\circ} \mathrm{C}$. In vitro these conditions are ensured by incubator systems, however, the increase of an incubator throughout all the mechanical systems of the bioreactor limits the accessibility to the culture itself. More recently, have been suggested heated atmospheres systems using heating plates; another proposed solution is insertion of the heating units within the culture system, which can be monitored by computer using low-voltage circuits and circuit breakers which avoid the electric shock (Pörtner, 2009; Minuth et al., 2005).

\section{pH}

Human primary cells are extremely sensitive to variations of $\mathrm{pH}$. Therefore, the culture medium is controlled at this level by a buffer solution which maintains the $\mathrm{pH}$ between 7,0 and 7,3, these values are considered in the literature as optimum values (Pörtner, 2009). In several experiments, the solution of carbon dioxide-bicarbonate at 5\% (Equation 1) has been widely used since it resembles to the solution existent in the blood, at in vivo conditions (Pörtner, 2009):

$$
\mathrm{CO}_{2}+\mathrm{H}_{2} \mathrm{O} \leftrightarrow \mathrm{HCO}_{3}^{-}+\mathrm{H}^{+}
$$

Under different conditions of $5 \%$ concentration of $\mathrm{CO}_{2}$ the physiological $\mathrm{pH}$ becomes slightly alkaline (under normal atmospheric conditions - 0,3\% $\mathrm{CO}_{2}$ concentration) which can be countered by reducing the concentration of $\mathrm{NaHCO}_{3}$ or by adding other buffer solutions such as sodium phosphate or HEPES, which can be monitored by the $\mathrm{pH}$ indicator phenol red (Pörtner, 2009; Minuth et al., 2005).

\section{Medium Chemical composition}


The cell activity in vivo, is usually associated with the activity of sodium-potassium pump, whose function is to transport nutrients and other ions from the extracellular medium to the intra-cellular (Minuth et al., 2005). In addition to the necessary activity to normal cells ions is necessary to ensure power supply in the form of carbohydrates, is essentially reported, the glucose concentrations of $446 \mathrm{mg} / \mathrm{dl}$. In addition, amino acids are also added (which are only precursors activity of protein synthesis), vitamins, minerals and other compounds.

In addition to all these components, is also generally associated with a serum concentrations ranging between 5 and 10\%, and whose function is to provide certain growth and protect cells from shear stress. An example of such a serum are the fetal of calf or horse. However, the addition of this component to the culture medium of cells entails some disadvantages, such as: (1) the composition of the solution is not well defined; (2) the high cost of serum; (3) the difficult purification of the solution; (4) variation of loads in the solution; (5) the risk of contamination and spread of viruses.

However, the absence of this component in the growth medium and cell differentiation greatly delays the culture process (Pörtner, 2009; Butler, 2004).

\section{Oxigenation}

To achieve the aerobic metabolic cycles of the cells is necessary to take into account the distribution of gas in the culture medium, the transfer of nutrients and also the wastes of cellular reactions. Transferring sufficient amount of oxygen to cells is difficult essentially due to the low oxygen solubility in the culture medium (about $0,2 \mathrm{mmol} / \mathrm{L}$ ). However in order to have a viable cell culture is necessary to have an equal or approximated concentration of both $\mathrm{O}_{2}$ and Glucose (Martin and Vermette, 2005). In recent culture systems, the oxygen concentration is kept constant between $20 \%$ and $100 \%$ of air saturation that creates a balance between oxygen needs and tolerance to the formation of harmful free radicals that causes cytotoxic effects on cells.

Oxygenation can be performed by two methods: (1) gas sparging and (2) without oxygen bubbles. The gas sparging method is often used since it proves to be simple to provide the oxygen to the bioreactor. This method allows a high oxygen transfer due to a high interfacial area per bubble. However, the bubbles can lead to failure in cell viability, since the bubbles can damage the cells. The preferable process in bioreactor systems is the method without bubbles 
of the used gas that can be divided in two methods, the superficial gas sparging and the permeable membrane (porous or diffusion) (Bliem et al., 1991).

On the superficial gas sparging process, the culture medium is directly exposed to a controlled atmosphere rich in $\mathrm{O}_{2}$ and 5\% $\mathrm{CO}_{2}$ constantly occurring diffusion of these gases and keeping them in the culture medium.

The permeable membranes transfer the gas to the culture medium and they can be defined in two different types: porous or diffusion. In the first case, the culture medium is in continuous contact with the gas through pores arranged on the membrane. The interface created in the pores is controlled by pressure effects and hydrophobic forces. In the other end, the diffusion membranes diffuse the oxygen from the initially gas phase to a soluble membrane in oxygen and then into the culture medium. Although these two cases avoid the formation of bubbles they are influenced by factors such as the concentration of oxygen, the porosity of the membrane and the surface area of the membrane. However, these processes of oxygenation present difficulties in their implementation, namely, the complexity of the process, control of intrinsic variables of the process, the need for high membrane area exposed to the gas phase, difficulties in maintenance and cleaning of the membrane. In addition, the deposition of proteins (derived from the culture medium) at the base of the membrane, modify its hydrophobic property.

\subsubsection{Cell damage and critical tensions}

Human cells are very sensitive to changes in the culture environment, the hydrodynamic forces and the accumulation of toxic residues derived from the cellular respiration. Knowledge of the critical shear stress for cell development is of vital importance in TE because of this knowledge depends greatly on the success of the strategies adopted.

Human cells are highly sensitive to shear stresses due to their size (cell size ranging between 10 and $30 \mu \mathrm{m})$ and also because of the cell contents are only protected by the cell membrane. While, in some cultures, cells can grow freely in suspension, others require connection to a biocompatible structure to occur adhesion, proliferation and differentiation of cells. In these previous circumstances, if the connecting surface is fixed, the cell has an increased susceptibility to experience shear stress, since the cell cannot move freely and adapt to the forces imposed by the environment. In this case, it should be imposed laminar flow, to minimize shear forces (Minuth et al., 2005). 
Although excessive shear stresses may be harmful to the cells, it is desirable that there are controlled stresses, since these have a positive effect on adhesion, proliferation and cell differentiation, such as: (1) increase the permeability of the cell; (2) increase the secretion of extra-cellular proteins; (3) influence the shape of the cell.

The application of the shear stress and the definition of its value depends on the following factors (Minuth et al, 2005): (1) cell type; (2) method of culture (in suspension /fixed); (3) time of exposure to shear stresses. Regarding the exposure time, most of the studies on cell viability associated with critical shear stress reports short-term experiments (less than 24 hours). However long time cultures with levels of shear stresses away from the critical values may be advantageous, this study also shows that, apparently, the cells cultured in suspension support higher levels of shear stresses that the fixed cells (Minuth et al., 2005).

The culture of mesenchymal stem cells with a goal for osteogenic cell differentiation has been widely studied and it is concluded that this differentiation process is very sensitive to shear stresses caused by fluids. Godara et al., (2008) mentioned that throughout the process of cell differentiation, the critical shear stresses varies and after clarified that shear stresses ranging between $10^{-5} \mathrm{~Pa}$ and $10^{-4}$ have some responsibility in the osteogenesis process (in addition to the chemical differentiation factors), and that the differentiation of osteocytes is enhanced by the action of shear stress ranging 0,5 and 1,5 Pa. According to Cartmell et al. (2003), the optimal shear stress value to maximize cell viability of the osteoblasts is about $5 \times 10^{-5} \mathrm{~Pa}$ under the influence of a flow of $0,01 \mathrm{ml} / \mathrm{min}$ and that flow values above $0,2 \mathrm{ml} / \mathrm{min}$ are negative to cell viability of osteoblasts. Porter et al. (2005) reported that the shear stresses above $5,7 \times 10^{-2} \mathrm{~Pa}$ are associated with the death of cells within the scaffold. Similarly, Schinagl et al. (1999) demonstrated that the chondrocytes present in the hyaline cartilage suffer damage with values of shear stress of about 0,1 Pa. For the culture of cardiomyocytes Radisic et al. (2008) indicated that low values of shear stress leads to phenotypic changes of cardiac cells (primarily elongation) but values above $0,24 \mathrm{~Pa}\left(2,4 \mathrm{dyn} / \mathrm{cm}^{-2}\right)$ can lead to cell death without apoptosis. Park et al. (2008) have shown that hepatocytes exposed to shear stresses exceeding 0,5 Pa (5 $\mathrm{dyn} / \mathrm{cm}^{2}$ ) show a decreased production of albumin and urea, but shear stresses lower than 0,033 $\mathrm{Pa}\left(0,33 \mathrm{dyn} / \mathrm{cm}^{2}\right)$ does not affect the normal function of the cell (Table 5). 
Table 5 Example of limit and optimal stresses of several types of cells.

\begin{tabular}{|c|c|c|}
\hline Cell Type & Shear Stress & Reference \\
\hline \multicolumn{3}{|c|}{ Osteogenesis } \\
\hline \multirow{2}{*}{ Osteoblasts } & $5 \times 10^{-5} \mathrm{~Pa}$ (optimal stress) & Cartmell et al., 2003 \\
\hline & 5,7x10-2 $\mathrm{Pa}$ (cell death) & Porter et al., 2005 \\
\hline Osteocytes & 0,5 to $1,5 \mathrm{~Pa}$ (optimal stress) & Godara et al., 2008 \\
\hline \multicolumn{3}{|c|}{ Chondrogenesis } \\
\hline Chondrocytes & 0,1 Pa (normal stress) & Schinagi et al., 1999 \\
\hline \multicolumn{3}{|c|}{ Myogenesis } \\
\hline Smooth Muscle Cells & 0,5 to 2,5 (optimal stress) & Martin and Vermette, 2005 \\
\hline Cardiomyocytes & 0,24 Pa (cell death) & Radisic et al., 2008 \\
\hline \multicolumn{3}{|c|}{ Others } \\
\hline \multirow{2}{*}{ Hepatocytes } & 0,033 Pa (optimal stress) & \multirow{2}{*}{ Park et al., 2008} \\
\hline & 0,5 Pa (critical stress) & \\
\hline Heart Valves Cells & 2,2 Pa (optimal stress) & Martin and Vermette, 2005 \\
\hline
\end{tabular}

\subsection{Bioreactors for Tissue Engineering}

\subsubsection{Bioreactors, concepts and definitions}

The bioreactors are generally defined as locations in which occurs the development of biological, biochemical and biophysical processes in controlled and monitored environmental conditions (e.g. $\mathrm{pH}$, temperature, pressure, concentration of nutrients). The reproducibility, control and automation of the process are important aspects when culturing new tissues (Lyons and Pandit, 2005; Martin et al., 2004). These devices have been used for many years in the fermentation of food, water treatment, manufacture of pharmaceuticals, and also in the production of recombinant proteins (e.g. growth factors, antibiotics and vaccines). More recently, the concept has been adapted in order to be used in TE taking into account the requirements of this field (Figure 7) (Pörtner et al., 2005; Martin and Vermette, 2005; Korossis et al., 2005). 


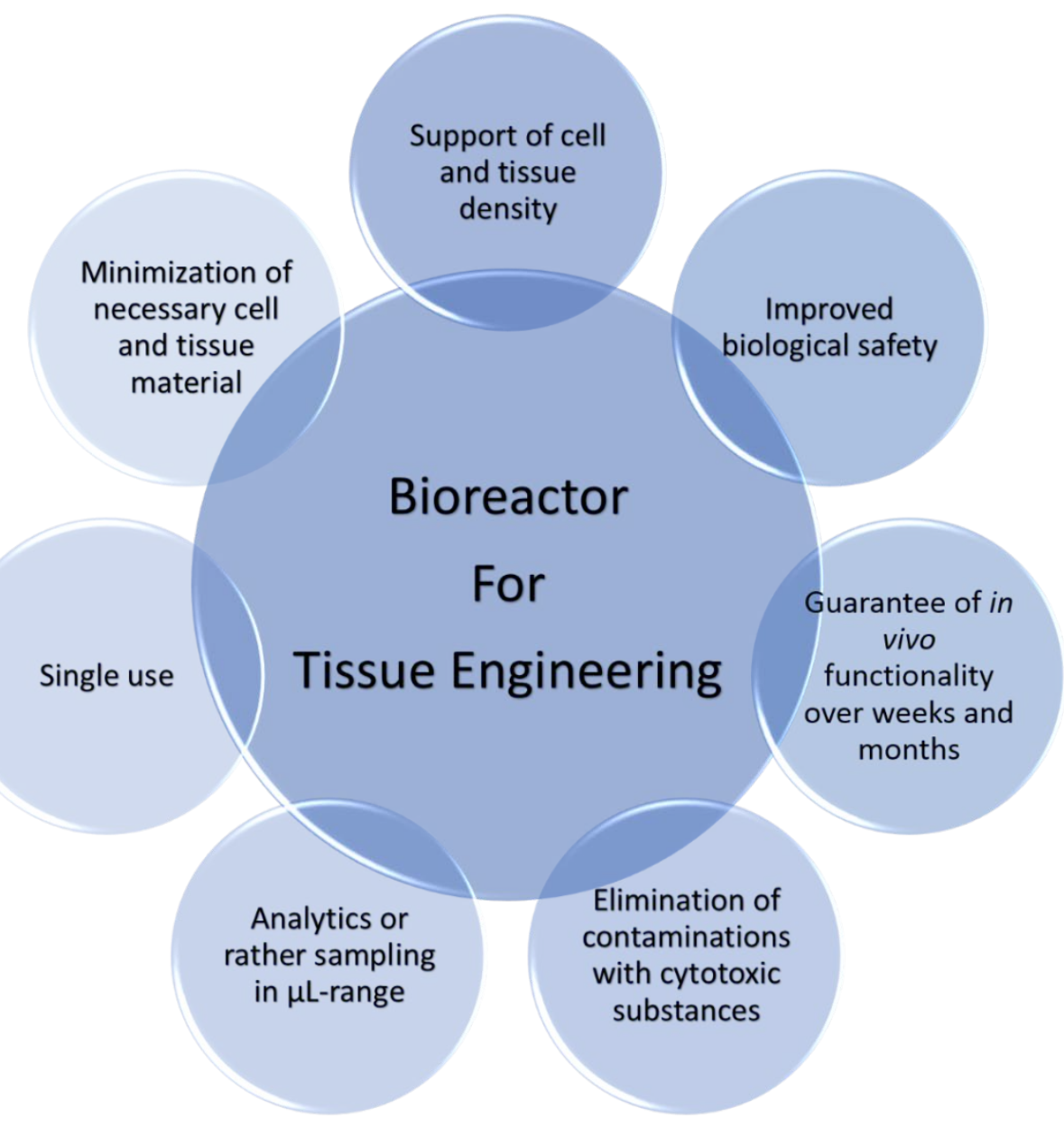

Figure 7 Properties of a bioreactor to use in TE.

The use of bioreactors in TE aims to provide an environment conducive to adhesion, proliferation and differentiation of living animal cells. Moreover, these devices provide the necessary conditions to perform in vitro studies about the effects of mechanical and biomechanical stimuli on cells. The most critical aspect in a bioreactor is related to the mass transfer (nutrients, gases and waste removal) (Martin and Vermette, 2005; Pörtner et al., 2005), since in vivo cells benefit from their proximity to blood capillaries of 100-200 $\mu \mathrm{m}$ (Rouwkema et al., 2008), which is extremely difficult to replicate in vitro.

\section{i. Classification and design of bioreactors}

Bioreactors may be classified according to many aspects, including:

- The environment in which unfolds the tissue culture - cell culture may be conducted in static or dynamic conditions; 
- The type of stimulus involved - the bioreactor can apply several kinds of stimuli during cell culture or act in various ways to provide the same type of stimulus (e.g. stirring action, infusion mechanical compression or rotation);

- The tissue in culture - each tissue requires different requirements from the bioreactor (the stimulus involved or the level design).

A bioreactor is designed according to the desired size, complexity and functionality. However, regardless of these considerations a bioreactor must possess a number of basic requirements as described in Table 6.

Table 6 Main requirements of a bioreactor for the use in TE (Chen and Hu, 2006; Lyons and Pandit, 2005; Pörtner et al., 2005; Korossis et al., 2005; Martin et al., 2004).

\begin{tabular}{lll}
\hline & Bioreactor Main Requirements \\
\hline $\begin{array}{l}\text { Adequacy of vascularity of the } \\
\text { cells/tissue providing nutrients in } \\
\text { the proper time and amount }\end{array}$ & $\begin{array}{l}\text { Application of stimuli in order to } \\
\text { proliferation and differentiation } \\
\text { adhesion, }\end{array}$ & $\begin{array}{l}\text { Avoid flow turbulence } \\
\text { excessive pressure on the culture } \\
\text { and impair the formation of new } \\
\text { tissue }\end{array}$ \\
\hline $\begin{array}{l}\text { Control of environmental, } \\
\text { chemical and physical conditions } \\
\text { of culture }\end{array}$ & $\begin{array}{l}\text { Ensure aseptic and sterilized } \\
\text { conditions }\end{array}$ & $\begin{array}{l}\text { Ensure the biocompatibility of the } \\
\text { building materials }\end{array}$ \\
\hline $\begin{array}{l}\text { Monitoring of cell growth and } \\
\text { formation of new tissue }\end{array}$ & $\begin{array}{l}\text { Allow removal of the waste } \\
\text { generated by cells }\end{array}$ & $\begin{array}{l}\text { Easily place the scaffold inside } \\
\text { Maintain a high degree of } \\
\text { reproducibility }\end{array}$ \\
\hline
\end{tabular}

The general requirements listed above are determined by the needs of the mechanical, physical, biophysical and biomechanical level of the tissue in culture. For example, the use of pulsed mechanical/perfusion instead of continuous stimulation on tubular scaffolds with Smooth Muscle Cells (SMC) increases the structural organization of blood vessels and their mechanical properties; while applying dynamic stresses to chondrocytes in appropriate environments stimulates the synthesis of Glycosaminoglycans (GAG) and increases the mechanical properties of the formed cartilage (Chen and $\mathrm{Hu}, 2006)$. Studies on cell proliferation in vitro have shown that mechanical stimuli have a positive impact regarding the formation of new tissue, improving the acceleration of the processes of cell differentiation and proliferation (Chen and $\mathrm{Hu}, 2006$; 
Pörtner et al, 2005; Martin et al. 2004). This effect is particularly evident in the formation of cartilage, bone and cardiovascular tissue (Pörtner and Giese, 2007). The most important stimulus on cellular differentiation and proliferation are the shear forces resulting from the fluid passage from the surfaces and pores of the scaffold enabling signal transmission/stimulation of the cells (Chen and $\mathrm{Hu}, 2006)$.

As a result of the specific needs of each type of cell in the culture process, various types of bioreactors were studied in particular on the level of operation and ability to apply stimuli.

\section{a. Systems of static culture}

The static culture systems are the most simple ones and includes systems like T-flasks, Well plates and Petri dishes (Figure 8), which are designed to culture cells in static conditions (Kumar et al., 2004). The main characteristics of these devices include ease of use, low cost and the possibility of sterilization. In return, these systems have several limitations such as: (1) the weak agitation of the medium which translates into low nutrient concentrations in certain places; (2) poor reproducibility; (3) difficulty of changing the culture medium, and (4) low amount of cell numbers. Furthermore the application of stimuli and the monitoring and control of environmental conditions, such as $\mathrm{pH}$, moisture and $\mathrm{CO}_{2}$ is practically impossible (Pörtner and Giese, 2007; Pörtner et al, 2005; Kumar et al, 2004).

These devices are widely used in cell culture for shorter periods of time being used mainly to increase the number of cells (Pörtner et al, 2005; Cabrita et al, 2003). After this period the cells are transferred to bioreactors in which will occur the development of the new tissue (Lyons and Pandit, 2005; Kumar et al, 2004).

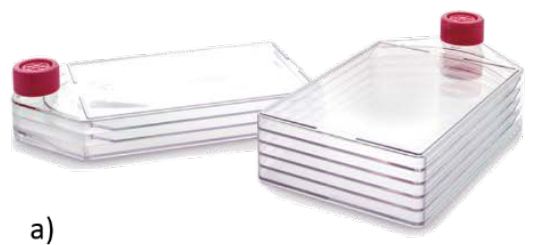

a)

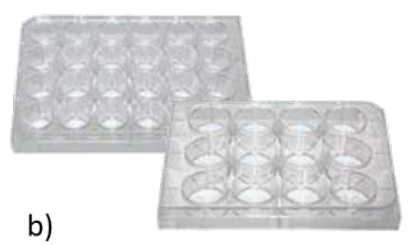

b)

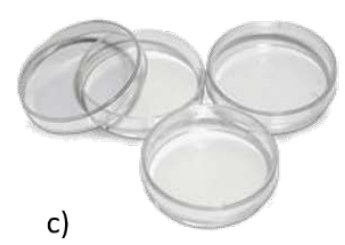

c)

Figure 8 Example of static culture systems a) T-flasks, b) Well plates and c) Petri dishes.

Static culture in 3D scaffolds generally produces tissues with small thickness and located at the periphery of the structure. The created tissue is characterized by its heterogeneity, a result of 
inadequate mass transfer (Porter et al., 2005). In order to solve the mass transfer limitations of these simple culture systems other bioreactor systems were developed such as, spinner flasks, Rotating-Wall Vessel (RWV), perfusion bioreactors, mechanical compression bioreactors, among others (Zhang et al., 2009; Bueno et al., 2004).

\section{b. Agitation Systems}

The agitation bioreactors provides a homogeneous environment, presenting results that are superior to the static culture. The main purpose of these systems (e.g. Spinner flask, wavywalled bioreactor (WWB) and Stirred vessel bioreactor), is the increase in mass transfer (Kumar et al., 2004).

\section{Spinner Flask}

Spinner flask is the simplest type of bioreactor (Figure 9), in which the porous matrices containing the fixed cells are suspended on needles in the cap. Stirring of the medium is performed by using a magnetic bar, depending on its rotation, helps to induce the mixing of oxygen and nutrients to increase the homogeneity of the medium and consequently tissue growth (Chen and Hu, 2006). These devices can allow monitoring of variables such as $\mathrm{pH}$ and $\mathrm{CO}_{2}$ (Kumar et al., 2004), the rotation speed of the medium between 50 and $80 \mathrm{rpm}$. The culture medium is renewed periodically (usually in periods of 2-3 days) to maintain or increase the concentration of nutrients. In this system the bottle allows aeration of the culture medium and the resulting gas exchange. The nutrient delivery and waste removal occurs by convection and by the fluid passage on the surface of the porous matrix. Their disadvantages are related to the agitation of the medium, which can generate high shear stress values and turbulent regimes harmful to the cell culture (Zhang et al., 2009; Chen and Hu, 2006; Lyons and Pandit, 2005; Korossis et al., 2005; Martin et al., 2004). 

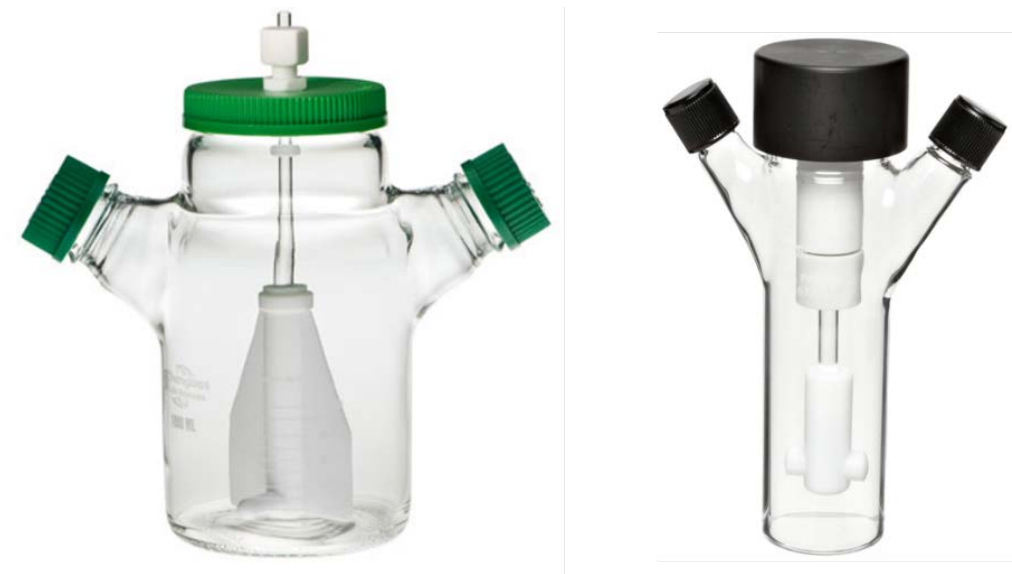

Figure 9 Examples of Spinner flasks from Chemglass ${ }^{\circledR}$ (left) and Capitol Scientific ${ }^{\circledR}$ (right).

\section{Wavy-walled bioreactor}

In order to overcome the limitations of the turbulence and shear stresses observed in Spinner flask systems, was developed a new bioreactor, the Wavy-Walled Bioreactor (WWB) (Figure 10). This machine has ribbed walls which allow reducing turbulence levels of the medium and its shear stresses (Bueno et al., 2004). Studies conducted allowed to verify that this new system has an increase in cell proliferation and deposition/formation of extra-cellular matrix in polymeric scaffolds containing chondrocytes (Chen and Hu, 2006; Bueno et al, 2004).

Bilgen et al., (2006) studied the hydrodynamic parameters involved in the bioreactor WWB, comparatively to the Spinner flask and its influence on the cartilage tissue engineering. This study concluded that the fluid flow is significantly different between them and it was also found that the position of the scaffold inside the bioreactor it is an important parameter because alters the hydrodynamic behaviour of the fluid and the uniformity tensions on the scaffold.
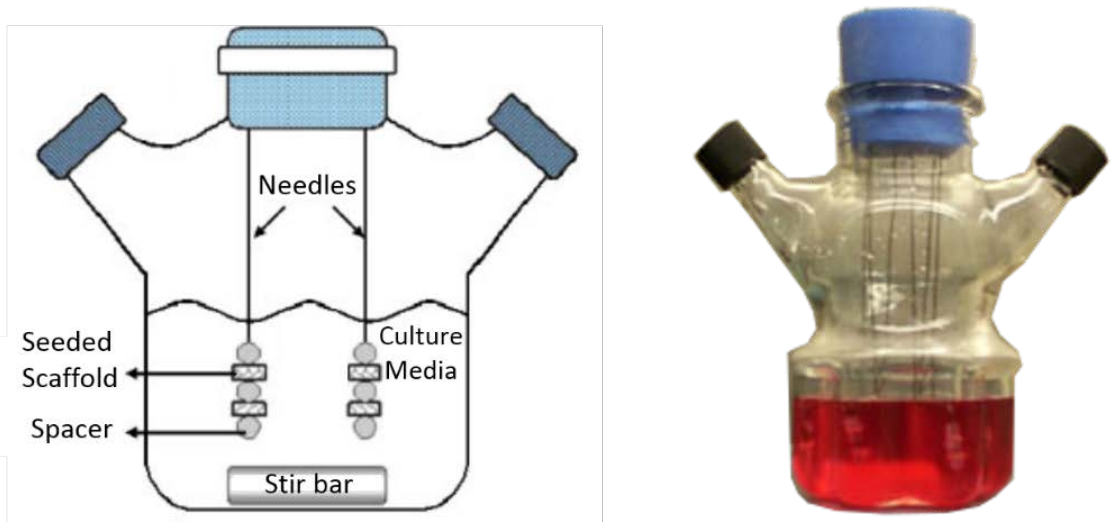

Figure 10 Wavy-walled bioreactor (Chen and Hu, 2006) 


\section{Stirred vessels bioreactors}

This type of bioreactor (Figure 11) it's characterized by obtaining a homogeneous hydrodynamic environment and also because it is easy to operate. Generally it comprises a container (where the cell culture takes place) pipes, sensors, valves, pumps and motor. This system is in motion, usually at a rotation speed of 50-80 rpm (Martin and Vermette, 2005), while the sensors provide continuous monitoring of parameters such as temperature, $\mathrm{pH}$, glucose, among others (Wang et al., 2005; Kumar et al., 2004). This system is similar to spinner flask glass however allows the control over a large number of variables, therefore presenting greater reproducibility. These bioreactors have been used in the culture and differentiation of various cells types of stem cells from human to rats (Serra et al., 2009; Cabrita et al., 2003). It is important to refer that the agitation of the medium can originate high shear stresses harmful to the cells which is a disadvantage of this type of equipment. One possible solution involves changing the shape and/or the diameter of the rotor blade (Wang et al., 2005).
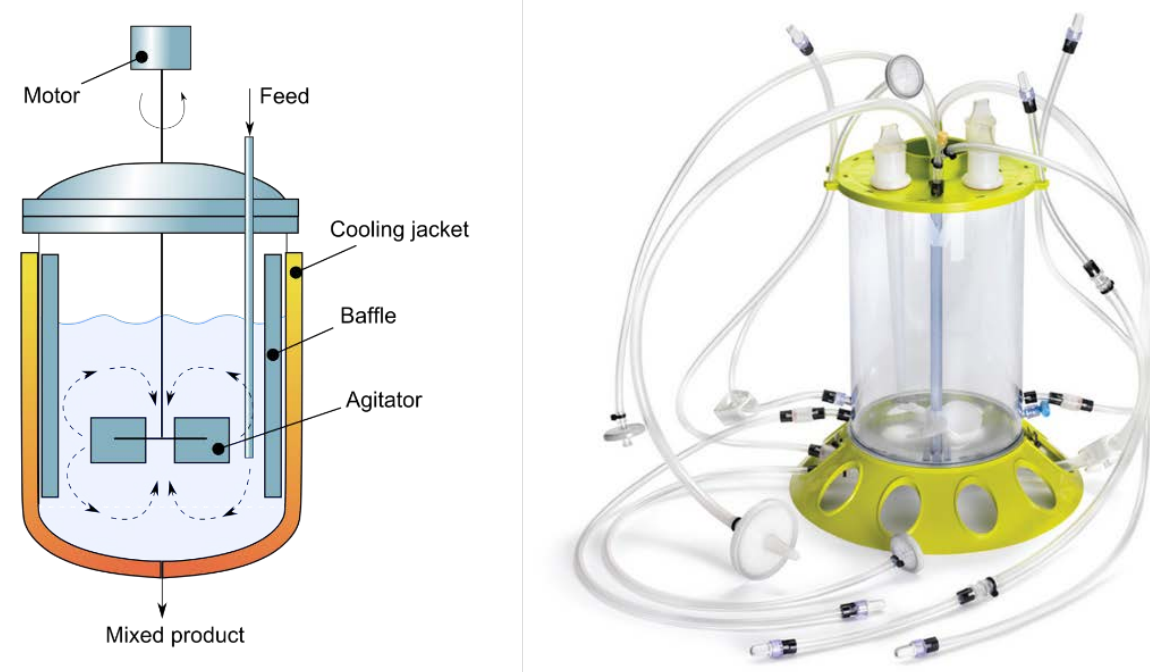

Figure 11 Schematic of a stirred vessel (left) (Redondo, 2014) and a stirred bioreactor from Merckmillipore ${ }^{\circledR}$ (right).

Serra et al., (2009) used successfully this bioreactor to culture pancreatic stem cells from rats using a process of controlled expansion of the pancreatic stem cells in order to apply in the development of new cell therapies. In another study Martin and Vermette (2005) mention the success of culturing cartilage with a thickness of 0.3-0.5 mm using this bioreactor, a value still far from clinical implant thickness (2-5 mm). 


\section{c. Rotation Systems}

The rotation bioreactors base their operation on the application of a rotation about one or more axes. This movement helps to increase the agitation of the culture medium and thus increase the mass transfer. Some bioreactor examples include Rotating-wall vessel bioreactor (RWV), Rotating Shaft bioreactor and biaxial rotating bioreactor.

\section{Rotating-wall vessel}

Despite the importance of shear forces in modelling the mechanical properties of new tissue, high shear stresses can lead to cell death (Chen and Hu, 2006). Because of this were developed bioreactors that during its operation can apply low shear stress values.

The RWV bioreactor (Figure 12) developed by the National Aeronautics and Space Administration (NASA) operates in a microgravity environment. This equipment was the first to combine the dynamic culture environment with low shear stress allowing a high mass transfer (Chen and Hu, 2006; Lyons and Pandit, 2005; Pörtner et al., 2005). In this bioreactor, the scaffold containing the cells is found floating in constant motion by the action of the forces involved (gravity, centrifugal and tangential force). The RWV bioreactor is presented as an alternative to overcome mass transfer limitations, typical of the bioreactors with low agitation (Martin et al., 2004). This equipment has been further modified to allow the fluid inlet at one end and its output through a filter located in the centre of the cylinder, originating the Rotating Wall Perfusion Vessel bioreactor (RWPV). The RWPV is used for cartilage engineering in a gravitic environment and was shown that the proliferation of cartilage tissue and heart tissue was superior at a structural and functional point of view to static culture and spinner flask (Chen and $\mathrm{Hu}, 2006)$. 


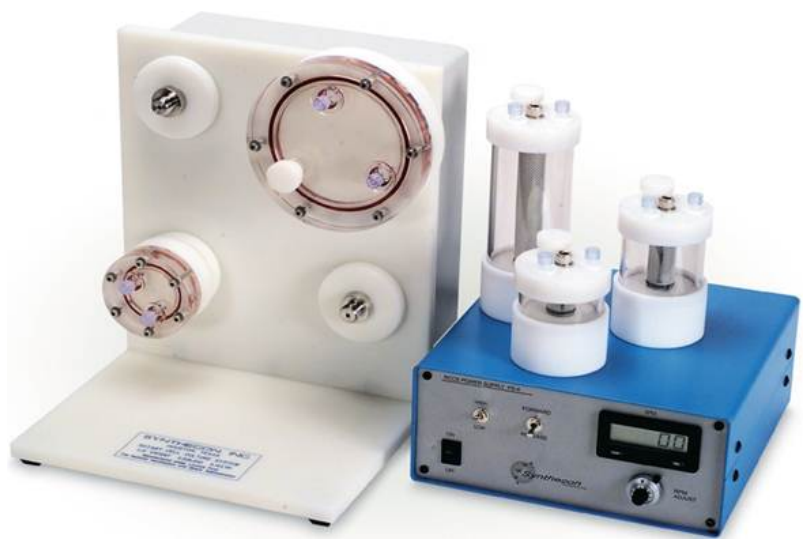

Figure 12 Rotating wall vessel (RWV) bioreactor from Synthecon ${ }^{\circledR}$

Klement et al., (2004) used the bioreactor RWV to determine its influence on the number of processes involved in the formation of bone tissue. To do this, bone tissues have used embryonic rat at four different stages of differentiation. In the study carried out it was found that tissues in the three advanced stages of differentiation, when placed in the bioreactor showed substantial growth, differentiation and mineralization.

Other examples include crop rotation, the Slow Turning Lateral Vessel (STLV) and High Aspect Ratio Vessel (HARV). The STLV is a horizontal rotating bioreactor (Figure 13) consists of two concentric cylinders. The inner cylinder is stationary and consists of a silicone membrane that permits the exchange of gases, while the outer cylinder is of the rotary type and comprises a waterproof material. The rotation speed is variable and adjustable (between 15-40 rpm) allowing the scaffold remains suspended in the bioreactor stationary point due to the dynamic equilibrium of forces (Chen and Hu, 2006; Lyons and Pandit, 2005; Martin and Vermette, 2005). The HARV bioreactor is very similar to STLV and comprises two concentric cylinders, which have a membrane for gas exchange at the base. This equipment is characterized by having a large diameter, a small length and have low rotation velocities, about 12-15 rpm (Martin and Vermette, 2005). In this system the cylinders are connected to two independent motors allowing different rotation speeds and thus different levels of stress and turbulence (Lyons and Pandit, 2005). The operation is carried out to a horizontal working volume of 100-110 $\mathrm{ml}$ (Chen and $\mathrm{Hu}, 2006)$. 

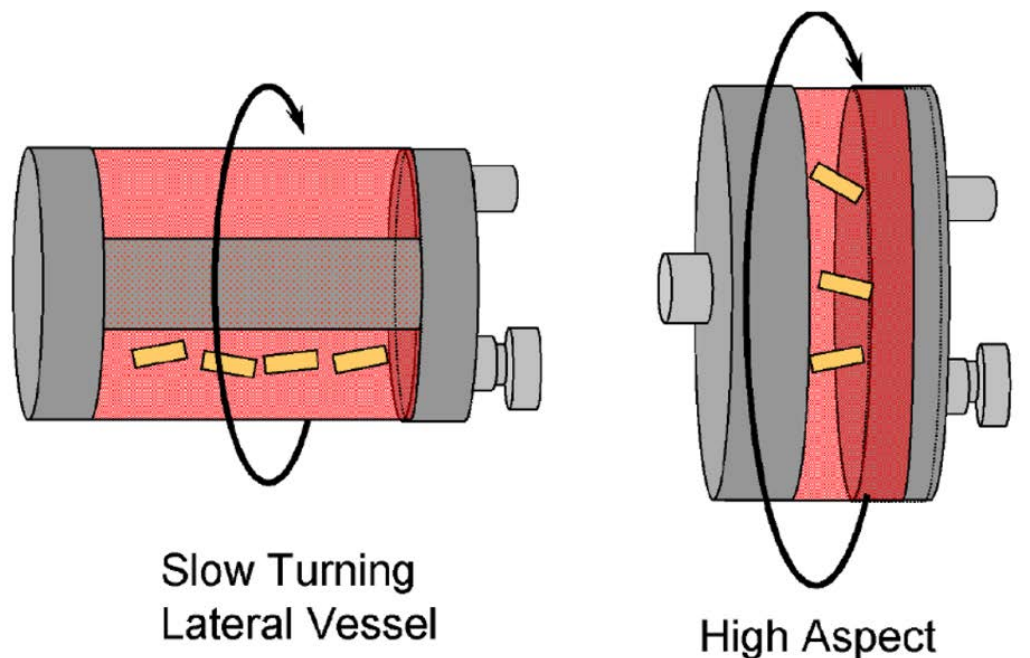

High Aspect

Ratio Vessel

Figure 13 Illustration of a STLV and HARV bioreactor (Ghosh and Kaplan, 2008)

The limitations associated with the above bioreactors include the possibility of a heterogeneous cell proliferation occur due to the low voltages involved and even possible damage due to collisions with the wall of the bioreactor (Zhang et al., 2009; Chen and Hu, 2006). These bioreactors have also some limitations in culturing tissues with high mass (Martin and Vermette, 2005).

\section{Rotating Shaft Bioreactor}

To solve problems related to non-uniformity of the growth of tissues Chen et al., (2004), developed a Rotating Shaft Bioreactor (RSB). This equipment consists of a central horizontal axis of stainless steel, in which is coupled 22 support needles, as shown in Figure 14. This device has two distinct phases: a gas phase and a liquid phase (medium). Through a rotation provided by a motor, the assembly cells/scaffold is continuously transiting between phases at a given rotational speed, which helps to increase the efficiency of mass transfer (Chen and $\mathrm{Hu}$, 2006, Chen et al., 2004). 


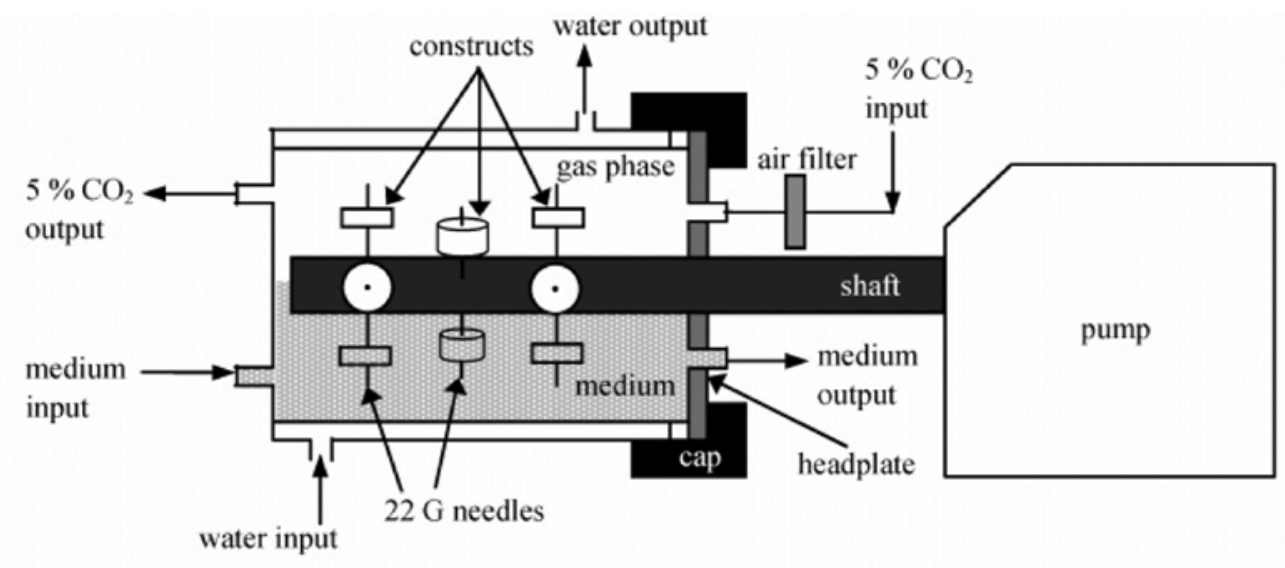

Figure 14 Schematic of a Rotating Shaft Bioreactor (Chen et al., 2004)

\section{Biaxial rotation bioreactor}

Hutmacher et al., (2006) developed a biaxial rotational bioreactor (Figure 15) which allows continuous movement of the culture medium and the control and monitoring in real time of key variables for the cell growth. This system allows the rotation of the culture chamber into two separate axes $(\mathrm{x}, \mathrm{z})$ and independent rotation speeds. The container and the reservoir are connected, allowing the culture medium to circulate between them, resulting in a perfusion system. Thus, it is possible to maximize mass transfer across the scaffold and achieve greater uniformity in the new tissue (Hutmacher et al., 2006; Singh et al., 2005).

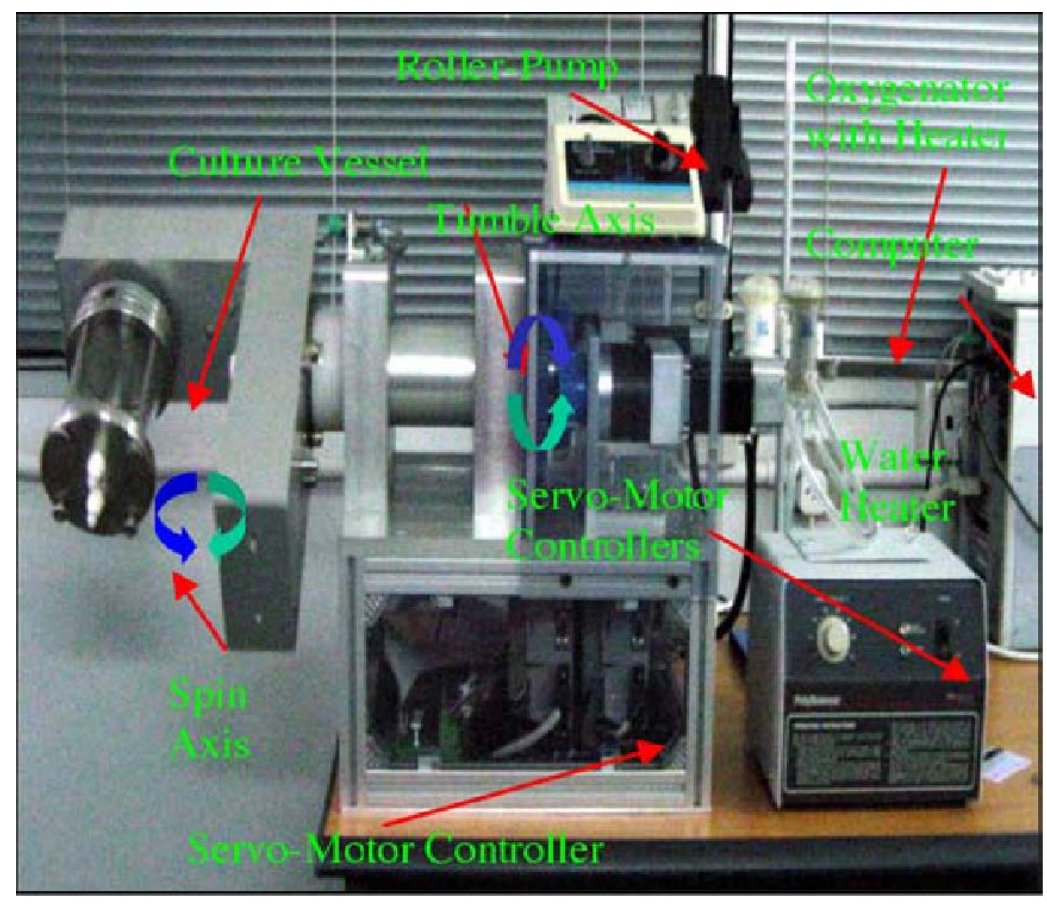

Figure 15 Biaxial Rotating Bioreactor (Singh et al., 2005) 
Several studies have been conducted with the aim of evaluating the influence of the rotation on cell proliferation. Zhang et al., (2009) investigated the ability of forming a bone graft using human mesenchymal stem cells contained in scaffolds of poly( $\varepsilon$-caprolactone)/tricalcium phosphate (PCL/TCP). This study compared the cell culture under static conditions and in a biaxial rotating bioreactor, performed tests in vitro and in vivo. Subsequently, they concluded that the static conditions are associated with a lower cell proliferation and differentiation. Furthermore, the use of the bioreactor allow to reduce the culture time in vitro and to obtain a better distribution of extracellular matrix and increased bone mineralization.

\section{d. Mechanical stimulation systems}

By applying mechanical stimuli to cells it will increase and aid the proliferation, differentiation and alignment of the cells (Martin and Vermette, 2005; Altman et al., 2002), taking into account that the maximum value of the applied stress depends on the cell type being used. For mammalian cell suspensions Martin and Vermette (2005) report that for most cells, shear stresses of 0,1 Pa cause cellular damage being the ideal values around 0,01 $\mathrm{Pa}$ and also it was reported that stress values of 0,001 Pa are insufficient to promote the growth of tissue. Begley and Kleis, (2000) reported that in mammalian cells the levels of shear stress between 0,3 and 1 Pa cause cellular damage and reduce viability while very low values such as 0,092 Pa, adversely affect the proliferation, morphology and cellular function. To stimulate the proliferation and growth of a 3D tissue shear stresses should be in the range of $0,01 \mathrm{~Pa}$. In order to reach this goal it is necessary a laminar flow avoiding high shear stresses generated for example by turbulent flows.

The bioreactors that apply mechanical stimulus, in particular mechanical compression (Figure 16), allow the application of stress in cells with a given magnitude, frequency and duration. Thus, the performance can be of two types: static or dynamic mechanical compression (the first does not include the frequency). The application of the stress is controlled by an engine and its intensity is regulated by a load cell (Martin et al., 2004). This type of stimulation has been applied in the culture of bone and cartilage (Altman et al., 2002) with an uniaxial compression considered the most important stimulus method that acts on cartilage in vivo (Schulz and Bader, 2007). 


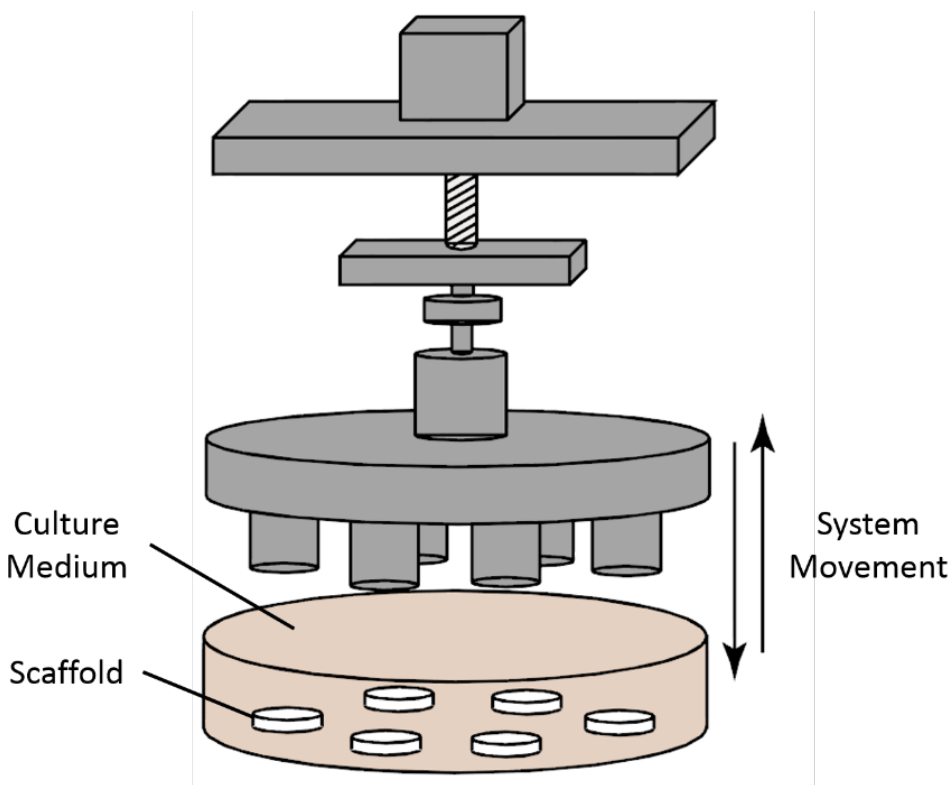

Figure 16 Schematic of a bioreactor that apply controlled mechanical forces (Martin et al., 2004)

Demarteau et al., (2003) developed a bioreactor and used it in the chondrocyte culture under action of dynamic compression stimulus. This study concluded that the application of the stimulus for a period of time more than three days is associated with increased formation of GAG. Orr and Burg (2008) also developed a bioreactor (Figure 17) which combines the application of hydrostatic compression stimuli (about $300 \mathrm{kPa}$ and frequency 0,5 $\mathrm{Hz}$ ) and perfusion (shear stress of $0,07 \mathrm{~Pa}$ ).

The hydrostatic pressure is applied on a diaphragm which compresses a volume of fluid contained in the culture zone. Preliminary tests showed cell viability using this type of bioreactor. 

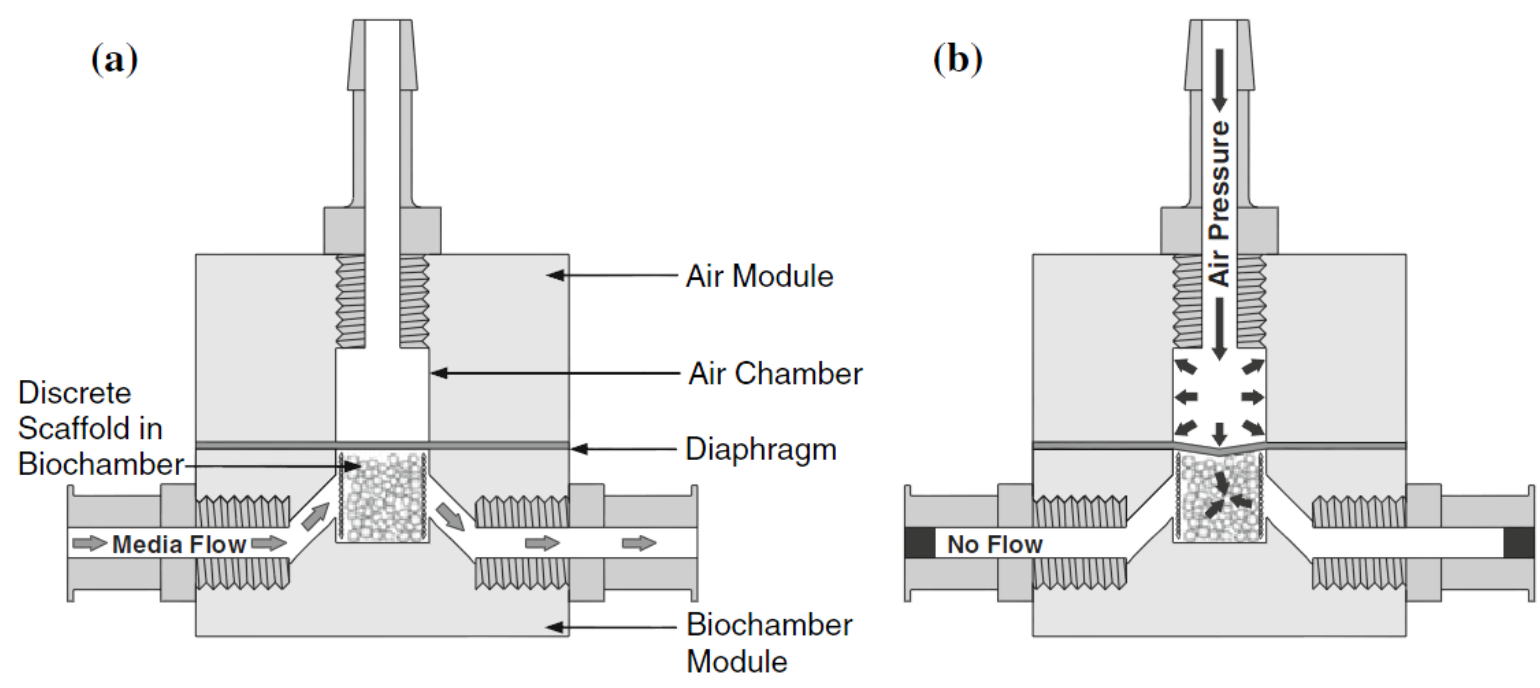

Figure 17 Schematic illustration of a bioreactor assembly that demonstrates (a) perfusion flow and (b) hydrostatic compression (Orr and Burg, 2008)

\section{e. Perfusion Bioreactor}

Perfusion systems aim to overcome the problems with non-uniform cell proliferation (Chen and $\mathrm{Hu}$, 2006). These devices draw their operation in the existence of a flow through the scaffold and cells while allowing simultaneously the constant renewal of the culture medium and cell retention. The applied flux can be continuous or discontinuous and can be applied at different frequencies and speeds. The existence of a flow through the scaffold helps to increase the transfer of nutrients into the scaffold and remove the toxic waste produced by cellular respiration. Furthermore, cells are continuously subjected to hydrodynamic stimuli that have the ability to induce their alignment in the direction of the flow (Chen and $\mathrm{Hu}, 2006)$.

The perfusion bioreactors (Figure 18) can operate in two distinct ways. In the first set scaffold/cell is fixed in a column within the culture zone, while the second set has freedom of movement. Regardless the option made is necessary to ensure that the cells are not entrained by the flow of the culture medium (Schulz and Bader, 2007). 
(a)

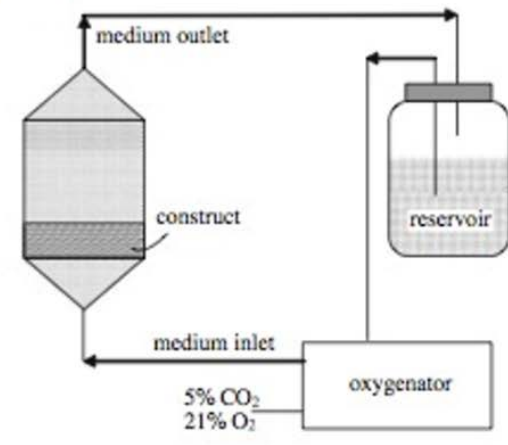

(b)

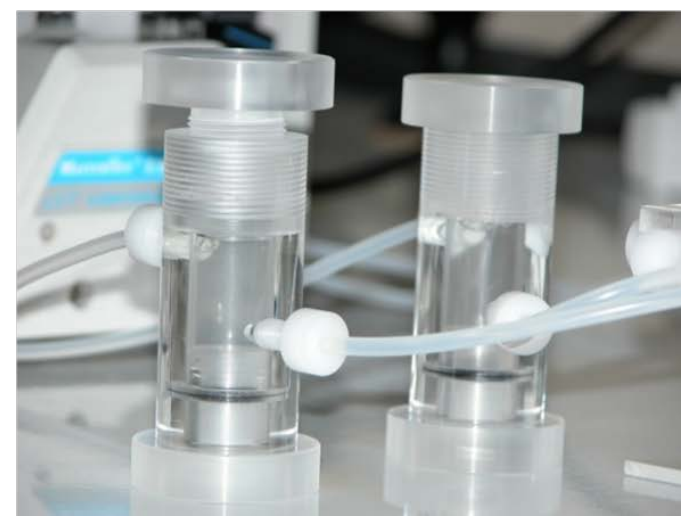

Figure 18 Illustration of a (a) perfusion bioreactor and (b) an example of a perfusion bioreactor (Chen and $\mathrm{Hu}$, 2006; C.I.T., 2014).

In perfusion bioreactors nutrient delivery is not performed only on the periphery of the scaffold it also covers the internal zones (Chen and Hu, 2006; Martin et al., 2004). In addition, the continuous movement of the medium contributes to a more homogenous distribution of cells in the structure and also for greater homogenization of concentrations of gases, nutrients, metabolites and growth factors present in the medium (Korossis et al., 2005). The success of this type of bioreactors depends on the following factors: (1) the relationship between the fluid velocity and the stage of cell maturation; (2) balance between the supply of nutrients and removing waste from the cells; (3) shear stresses exerted by the fluid passage and; (4) ability to retain the extra-cellular matrix (Martin et al., 2004). One of the limitations is the difference between stress and fluid speeds on the scaffold extremities compared with the inner part. This phenomenon can cause non-homogeneous distributions of cells or even cell drag if the fluid velocity is very high (Zhang et al., 2009).

Several studies have demonstrated the feasibility of perfusion in the bioreactor cell culture (Jaasma et al., 2008; Janssen et al., 2006; Bancroft et al., 2002; Pazzano et al., 2000). In these works, Pazzano et al., (2000) demonstrated the improved effectiveness of chondrocyte culture in the perfusion bioreactor comparatively to static culture. They have also observed an increase of $184 \%$ in the concentration of GAG, 118\% in DNA content and 155\% hydroxyproline.

Wendt et al., (2003) developed a bidirectional perfusion bioreactor which consists of two glass columns connected by a U tube (Figure 19). The equipment is composed by a set of sensors and actuators, as a result of detecting a level of fluid (detected by the sensors), vacuum is applied, pressing it in the opposite direction. 


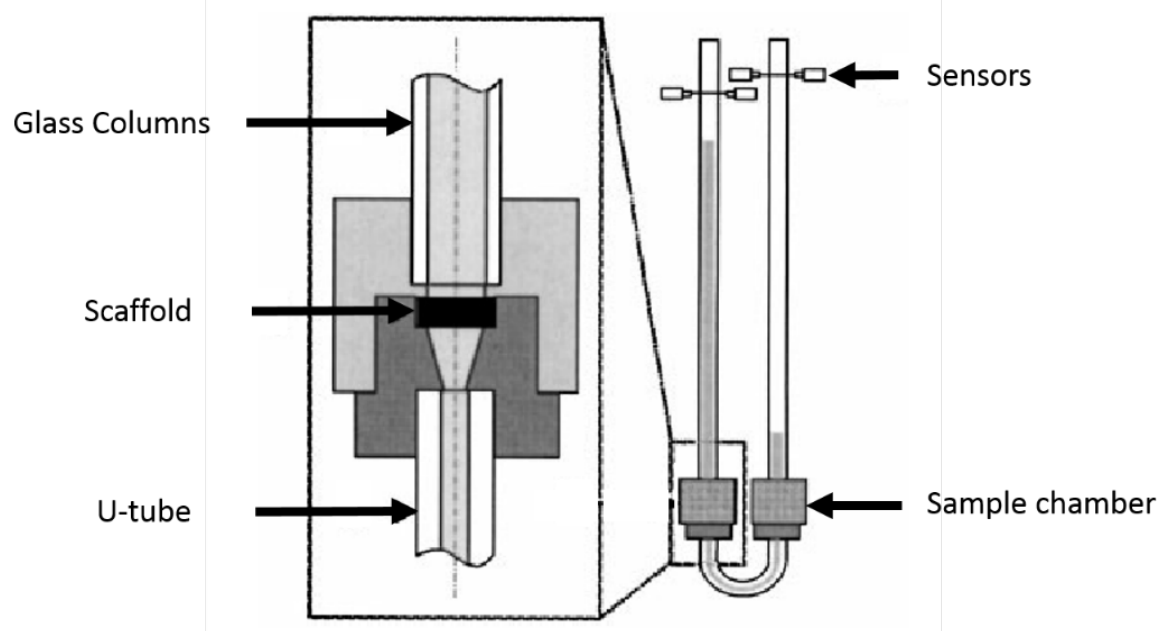

Figure 19 Bidirectional perfusion bioreactor in a U tube design (Wendt et al., 2003).

\section{Hollow Fibre Bioreactor}

These bioreactors were originally developed by Knazek et al. in 1972 (Kumar et al., 2004) and consist of a cylinder containing bundles of parallel hollow fibres (Figure 20). This system includes a porous membrane that acts as a selective barrier to the transport of particles in the medium and has the ability to retain nutrients (e.g. high molecular weight proteins) from the cell, increasing its availability (Martin and Vermette, 2005; Wang et al., 2005). In this type of bioreactor the main method of mass transfer is the diffusion however, the application of a pressure variation on the membrane surface can contribute to increase the process, which increases the flow of nutrients in a given direction (Wang et al., 2005). The cells are embedded in a gel inside the permeable membrane and the perfusion occurs by pumping the culture medium from the outside of the permeable membrane. Applications using the Hollow Fibre Bioreactor (HFB) are carried out in cell culture with high and very sensitive metabolism, such as hepatocytes (Martin et al., 2004) or skin cells (Pörtner et al., 2005).

The major advantage of these bioreactors is the ability to promote the delivery of nutrients to the centre of the growing tissue (Martin and Vermette, 2005). The main disadvantage includes the heterogeneity of culture, which is due to non-uniform gradients in the diffusion of oxygen and nutrients (Martin and Vermette, 2005; Nguyen et al., 2005). This makes their use in the culture of animal cells a little limited (Wang et al., 2005). 


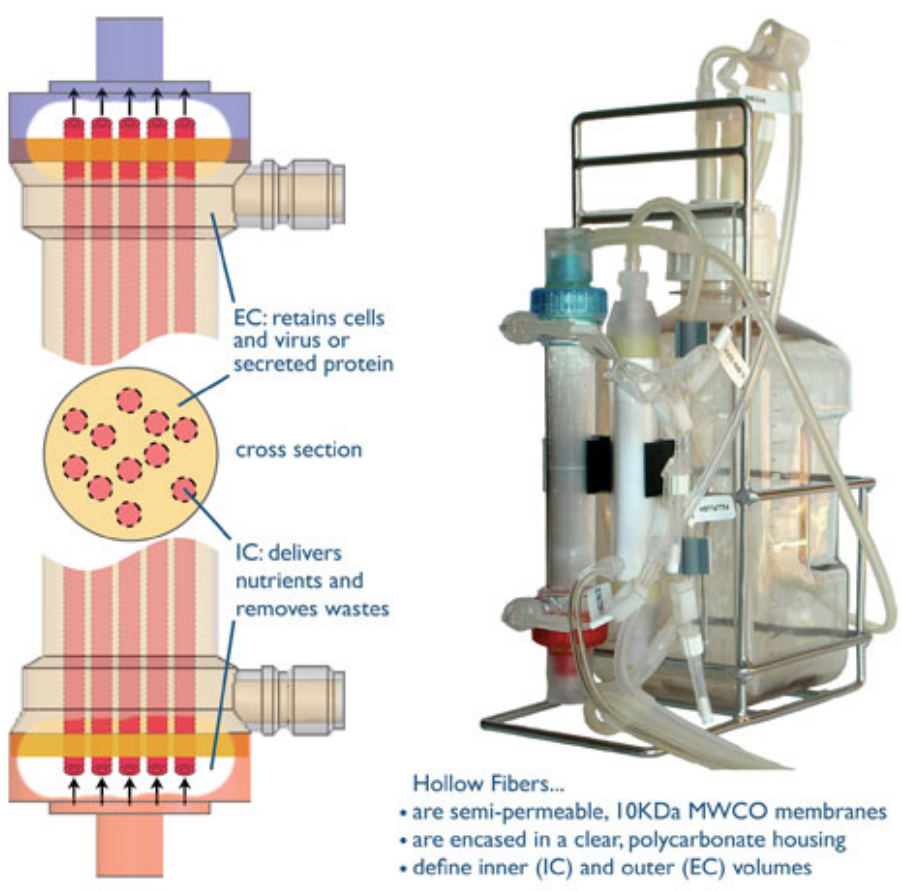

Figure 20 Basic hollow fibre bioreactor design and the HF Primer ${ }^{\mathrm{TM}}$ small-scale bioreactor (Hirschel et al., 2011).

Nguyen et al. (2005) presented a flow-type hollow fibre bioreactor with the aim of improving the delivery of nutrients. When studying the efficiency of the system in cultured hepatocytes concluded that with this strategy it is possible to increase the lifetime and the cell viability when compared to the same system without the introduction of a pulsed flow. Also, Hoesli et al. (2009) used this bioreactor in the encapsulation of mammalian cells in alginate process obtaining good results.

\section{Packed and Fluidized bed bioreactors}

In this bioreactor (Figure 21) cells are immobilized in a column containing porous supports which are found fixed (packed bed) or floated (fluidized bed). This column is under continuous perfusion which causes the cells to suffer stimuli of hydrodynamic nature (Pörtner et al., 2005). When comparing the fluidized bed bioreactor with the packed bed, it is found that the former allows a greater productivity, however, their complexity hydrodynamic level is higher (Godia and Solà, 1995). These bioreactors are used in the culture of mammalian cells, production of pharmaceuticals, cartilage cell culture, among others (Pörtner et al., 2005). 


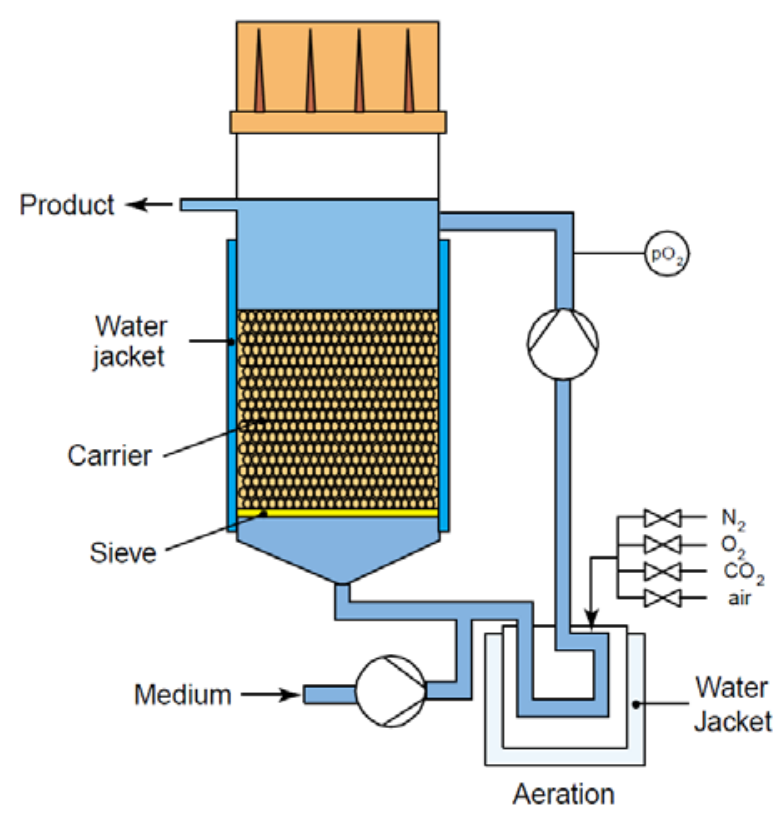

Figure 21 Schematic of the fluidized bed or packed bed bioreactor (Cabrita et al., 2003).

\section{Pulsatile flow bioreactor}

The pulsatile flow bioreactor (Figure 22) is used primarily in cardiovascular tissue engineering and aims to simulate the conditions in vivo that these tissues are subjected. In these devices, the flow is pulsed through the cells and can have different frequencies and intensities; the fluid pressure is also similar to blood pressure in the human body. The pulsatile flow results from periodic inflation and deflation of a highly elastic membrane caused by an air pump (Chen and Hu, 2006; Niklason et al., 1999).

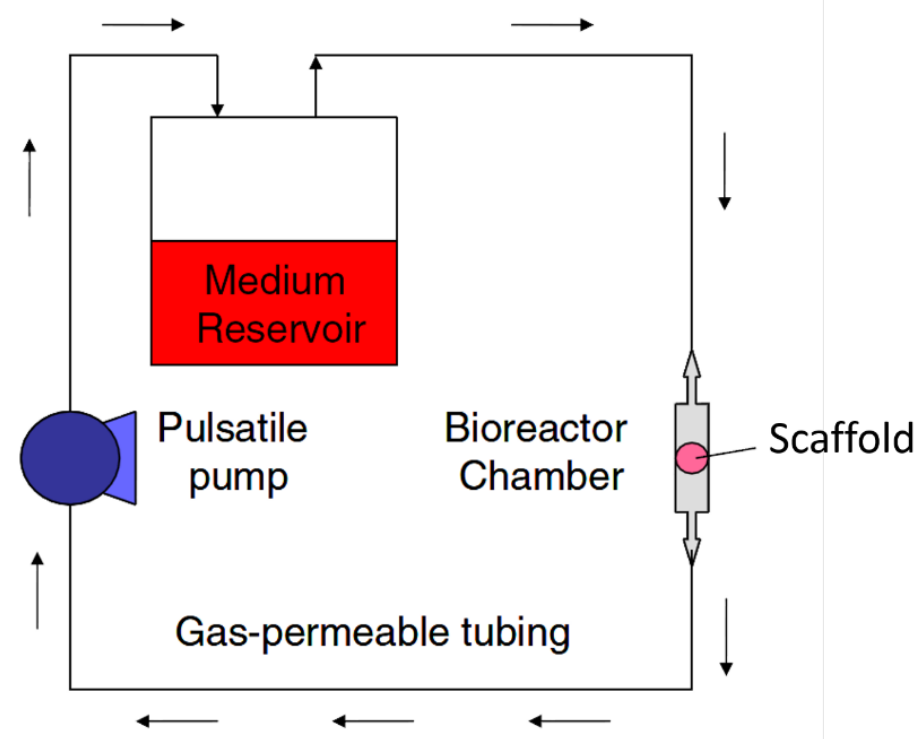

Figure 22 Schematic diagram of the pulsatile flow bioreactor system (Cooper et al., 2007). 
Niklason et al. (1999) carried out the culture of smooth muscle cells using a pulsatile flow bioreactor for a period of 8 weeks. After this period, the appearance of the cultures blood vessels was similar to the original human arteries. Also Brown et al. (2008) developed a perfusion bioreactor capable of applying pulsatile flows and allow the application of significant levels of shear stress. The system allows the regulation of the flow rate of the fluid carried by them, as well as their frequency of use. The same group of investigators tested in bioreactor a culture of cardiac tissue and concluded that the pulsatile stimulus positively contributes to the contractile properties of the tissue originated.

The perfusion bioreactor, together with spinner flask and RWV are widely used in the tissue engineer of cartilage tissue, demonstrating successful in vitro culture of chondrocytes embedded in polymeric scaffolds (Chen and $\mathrm{Hu}, 2006$ ). 


\section{Computational Modelling of Fluid Dynamics}

In this chapter it is described the properties of fluids and also how to characterize it computationally using several mathematical models in the computational calculations to determine the fluid behaviour across the bioreactor.

\subsection{Fluid Classification}

Basically a fluid is characterised by its inability to sustain deviatoric stresses when at rest and are classified in two major groups, the Newtonian and the non-Newtonian fluids. Essentially the difference between them depends strictly on the variation of the shear stress and the deformation ratio which can be represented by (Zienkiewicz at al., 2005, Nguyen and Choi, 2012):

$$
\tau=\tau_{y}+\eta\left(\frac{d u}{d y}\right)^{n}
$$

where $\tau$ is the shear stress, $\tau_{y}, \eta$ and $n$ are constants, $\tau_{y}$ is the yield stress and is $\eta$ the dynamic viscosity, $d u / d y$ is the deformation ratio. Figure 23 classifies the fluids according to their rheological properties. The viscosity of a Newtonian fluid is independent of time and shear rate and for that reason has an ideal behaviour (linear) as shown in Figure 23. Fluids are mention as plastic when the shear stress reaches a minimum value before it begins to flow. The nonNewtonian fluids are classified as plastic, Bingham plastic, pseudo-plastic and dilatant fluids (Douglas et al., 2005). The variation between the different classifications of non-Newtonian fluids varies with the constant $n$ presented in Equation (2). If $n$ is equal to one, the material is a Newtonian fluid but if the deformation rate don't reach a critical value of the shear stress the material is denominated as a Bingham plastic. If the dynamic viscosity decreases as the shear rate increases it is called a pseudo-plastic or shear-thinning fluid. If the opposite occurs, i.e., 
the dynamic viscosity increases as the shear rate increases it is called a dilatant or shearthickening fluid. In short, a dilatant fluid is represented by $n>1$, a pseudo-plastic is represented by $n<1$ and a Newtonian fluid is represented by $n=1$ (Nguyen and Choi, 2012).

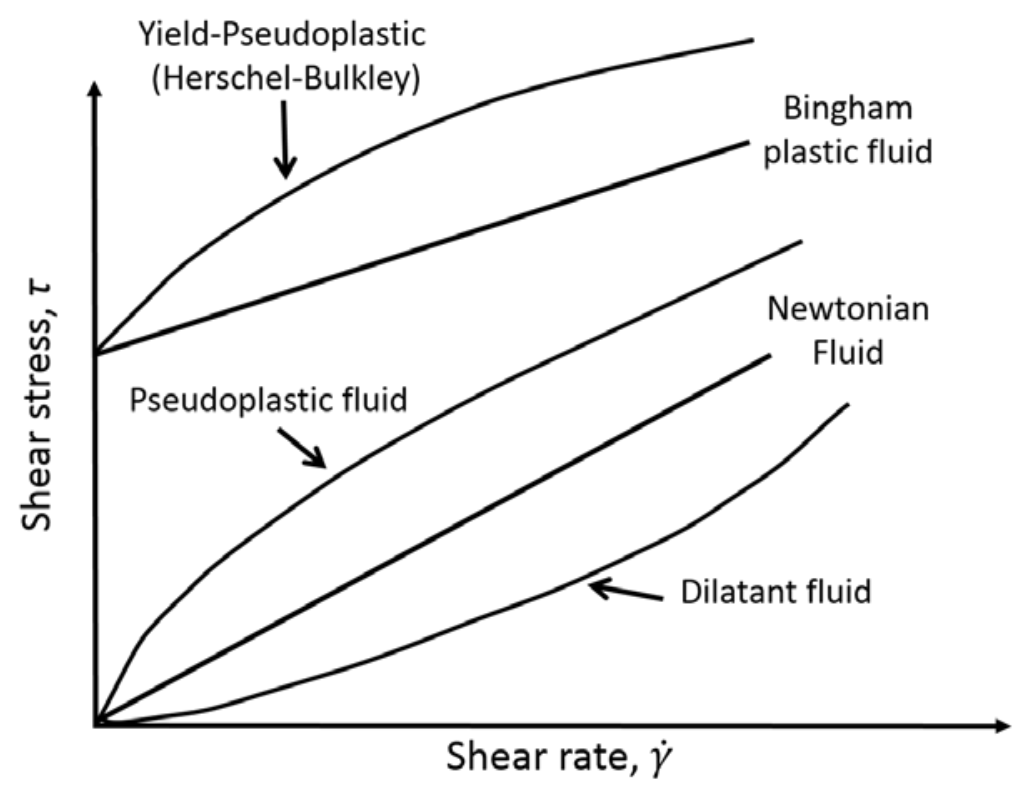

Figure 23 Classification of the rheological behavior of fluids (adapted from Nguyen and Choi, 2012).

The materials can be yet characterized as thixotropic or rheopectic fluids depending on the variation of viscosity with the applied shear stress along time. If the viscosity decreases the fluid is called thixotropic if increases is called rheopectic (Derakhshandeh et al., 2012).

\subsection{Computational Modelling}

\subsubsection{Navier-Stokes equation}

The Navier-Stokes equations (Pozrikidis, 2009) are differential equations that describe the flow of Newtonian fluids. These equations are partial derivatives for determining the velocity field and pressure in a flow. They were called after Claude-Louis Navier and George Gabriel Stokes that developed a set of equations that describe the motion of fluid substances such as liquids and gases. 
The Navier-Stokes equation follows from the motion equation:

$$
\rho \frac{d u}{d t}=\nabla \cdot \sigma+\rho g
$$

by substituting the constitutive equation for the stress tensor for an incompressible Newtonian fluid given by:

$$
\sigma=-p I+2 \mu E
$$

where $\sigma$ is the stress, $\mu$ is the offset, $t$ the time, $\rho$ is the density, $g$ is the gravitational acceleration, $p$ is the pressure, $\mu$ is the fluid viscosity, $I$ is the identity matrix and $E$ is the strain rate tensor. For a fluid of uniform viscosity the force of hydrodynamic volume is given by:

$$
\sum \equiv \nabla \cdot \sigma=\nabla \cdot(-p I+\mu 2 E)=-\nabla p+\mu 2 \nabla \cdot E
$$

In indicial notation it is possible to observe that the nth to default component of the second divergence tensor index of strain rate, $E$, is:

$$
\begin{gathered}
2 \frac{\partial E_{j i}}{\partial x_{j}}=2 \frac{\partial}{\partial x_{j}}\left[\frac{1}{2}\left(\frac{\partial u_{i}}{\partial x_{j}}+\frac{\partial u_{j}}{\partial x_{i}}\right)\right]=\frac{\partial^{2} u_{i}}{\partial_{x_{j}} \partial_{x_{j}}}+\frac{\partial^{2} u_{j}}{\partial_{x_{j}} \partial_{x_{i}}} \\
=\frac{\partial^{2} u_{i}}{\partial_{x_{j}} \partial_{x_{j}}}+\frac{\partial}{\partial_{x_{i}}}\left(\frac{\partial_{u_{j}}}{\partial_{x_{j}}}\right)
\end{gathered}
$$

Considering that the fluid is incompressible, the difference in velocity in the last term of Equation (6) enclosed in brackets is zero. In Equation (6) it is also possible to considerer: 


$$
\frac{\partial^{2} u_{i}}{\partial_{x_{j}} \partial_{x_{j}}}=\frac{\partial^{2} u_{i}}{\partial x^{2}}+\frac{\partial^{2} u_{i}}{\partial y^{2}}+\frac{\partial^{2} u_{i}}{\partial z^{2}} \equiv \nabla^{2} u_{i}
$$

Using these results in order to simplify the Equation (5) it is possible to verify that the force of hydrodynamic volume is given by:

$$
\sum \equiv \nabla \cdot \sigma=-\nabla p+\mu \nabla^{2} \mathrm{u}
$$

Therefore, the Equation (3) of movement is reduced to the Navier-Stokes equation.

$$
\rho \frac{d u}{d t}=-\nabla p+\mu \nabla^{2} \mathrm{u}+\rho \mathrm{g}
$$

that distinguishes from the Euler equation,

$$
\rho \frac{D u}{D t}=-\nabla p+\rho g
$$

by the presence of the viscous force represented by the product of the viscosity and the Laplacian of the velocity.

The Eulerian form of the Navier-Stokes equation involving the time and space derivatives is given by:

$$
\rho\left(\frac{\partial u}{\partial t}+u \cdot \nabla u\right)=-\nabla p+\mu \nabla^{2} u+\rho g
$$


The three main scalar Cartesian components of the Equation (11) are given by:

$$
\begin{gathered}
\rho\left(\frac{\partial u_{x}}{\partial t}+u_{x} \frac{\partial u_{x}}{\partial_{x}}+u_{y} \frac{\partial u_{x}}{\partial_{y}}+u_{z} \frac{\partial u_{x}}{\partial z}\right) \\
=-\frac{\partial p}{\partial x}+\mu\left(\frac{\partial^{2} u_{x}}{\partial x^{2}}+\frac{\partial^{2} u_{x}}{\partial y^{2}}+\frac{\partial^{2} u_{x}}{\partial z^{2}}\right)+\rho g_{x} \\
\rho\left(\frac{\partial u_{y}}{\partial t}+u_{x} \frac{\partial u_{y}}{\partial_{x}}+u_{y} \frac{\partial u_{y}}{\partial y}+u_{z} \frac{\partial u_{y}}{\partial_{z}}\right) \\
=-\frac{\partial p}{\partial y}+\mu\left(\frac{\partial^{2} u_{y}}{\partial x^{2}}+\frac{\partial^{2} u_{y}}{\partial y^{2}}+\frac{\partial^{2} u_{y}}{\partial z^{2}}\right)+\rho g_{y} \\
\rho\left(\frac{\partial u_{z}}{\partial t}+u_{x} \frac{\partial u_{z}}{\partial_{x}}+u_{y} \frac{\partial u_{z}}{\partial_{y}}+u_{z} \frac{\partial u_{z}}{\partial_{z}}\right) \\
=-\frac{\partial p}{\partial x}+\mu\left(\frac{\partial^{2} u_{z}}{\partial x^{2}}+\frac{\partial^{2} u_{z}}{\partial y^{2}}+\frac{\partial^{2} u_{z}}{\partial z^{2}}\right)+\rho g_{z}
\end{gathered}
$$

\subsubsection{Turbulence Kinect Energy}

One of the fundamental problems of Fluid Dynamics has been, and still is, the Turbulence. Taking that into account, there are several theoretical analysis and prediction models that are carried out in CFD simulations (Vickers and Thomas, 2013). The description of turbulent flow is so complex, and for that reason, the existing formulations may go from just simple definitions of skin friction or heat transfer coefficients, going up to a more specific energy spectra's and turbulence fluctuation magnitudes and scales (Celik, 1999).

Fluid can be characterised by several models: there are the zero-equation models, one-equation models, two-equation models and there are more advanced models. To carry out the study of the turbulence within the chamber of this perfusion bioreactor, the Turbulence Kinetic Model (TKE) was used and it is a one-equation model. It's an alternative to the algebraic model and it predicts, by solving one additional transport equation, the turbulent flow. Despite the fact that common turbulent scales are often used as the variable in the transport equation, one of the most used methods is the calculation of the characteristic turbulent velocity scale proportional 
to the square root of the specific kinetic energy of turbulent fluctuations that is usually referred as turbulence kinetic energy, denoted by $k$. The variable $k$ can be obtained by the mean of the turbulence normal stresses:

$$
k=\frac{1}{2}\left(\overline{u^{\prime} u^{\prime}}+\overline{v^{\prime} v^{\prime}}+\overline{w^{\prime} w^{\prime}}\right)
$$

where $k$ is the turbulence kinetic energy; $u^{\prime}, v^{\prime}$ and $w^{\prime}$ are the three fluctuating components of velocity. The full form of the TKE equation can be observed in the following equation:

$$
\begin{aligned}
\frac{\partial u}{\partial t}+\bar{u}_{j} \frac{\partial k}{\partial x_{j}} & =-\frac{1}{\rho} \frac{\overline{\partial u^{\prime}{ }_{l} p^{\prime}}}{\partial x_{i}}-\frac{\overline{\partial k u^{\prime}}}{\partial x_{i}}+v \frac{\overline{\partial^{2} k}}{\partial x_{j}^{2}}-\overline{u_{i}^{\prime} u_{j}^{\prime}} \frac{\partial \overline{u_{i}}}{\partial x_{j}} \\
& -v \frac{\overline{\frac{\partial u_{i}^{\prime}}{\partial x_{j}} \frac{\partial u_{i}^{\prime}}{\partial x_{j}}}-\frac{g}{\rho_{0}}-\overline{\rho^{\prime} u^{\prime}{ }_{i} \delta_{i 3}}}{}
\end{aligned}
$$

Where $\partial k / \partial t$ is the local derivative; $\bar{u}_{j} \partial k / \partial x_{j}$ is the advection value; $1 / \rho_{0} \partial u_{i}^{\prime} p^{\prime} / \partial x_{i}$ is the pressure diffusion; $\partial k u_{i}^{\prime} / \partial x_{i}$ is the turbulent transport $(T) ; v \partial^{2} k / \partial x_{j}^{2} v$ is the molecular viscous transport value; $\overline{u_{i}^{\prime} u_{j}^{\prime}} \partial \overline{u_{i}} / \partial x_{j}$ is the production $(P) ; v \partial u_{i}^{\prime} \partial u_{i}^{\prime} / \partial x_{j} \partial x_{j}$ is the dissipation $\left(\varepsilon_{k}\right)$; and the $g / \rho_{0}-\overline{\rho^{\prime} u_{i}^{\prime}} \delta_{i 3}$ is buoyancy flux (Baldocchi, 2005). 


\section{Simulation of the Perfusion Bioreactor}

In this fourth chapter will be described and illustrated the methods used in this work since the design of the perfusion bioreactor and the scaffold as also the simulation parameters. It will also be exposed and discussed the results obtained from the simulations.

\subsection{Methods}

The design of the bioreactor is at most importance to have the proper control of the entire cell culture due to the necessity of having several variables to be controlled such as stimulus, fluid velocity, fluid flow, direction of the flow, temperature and scaffold position among several others. In order to better understand the bioreactor's behaviour and also to obtain valid results, there are certain conditions to be fulfilled, such as: the simulation parameters and the type of fluid.

\subsubsection{Perfusion Bioreactor Design}

With the aid of a parametric CAD software, a perfusion bioreactor chamber with two dynamic pistons was modelled. The pistons have an axial movement and they are controlled separately. Figure 24 shows all the measurements of the perfusion chamber and the minimum and maximum lengths that each piston can have in order to obtain an adequate stimulus, necessary to the cell proliferation. 


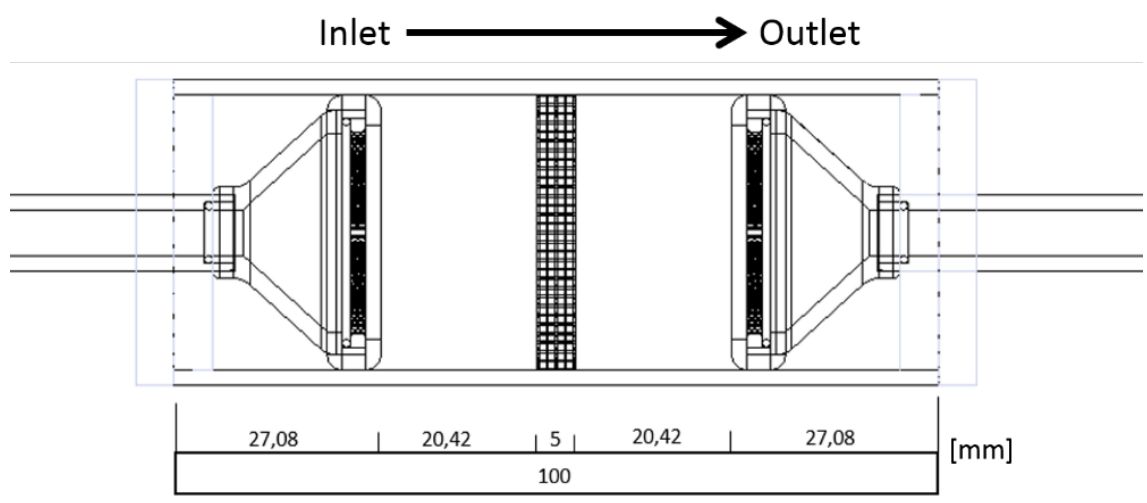

Figure 24 Model and measures of the perfusion bioreactor.

For the optimization and study of the fluid flow within the chamber, the pistons were positioned in four different configurations as showed in Figure 25. The piston positions are defined as the Open position the most distant to the scaffold and the Close position the closest to the scaffold. With these two piston positions, four different piston configurations were obtained: 1) both pistons in the Open position, $O O$ (Figure 25a); 2) Inlet piston (left) Open and the Outlet (right) piston in a Close position, OC (Figure 25b); 3) Inlet piston (left) Close and the Outlet (right) piston in an Open position, $C O$ (Figure 25c); 4) both pistons in the Close position, CC (Figure 25d). 
a)

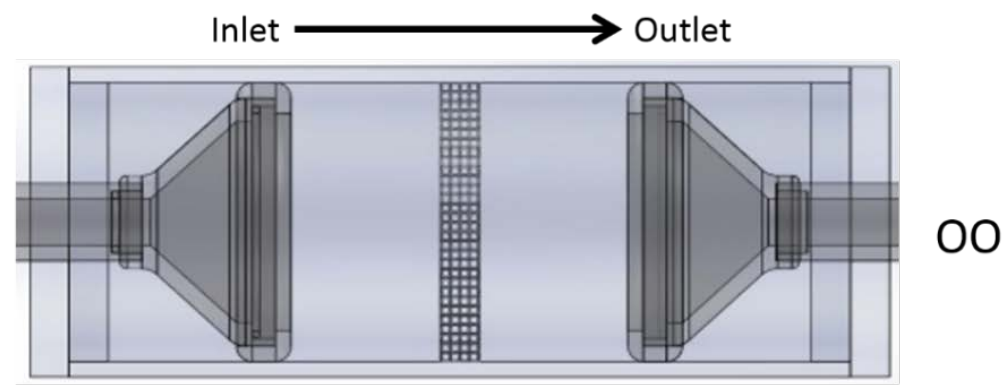

b)

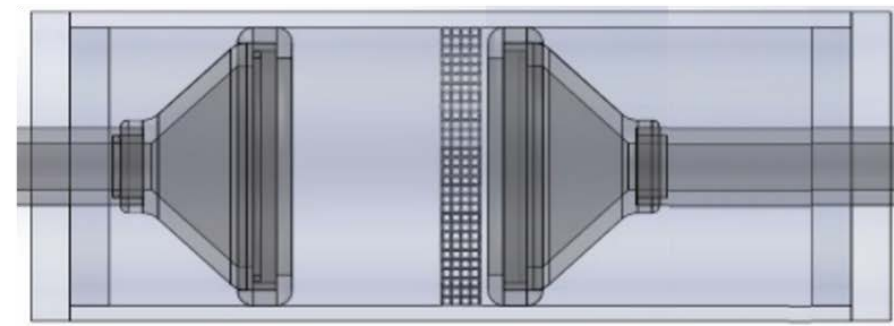

$\mathrm{OC}$

c)

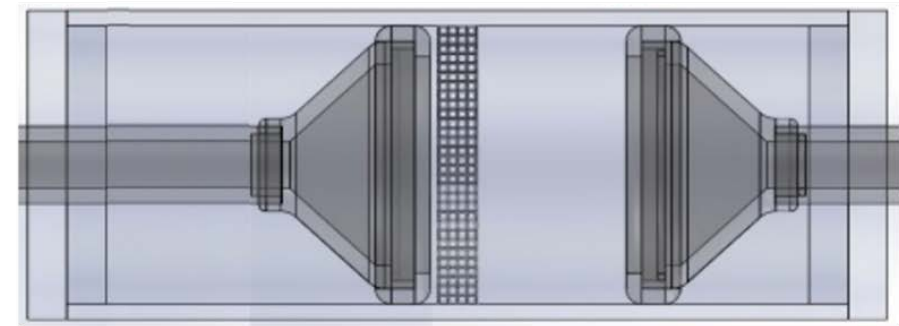

$\mathrm{CO}$

d)

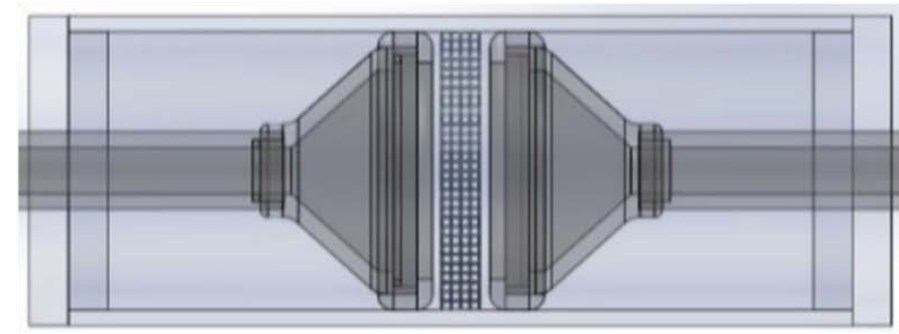

CC

Figure 25 Model of the perfusion bioreactor demonstrating the four pistons configurations, a) Open-Open, b) Open-Close, c) Close-Open and d) Close-Close positions.

Commonly in all the perfusion bioreactors the fluid flows directly to the scaffold in a linear way, originating most of the times a uniform distribution of the fluid in the scaffold surface but sometimes the fluid also reaches high values of shear stress due to the high impact of the fluid right into the scaffold resulting in cellular necrosis. In this particular perfusion bioreactor, besides the linear flow of the fluid, the aim is also to have, in a controlled way, different stresses and different velocities forcing the cells within the scaffold to proliferate with different stimulus and therefore creating a heterogeneous tissue. In order to accomplish these differences and to better understand the correlation between the changes of the fluid velocity on the surface of the scaffold, three different membrane configurations were modelled: 1) in the first membrane, the fluid flows parallel to the chamber walls (perpendicular to the scaffold surface) denominated as PF (Parallel Flow) as seen in Figure 26a); 2) in the second membrane configuration (Figure 26b), the pores of the membrane redirects the fluid to the centre of the chamber (Inward), 
referred as IF (Inward Flow); 3) in the third and last membrane (Figure 26c), the pores of the membrane redirects the fluid towards the walls of the chamber, referred as OF (Outward Flow).

a)

b)

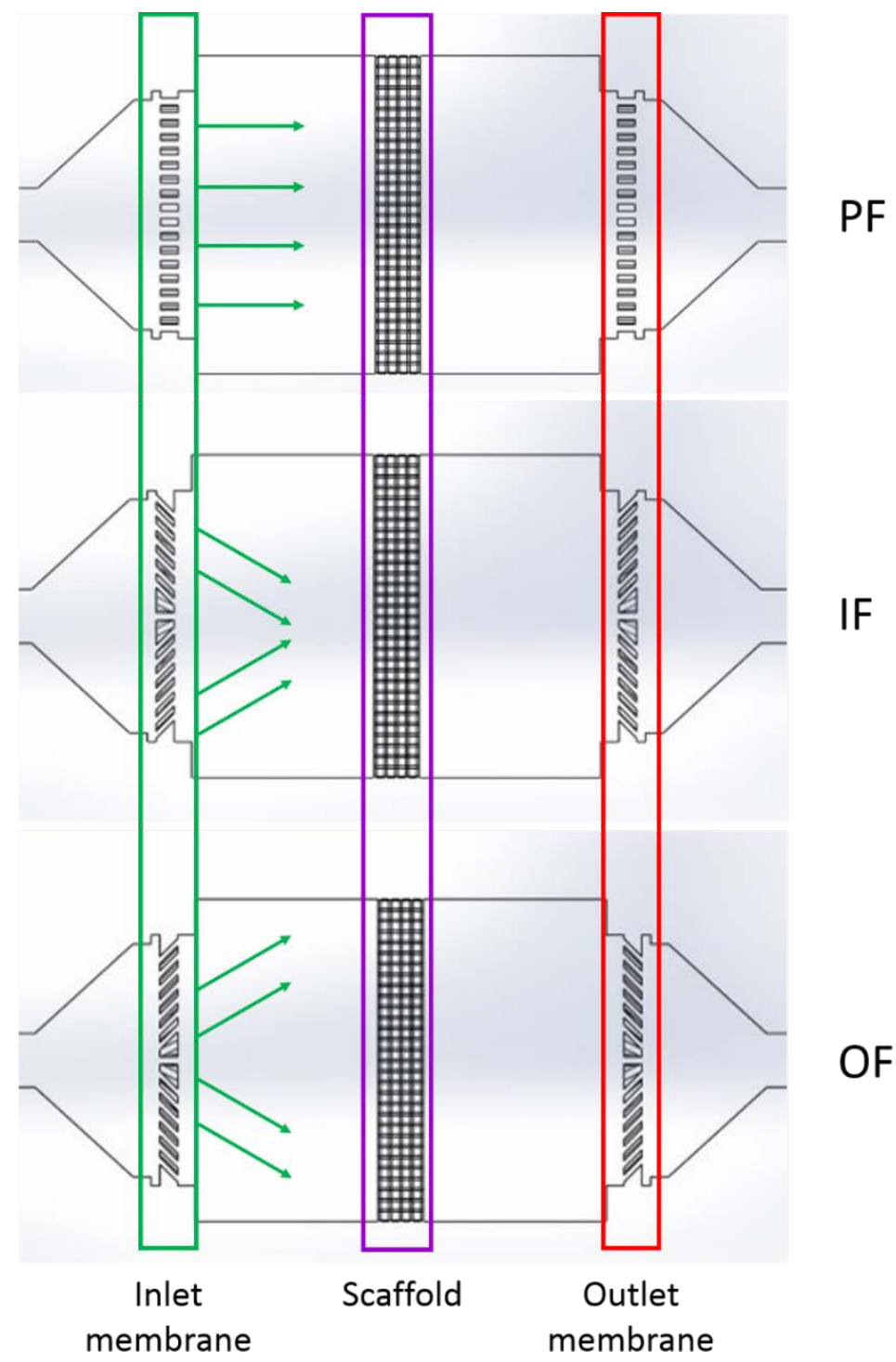

Figure 26 Membrane configuration to redirect the fluid flow where a) is the Parallel Flow configuration, b) the Inwards Flow configuration and c) the Outward Flow configuration.

\subsubsection{Scaffold Design}

The scaffold (Figure 27) was designed with a cylinder form in order to be fitted into the bioreactor. It was designed with $5.10 \mathrm{~mm}$ of thickness, a diameter of $36 \mathrm{~mm}$, with a filament of $0.3 \mathrm{~mm}$, a pore size of $0.9 \mathrm{~mm}$, a pattern configuration of $0^{\circ} / 90^{\circ}$ and a porosity of approximately $82 \%$. 


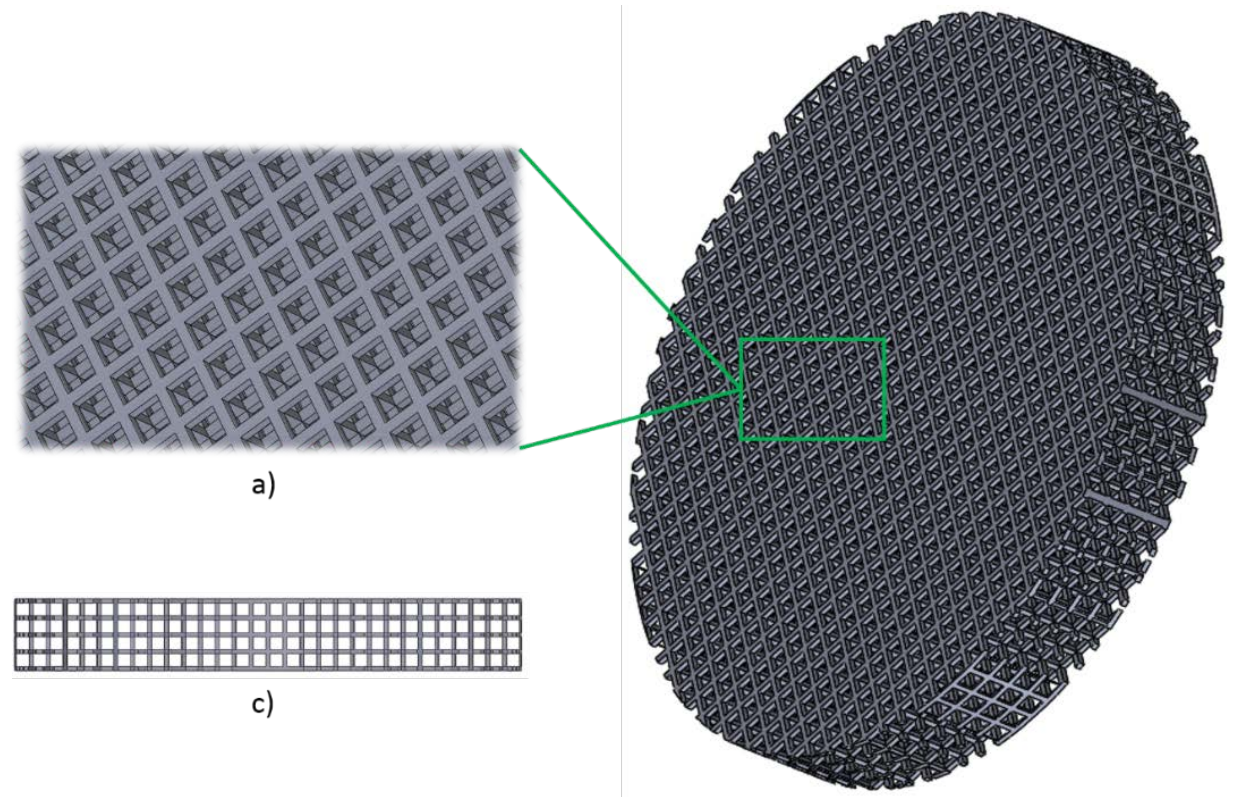

Figure 27 Design of the scaffold used in this work, a) detail of the filament pattern; b) lateral view of the scaffold.

\subsubsection{Simulation Conditions and Settings}

In order to accomplish a full study of the fluid behaviour within this novel perfusion bioreactor there were performed several simulations taking into account the conditions of the medium and other parameters described ahead. Due to the pertinence of this study and to better understand the fluid behaviour facing the different sets of both configurations, pistons and membranes, it was also established simulations with and without the presence of the scaffold inside the bioreactor. The absence of a scaffold in the simulations is of major importance to better understand the fluid behaviour along its entire course since the inlet up to the outlet without any constraints in the middle allowing to study the influence of each membrane configuration and each piston position identifying the turbulent effects caused by each of them.

In Figure 28 it is possible to observe the simulation schematic for one velocity.

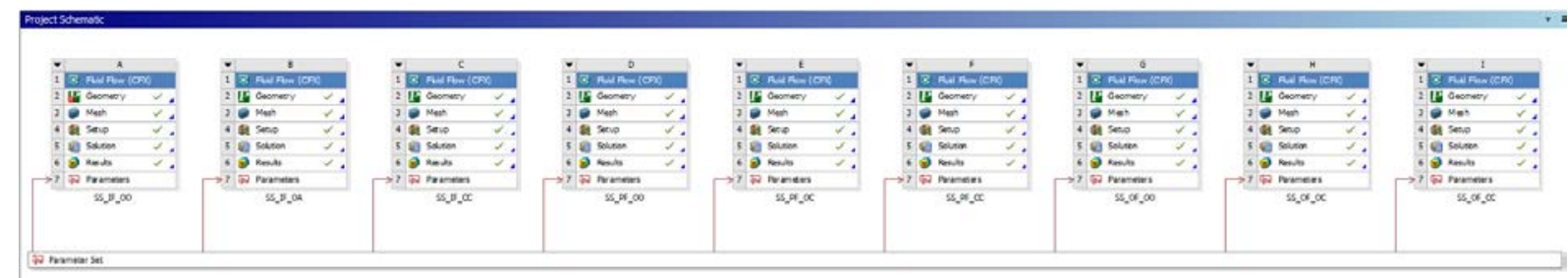

Figure 28 Computational simulation schematic. 


\section{i. CFD conditions}

For the Computational Fluid Dynamics (CFD) simulation it was considered twelve combinations (four piston configuration with the three membrane configurations). The number of finite elements and their average size used in the mesh of the CFD analysis for each configuration is displayed in Table 7.

Table 7 Mesh conditions used in the CFD analysis.

\begin{tabular}{ccc}
\hline Chamber Configuration & Total Elements & Average Elements Size [mm] \\
\hline$P F-O O$ & 3850276 & 0,825 \\
\hline$P F-O C / P F-C O$ & 4313385 & 0,826 \\
\hline$P F-C C$ & 4780823 & 0,828 \\
\hline$I F-O O$ & 3070320 & 0,817 \\
\hline$I F-O C / I F-C O$ & 3382761 & 0,819 \\
\hline$I F-C C$ & 3688855 & 0,820 \\
\hline OF-OO & 3088909 & 0,818 \\
\hline OF-OC/OF-CO & 3416962 & 0,819 \\
\hline OF-CC & 3718000 & 0,820 \\
\hline Average & $\mathbf{3 7 0 1 1 4 3}$ & $\mathbf{0 , 8 2 1}$ \\
\hline
\end{tabular}

The CFD simulations were carried out taking into consideration determined parameters, i.e., properties of the fluid and the flow, different velocities of the fluid, general dimensions of the perfusion bioreactor more specifically the chamber and the inlet and outlet dimensions as listed in Table 8.

Table 8 Fluid characteristics and chamber properties used in the CFD analysis.

\begin{tabular}{cc}
\hline Parameter & Value \\
\hline Density & $1030 \mathrm{Kg} / \mathrm{m} 3$ \\
\hline Dynamic Viscosity & $0,0025 \mathrm{~Pa} / \mathrm{s}$ \\
\hline Flow velocity & $0,1 / 0,2 / 0,3 \mathrm{~m} / \mathrm{s}$ \\
\hline Pressure & $1 \mathrm{~atm}$ \\
\hline Flow regime & Subsonic \\
\hline Turbulence model & Laminar \\
\hline Bioreactor in/outlet diameter & $8 \mathrm{~mm}$ \\
\hline Bioreactor chamber diameter & $50 \mathrm{~mm}$ \\
\hline Bioreactor volume (maximum) & $785,71 \mathrm{~mL}$ \\
\hline
\end{tabular}




\subsection{Results and Discussion}

Initially it will be presented and discussed the velocity, pressure and turbulence results with and without scaffold to better comprehend the flowing of the fluid through the chamber without obstructions and observe the influence of having the scaffold in the middle of the chamber and its impact on the fluid. Also will be presented the influence of the fluid on the surface of the scaffold in terms of velocity and wall shear stress.

\subsubsection{CFD Simulation Results}

The simulations performed without scaffold just occurred with three piston configurations $(O O$, $O C / C O$ and $C C$ ), because the piston configuration $O C$ and the $C O$ have the same volume and same geometry and so in the absence of the scaffold there is no difference.

\section{i. Velocity Results}

As mentioned, it will be presented and compared the velocity results in the presence and absence of scaffold within the perfusion bioreactor chamber.

\section{Velocity results without scaffold}

As it is possible to observe in Figure 29 the behaviour of the fluid in terms of velocity is almost identical throughout the three velocities with minor differences as the input velocity increases. In all the input velocities (V1, V2 and V3) the combination with the highest value of velocity was the OF-OC. In spite of the membrane configuration with the average low value for all velocities being the $I F$, the membrane configuration $P F$ presents the lowest value for the V2 and V3 for the same piston configuration CC. It can be observed that with the increase of the input velocity, the $O F$ and $P F$ membrane configurations has also a tendency to increase just for the piston configuration $O O$ and $O C$, decreasing abruptly in the $C C$ piston configuration. This may occur due to the decrease of the chamber volume since the inlet and the outlet are very close to each other. 

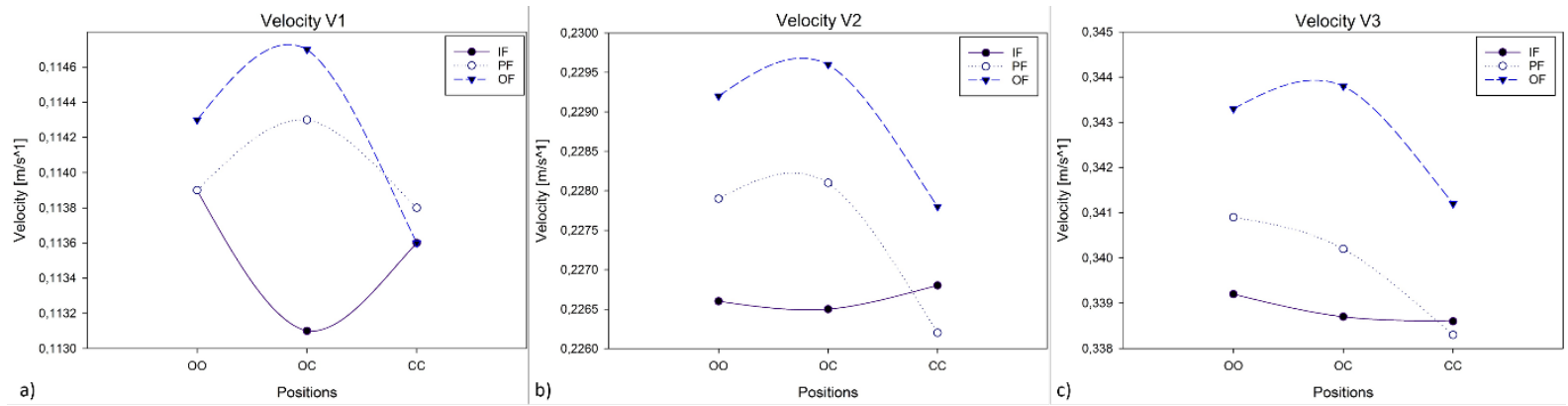

Figure 29 Velocity results for the three input velocities without scaffold.

As mentioned above, the highest velocity was achieved by the $O F-O C$ combination with 0,1147 $\mathrm{m} / \mathrm{s}$ and as we can see this velocity was obtained primarily in both the perfusion membranes in the pores and in the outlet tube but even if we analyse the minimum velocity of this combination it is higher than all the others. The combination that obtained the lowest maximum velocity was the $I F-O C$ with $0,1131 \mathrm{~m} / \mathrm{s}$. If we analyse both combinations of the Figure 30 we can see that both creates fluid vortices due to the inclination of the membrane pores, which acts differently depending on the membrane configuration because of two main reasons, the position and direction of rotation. In the case of the OF configuration, the vortex is located in the middle of the chamber in between the fluid flow with a clockwise rotation giving more velocity to the fluid towards the outlet (Figure 30a), while the IF configuration redirects the fluid inwards the chamber, creating the vortices close to the wall of the chamber and with a counter clockwise rotation which don't dramatically increase the velocity towards the outlet like the $O F$ configuration (Figure 30b).

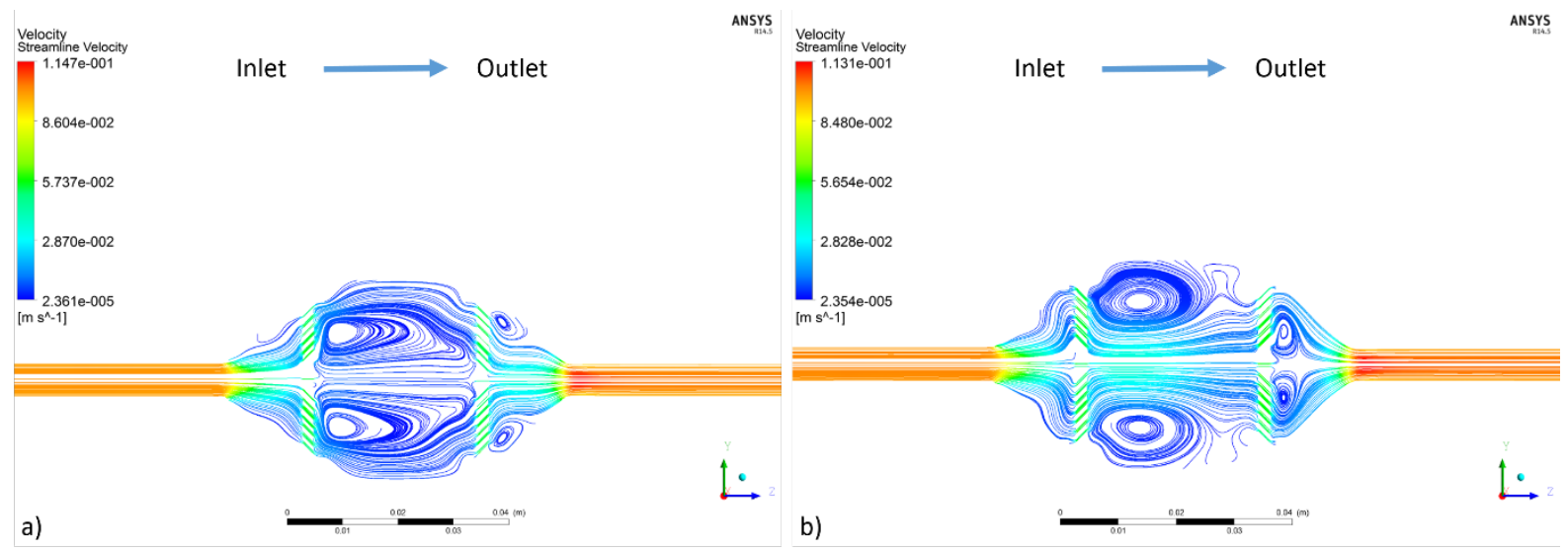

Figure $30 \mathrm{~V} 1$ velocity streamlines without scaffold for a) the OF-OC and b) the IF-OC.

In V2, the maximum value was obtained by the same combination, $O F-O C$ with $0,2296 \mathrm{~m} / \mathrm{s}$, but observing Figure 31a, it is possible to see the creation of vortices before the fluid passes through the membrane and also after the fluid passes the membrane, are higher in volume than 52 
in V1. Contrary to V1, the lowest maximum velocity was obtained by the combination PF-CC with $0,2262 \mathrm{~m} / \mathrm{s}$ and as we can observe in Figure 31b, this parallel flow also creates vortices before the fluid passes through the membrane in spite of the fluid in the chamber being more homogeneous towards the outlet.

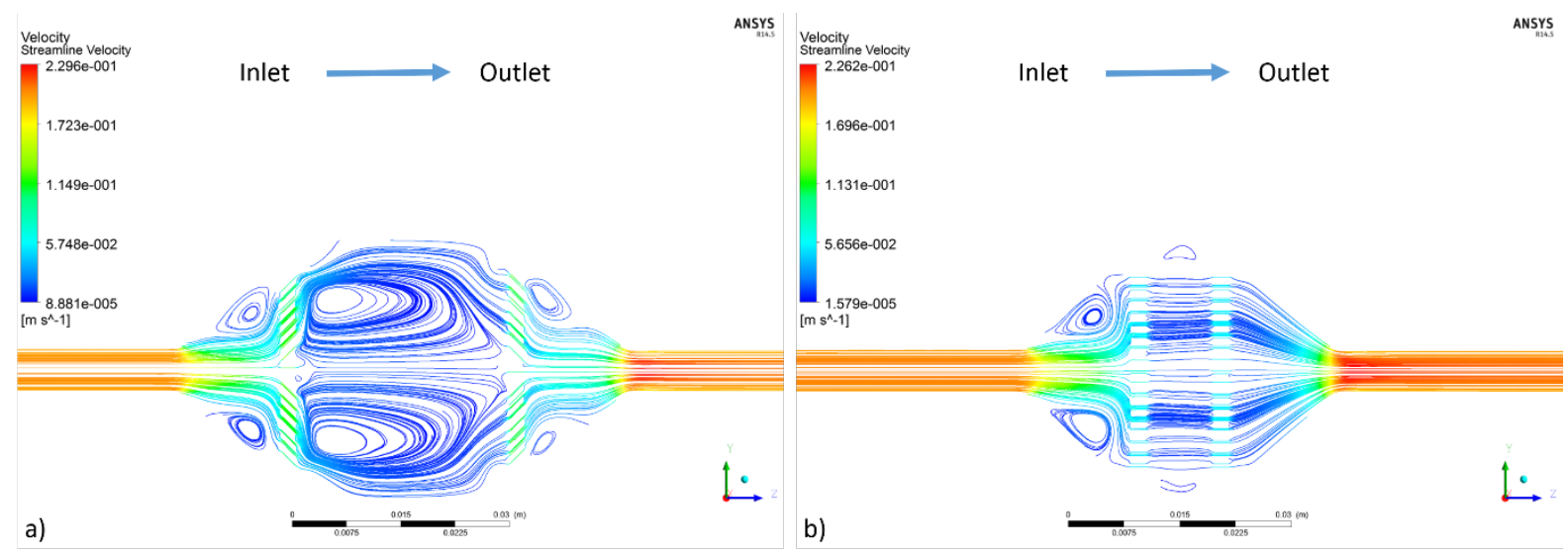

Figure $31 \mathrm{~V} 2$ velocity streamlines without scaffold for a) the OF-OC and b) the PF-CC.

For V3, the tendency was the same that in V2 with the combination OF-OC reaching the highest value, $0,3438 \mathrm{~m} / \mathrm{s}$ (Figure 32a) and $P F-C C$ with the lowest maximum value of velocity, 0,3383 $\mathrm{m} / \mathrm{s}$ (Figure 32b). It is also important to refer that the configuration of the pistons in CC plays a vital role in order to decrease the velocity of all membrane configurations. This is due to the decrease of the work volume of the bioreactor chamber by having both inlet and outlet close to each other.

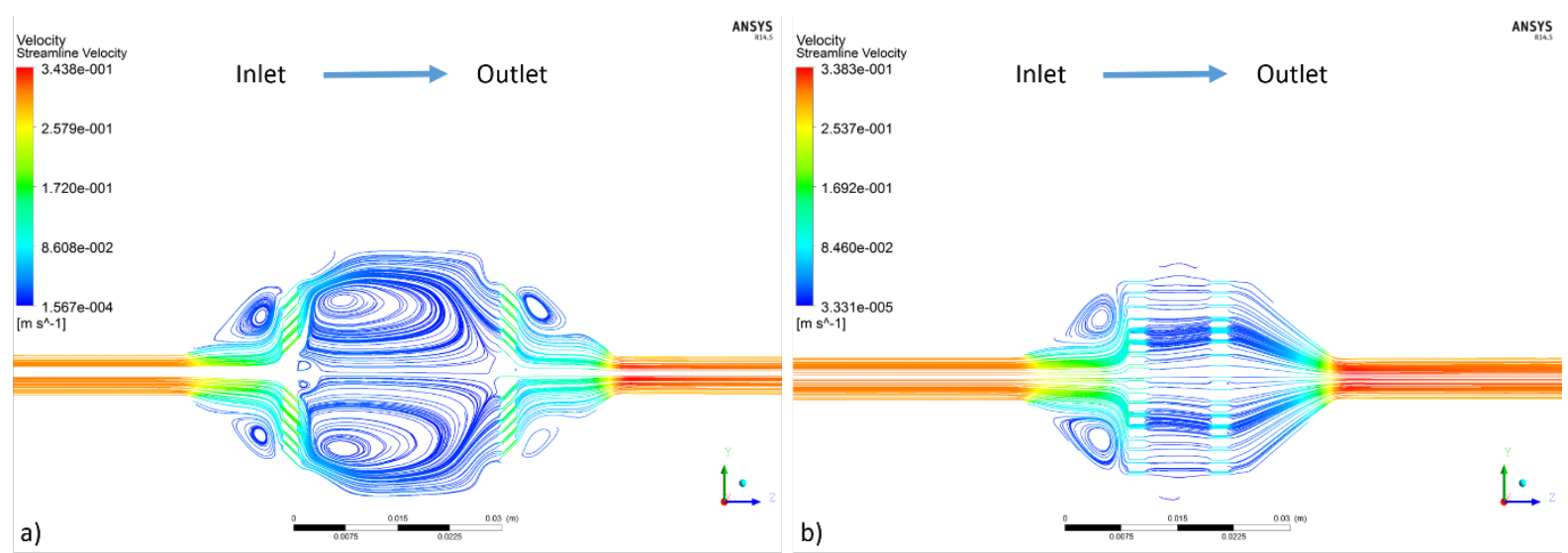

Figure 32 V3 velocity streamlines without scaffold for a) the OF-OC and b) the PF-CC.

\section{Velocity results with scaffold}

The velocity results of the simulations with scaffold have a distinct behaviour of the simulations carried out without scaffold. For V1, the combination that reaches the highest value of velocity 
is the $O F-C C$ reaching a value of $0,1144 \mathrm{~m} / \mathrm{s}$, being the lowest value the combination $P F-O O$ with $0,1125 \mathrm{~m} / \mathrm{s}$ (Figure 33a). Regarding the V2 input velocity, it's possible to observe that the OF configuration has generally the highest values, and the same value of $0,2283 \mathrm{~m} / \mathrm{s}$ was obtained by the combinations OF-CC and OF-CO (Figure 33b). For the V3 input velocity, the configuration $O F$ presents the highest fluid velocity in all the combinations and on the other hand, the IF configuration presents the lowest values in all the configurations (Figure 33c).
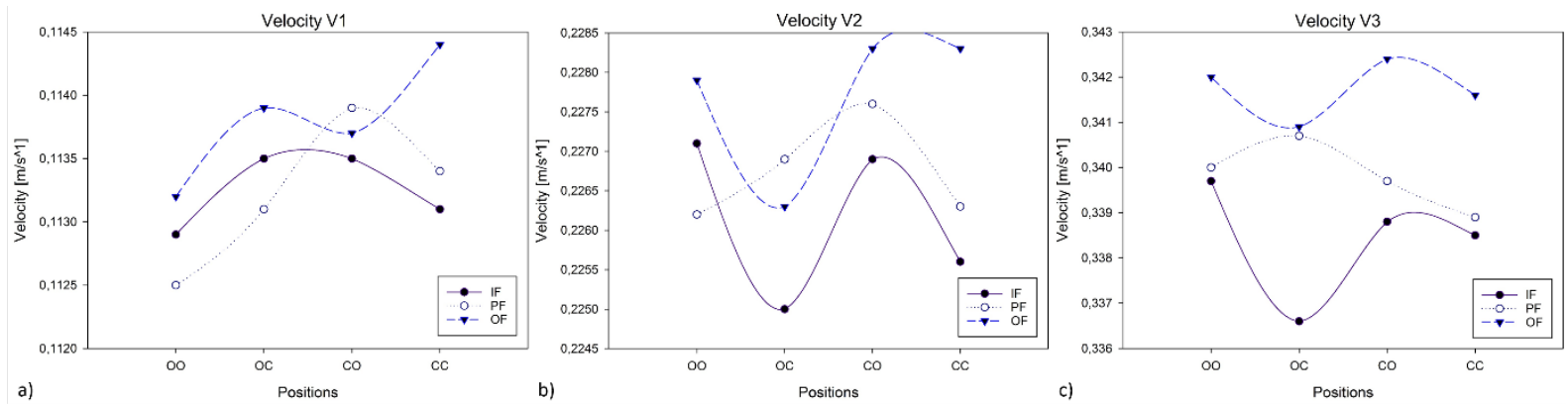

Figure 33 Velocity results for the three input velocities with scaffold.

Observing the velocity streamlines, it's possible to analyse that both the highest values reached within the perfusion bioreactors were achieved in the inlet and outlet tubes. Additionally, in the case of the OF-CC combination (Figure 34a), the membrane forces the flow towards the wall of the chamber creating vortices increasing the velocity within the chamber, even if the velocity drops down severely when it exits the membrane due to the higher volume of fluid present in the chamber. In the case of the PF-OO combination (Figure 34b), the flow is in a straight line and the values within the chamber are very low. Another interesting issue is that the $P F$ configuration has the lowest values of velocity except when it's in the position $C O$ when it presents highest value when compared to the other two configurations, namely IF and $O F$.

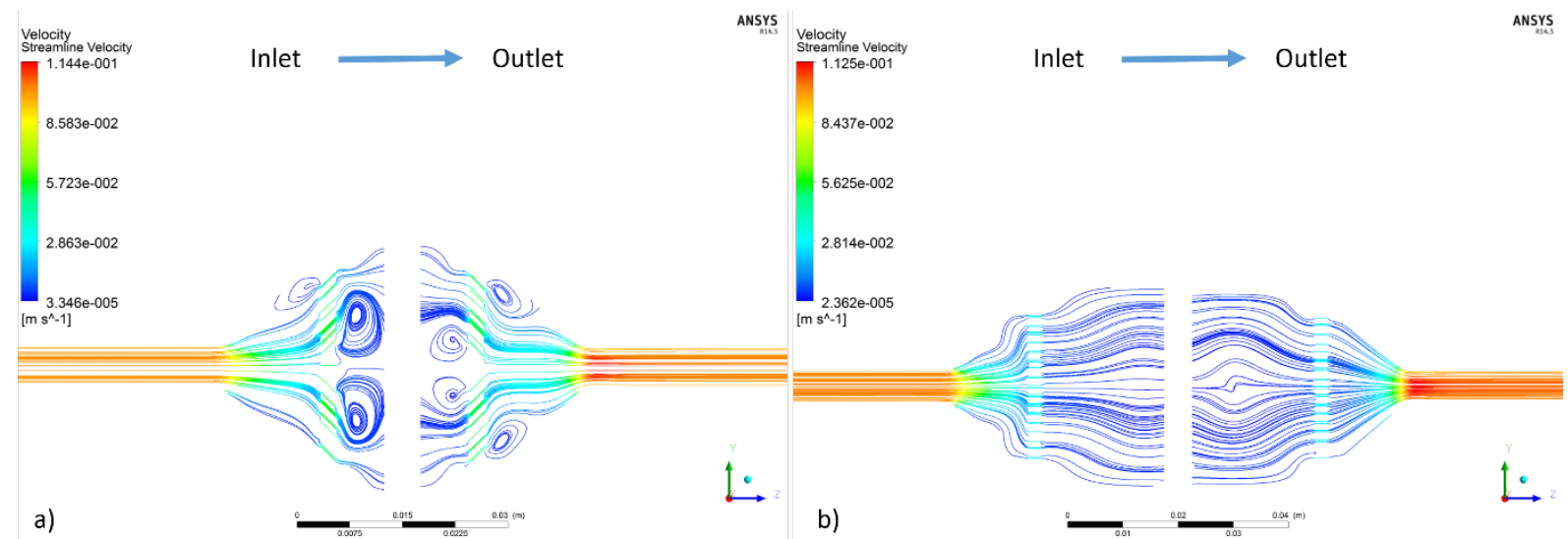

Figure $34 \mathrm{~V} 1$ velocity streamlines with scaffold for a) the OF-CC and b) the PF-OO. 
The lowest value was obtained by the combination $I F-O C$ with $0,2250 \mathrm{~m} / \mathrm{s}$, that it's also due to the vortex created by the oriented pores of the membrane, but in this case instead of redirecting the fluid towards the scaffold, the vortex has an opposite rotation (counter clockwise) removing the fluid that goes straight to the scaffold and redirecting it towards the wall of the bioreactor chamber as it shows in Figure 35b. With the increase of the input velocity the IF configuration obtained almost all the lowest values due to the referred vortices. The configuration $O F$ obtained the highest value for the two piston configurations $C O$ and $C C$, due to the Close position of the inlet piston creating vortices right next to the exit of the membrane pores. In spite of the fact that the velocity lowers when it exits the membrane due to the high diameter of the chamber, undeniably the OF configuration creates vortices (Figure 35a) aiding the fluid to reach higher velocities within the chamber.

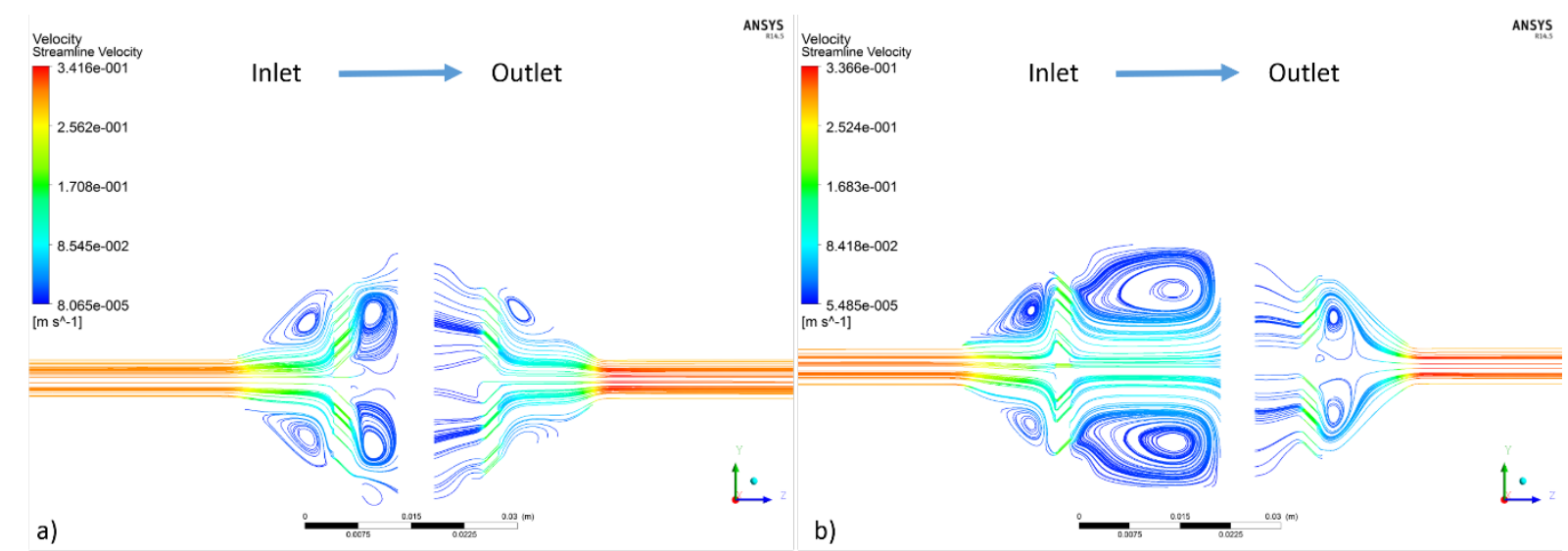

Figure $35 \mathrm{~V} 2$ velocity streamlines with scaffold for a) the OF-CC and b) the IF-OC.

The combination with the highest velocity value was the $O F-C O$ with $0,3424 \mathrm{~m} / \mathrm{s}$ due to the vortices created by the redirection of the fluid after passing through the membrane (Figure 36a) and the lowest velocity was obtained by the $I F-O C$ combination with $0,3366 \mathrm{~m} / \mathrm{s}$ also due to the vortices created by redirecting the fluid inwards the centre of the chamber creating an opposite force to the fluid coming from the inlet (Figure 36b). Important to refer that all the values of the charts present the maximum values for each combination to better understand what each of them is capable of and how to obtain a better configuration option in cell culture. 


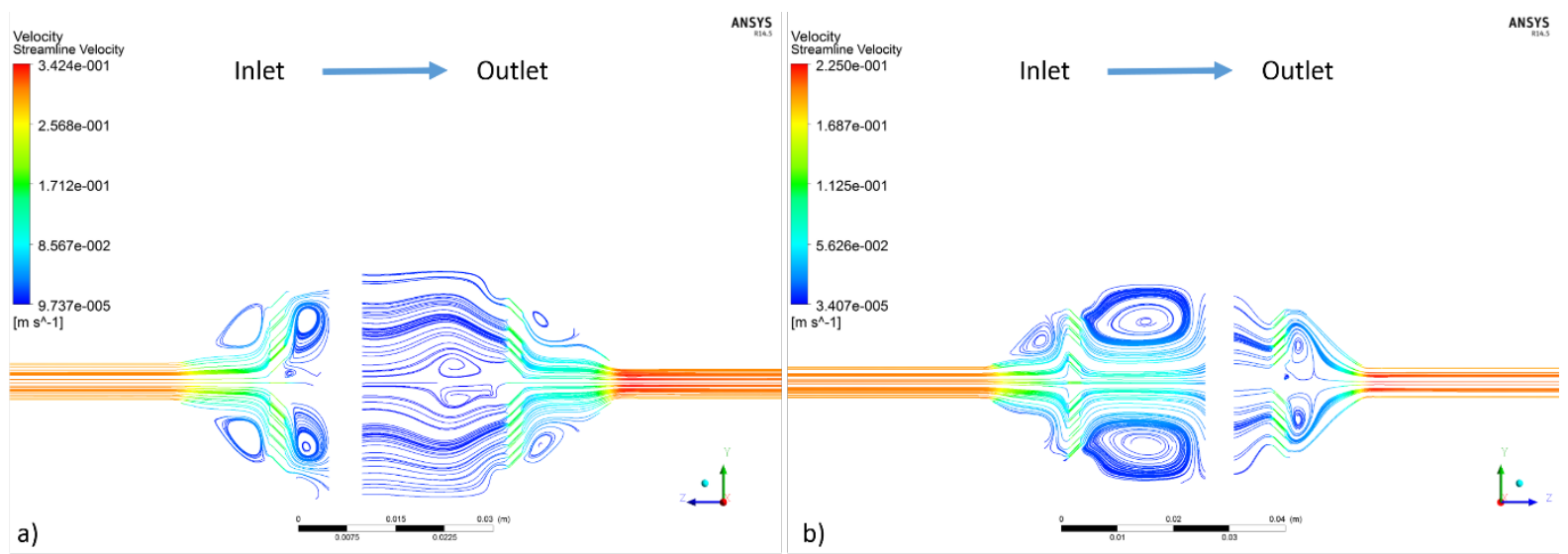

Figure $36 \mathrm{~V} 3$ velocity streamlines with scaffold for a) the OF-CO and b) the IF-OC.

\section{ii. Turbulence Results}

Turbulence was simulated using the one-equation model Turbulence Kinect Energy and the results will be presented comparing the simulations carried out with and without scaffold within the perfusion bioreactor chamber.

\section{Turbulence results without scaffold}

Analysing the results presented in Figure 37, it is possible to see that for all the input velocities the tendency is the same, the membrane configuration $I F$ has the highest value and the $P F$ configuration the lowest turbulence value. Although in V2, the combination IF-CC has a dropout and this results of both pistons being so close reducing significantly the work volume and also less fluid in the chamber, increasing the velocity of the flow also increases the pressure within such a short amount of volume forcing the fluid to rapidly exit the bioreactor creating vortices immediately after passing the outlet membrane due to the higher input velocity.
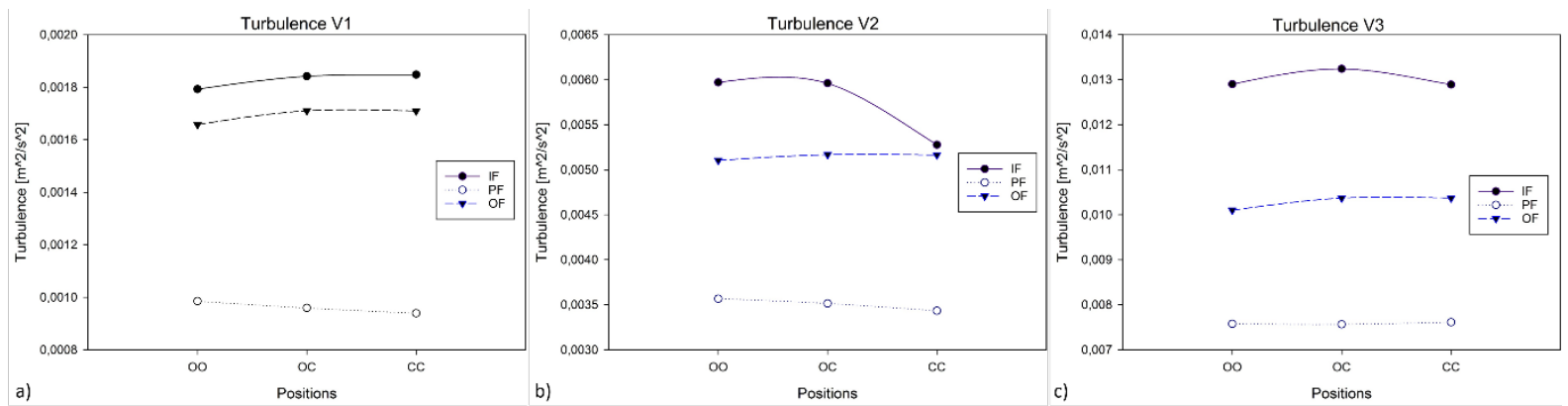

Figure 37 Turbulence results for the three input velocities without scaffold. 
For V1, the combination with the highest turbulent value was the IF-CC with $1,848 \times 10^{-3} \mathrm{~m}^{2} / \mathrm{s}^{2}$ (Figure 38a), contrarily to the result of this combination in the other two input velocities, since $\mathrm{V} 1$ is the lower input velocity there is no creation of vortices after the outlet membrane and therefore there are refluxes of the fluid increasing the turbulence. The lowest value was obtained by the combination PF-CC with $9,394 \times 10^{-4} \mathrm{~m}^{2} / \mathrm{s}^{2}$ and since the membrane has a parallel configuration and the piston a CC configuration, the fluid flows very smoothly towards the outlet membrane without creating vortices (Figure 38b).

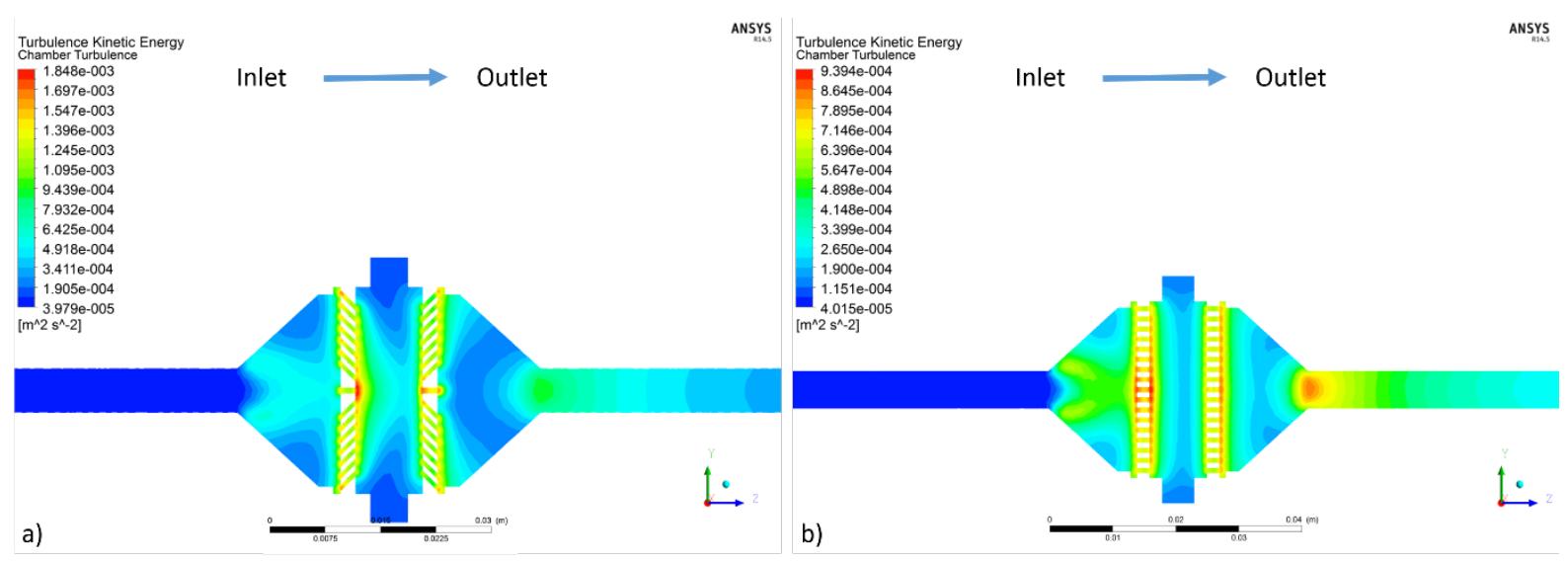

Figure $38 \mathrm{~V} 1$ turbulence results without scaffold for a) the IF-CC and b) the PF-CC.

In V2, the results are practically the same, with exceptions for the higher values imposed by a higher input velocity (V2) and the combination IF-OO presented the highest turbulence value of $5,971 \times 10^{-3}$ (Figure 39a). With an increase in the input velocity, vortices was created especially in the middle of the chamber increasing the turbulence towards the outlet. Like V1, in V2 the lowest combination was PF-CC with $3,433 \times 10^{-3} \mathrm{~m}^{2} / \mathrm{s}^{2}$ (Figure 39b).

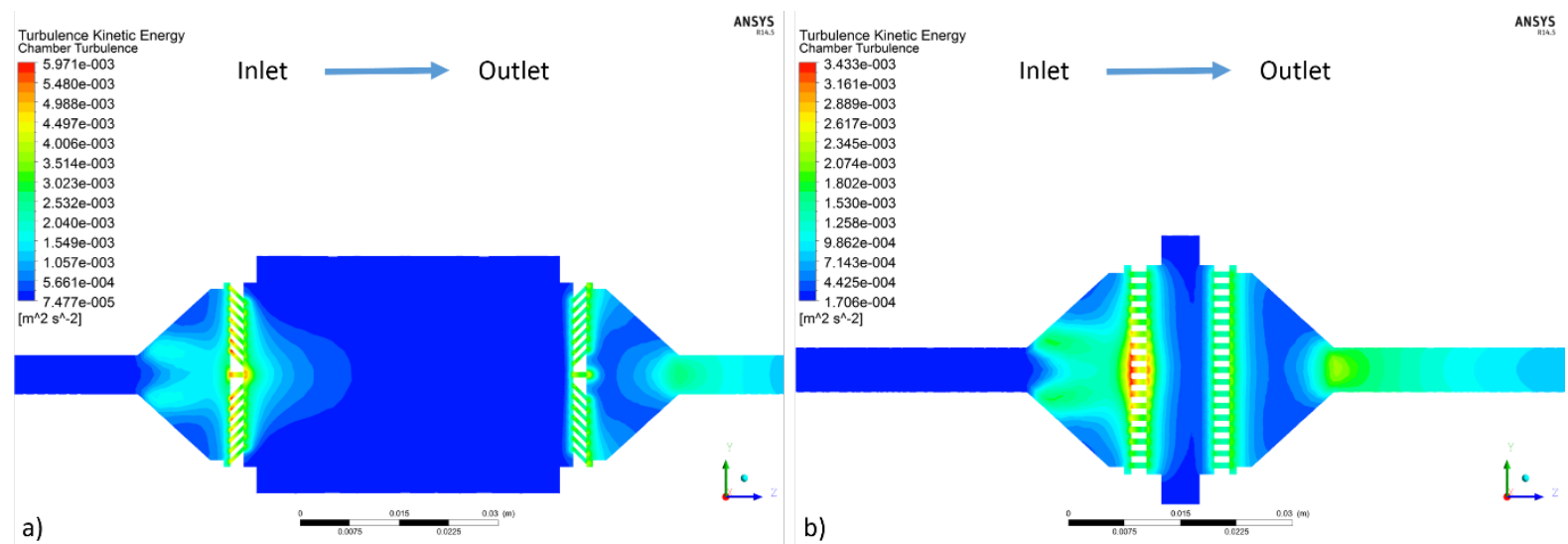

Figure $39 \mathrm{~V} 2$ turbulence results without scaffold for a) the IF-OO and b) the PF-CC. 
As the input velocity increases, the vortices also increase in turbulence, in V3 the combination IF-OC achieved the highest turbulence value $1,324 \times 10^{-2} \mathrm{~m}^{2} / \mathrm{s}^{2}$ (Figure $40 \mathrm{a}$ ) because of the vortices located near the wall of the perfusion chamber allowing the flow to run through the central part of the chamber. The combination PF-CC obtained the lowest high value of turbulence with $7,612 \times 10^{-3} \mathrm{~m}^{2} / \mathrm{s}^{2}$ (Figure $40 \mathrm{~b}$ ).

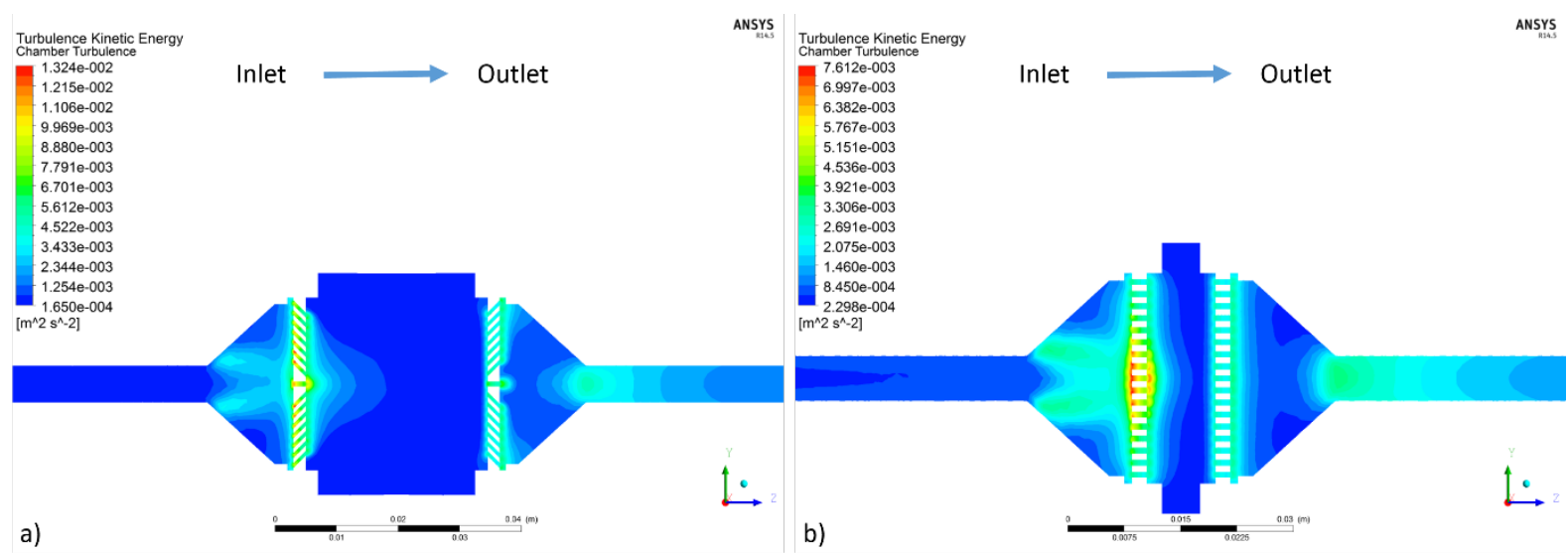

Figure 40 V3 turbulence results without scaffold for a) the IF-OC and b) the PF-CC.

\section{Turbulence results with scaffold}

Using the TKE one-equation model, it was possible to observe the fluid turbulence behaviour within the chamber and in the scaffold. For the V1 input velocity, it is possible to observe in the Figure 41a that the IF configuration has a highest value for all the combinations being the $I F-O C$ and IF-CC the ones with the higher value $1.822 \times 10^{-3} \mathrm{~m}^{2} / \mathrm{s}^{2}$. This value was reached in the middle of the inlet membrane exit because it redirects the fluid inwards to the chamber creating higher turbulence since it's a point where all the flows from the membrane pores converge. The turbulence results for the V2 input velocity doesn't differ too much from the V1, and for the V3 input velocity, the turbulence values are higher as expected while the tendency remains the same (Figure 41).
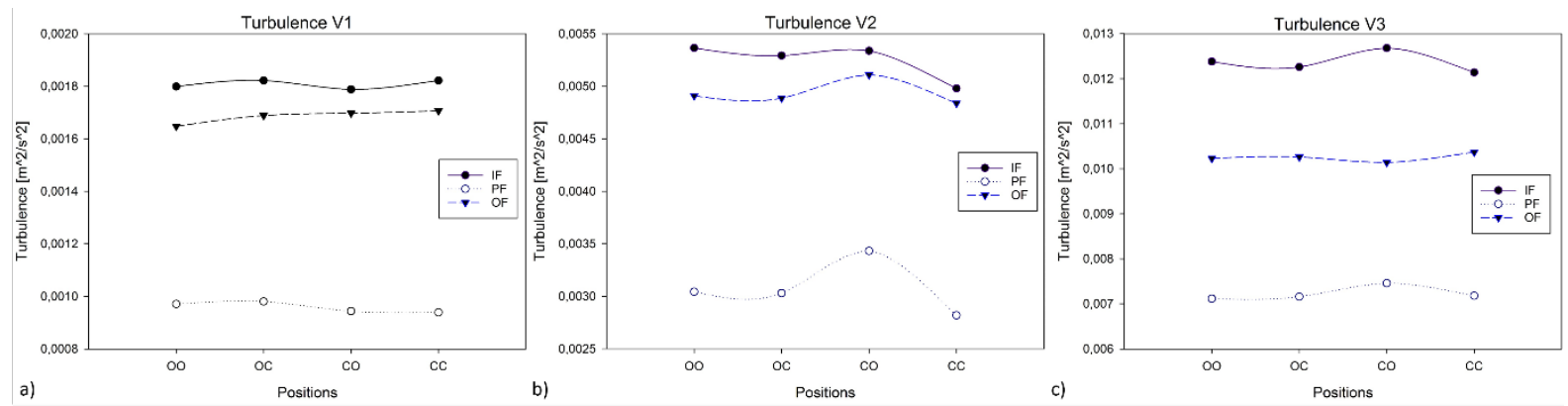

Figure 41 Turbulence results for the three input velocities with scaffold. 
For V1 velocity, the configuration with the lowest value of turbulence is the $P C$ with the value of $9,391 \times 10^{-4} \mathrm{~m}^{2} / \mathrm{s}^{2}$ in the combination PF-CC (Figure $42 \mathrm{~b}$ ) and this occurs due to the direction of the pores of the membrane being parallel to the chamber and to the direction of the inlet fluid. As explained above, the combinations IF-CC/OC reached the highest turbulence value of $1,822 \times 10^{-3} \mathrm{~m}^{2} / \mathrm{s}^{2}$ (Figure 42a).

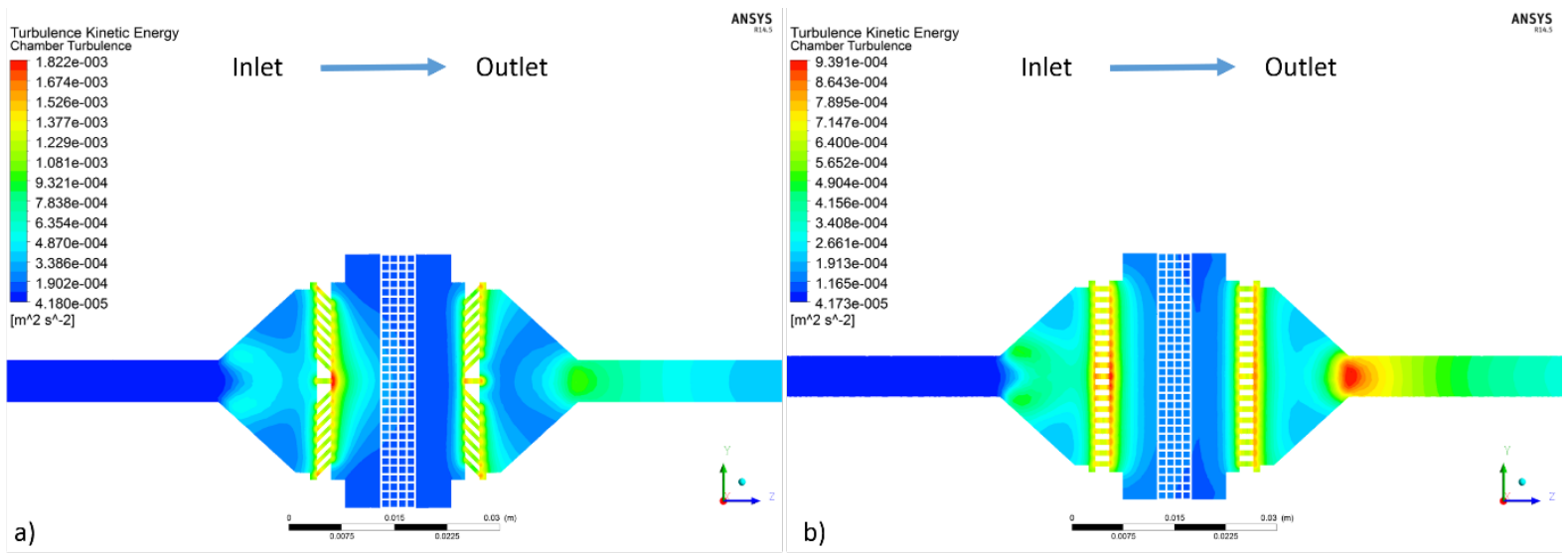

Figure $42 \mathrm{~V} 1$ turbulence results with scaffold for a) the IF-CC and b) the PF-CC.

In the V2 velocity, the highest value of turbulence was obtained by combination $I F-O O$ with a value of $5,365 \times 10^{-3} \mathrm{~m}^{2} / \mathrm{s}^{2}$, located in the exit of the fluid in the inlet membrane where, in this case, the fluid is being redirected to the centre (Figure 43a). The combination that obtained the lowest value was the $P F-C C$ with $2,819 \times 10^{-3} \mathrm{~m}^{2} / \mathrm{s}^{2}$ located in the middle of the inlet membrane (Figure 43b).

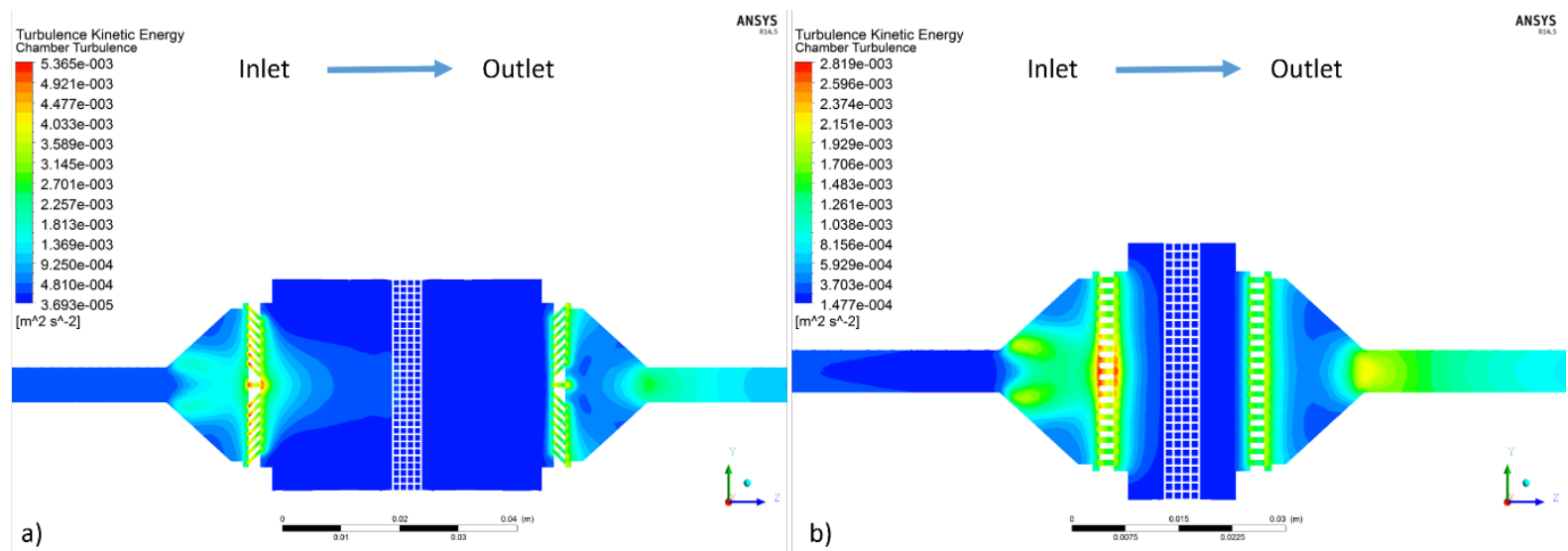

Figure $43 \mathrm{~V} 2$ turbulence results with scaffold for a) the IF-OO and b) the PF-CC.

In the V3 velocity, the combination that obtained the highest turbulence value was the IF-CO with $1,268 \times 10^{-2} \mathrm{~m}^{2} / \mathrm{s}^{2}$ located in the middle of the inlet membrane pores which redirects the fluid towards the centre of the perfusion chamber resulting in lower values of turbulence on the 
periphery of the scaffold as it is possible to observe in the section of the scaffold (Figure 44a). The PF-OO combination reached a turbulence value of $7,114 \times 10^{-3} \mathrm{~m}^{2} / \mathrm{s}^{2}$ in the middle of the pores of the inlet membrane, and in relation with the scaffold the turbulence is more homogenous, resulting in a uniform fluid stimulation of cells on the scaffold (Figure 44b).

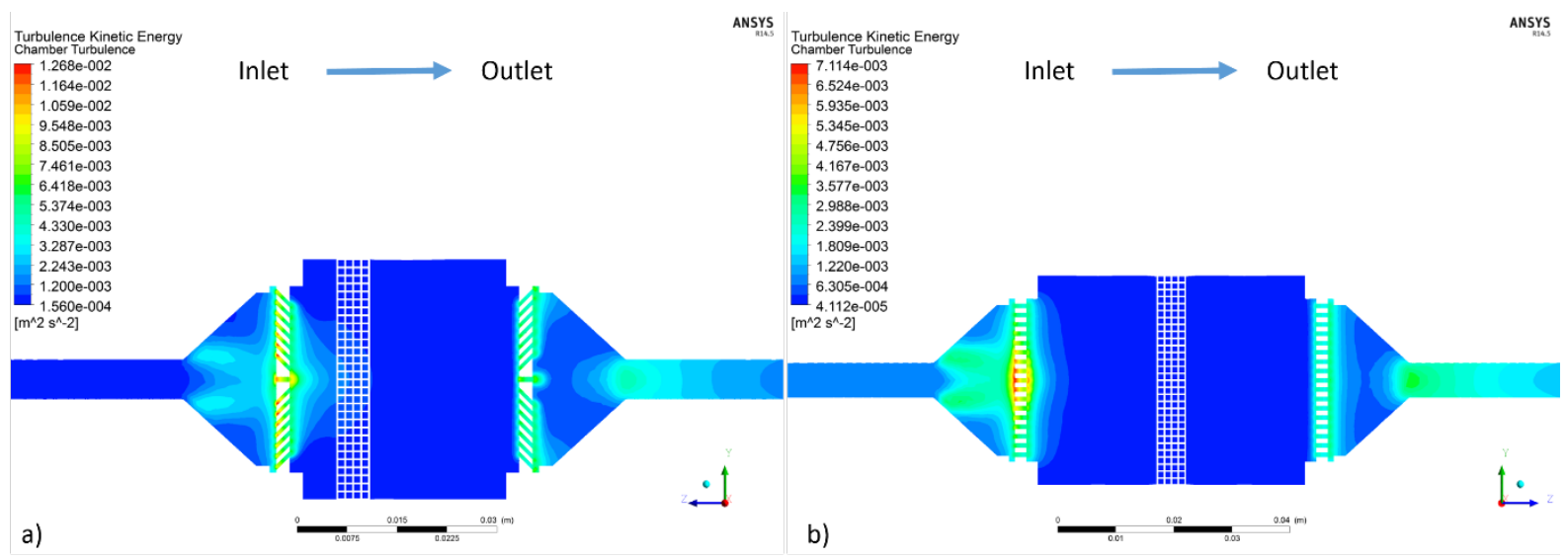

Figure 44 V3 turbulence results with scaffold for a) the IF-CO and b) the PF-OO.

\section{iii. Pressure Results}

The pressure results in the chamber able us to analyse the forces involved in the chamber and analyse the best velocities to use without compromise the cell viability in a tissue culture.

\section{Pressure results without scaffold}

When observing the results presented in Figure 45 the combination $O F-O C$ has the highest values for all the input velocities as $P F-O O$ combination has the lowest. When the input velocity increases from V1 to V2 and V3 the IF configuration approximates from the OF configuration mainly for the membrane configuration $O O$.
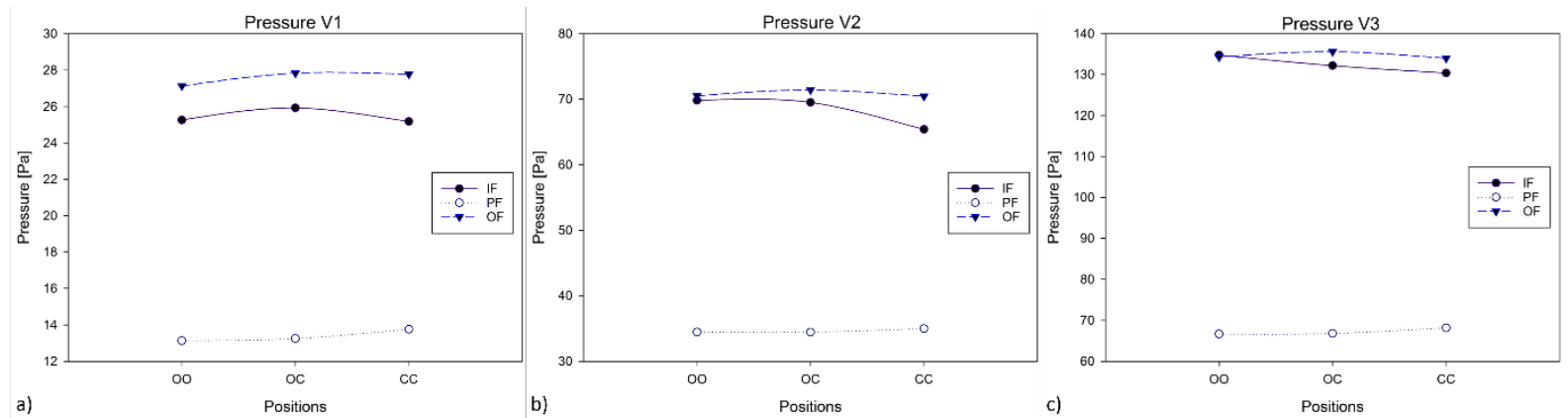

Figure 45 Pressure results for the three input velocities without scaffold. 
The combination OF-CC achieved the highest value for all the input velocities in which V1 obtained $2,713 \times 10^{1} \mathrm{~Pa}$, for V2 was $7,052 \times 10^{1} \mathrm{~Pa}$ and V3 achieved $1,343 \times 10^{2} \mathrm{~Pa}$. In Figure 46a it is illustrated the pressure for V2 as the colour plot doesn't change significantly in the other velocities. As mentioned before, the combination that obtained the lowest pressure values was the combination PF-OO (Figure 46b) with the following values: V1 with $1,313 \times 10^{1} \mathrm{~Pa}$; V2 obtained 3,445 $\times 10^{1} \mathrm{~Pa}$; and V3 with $6,665 \times 10^{1} \mathrm{~Pa}$. In Figure 46 it is possible to observe that in the work volume (green region between the inlet and outlet membranes) the pressure is homogeneous resulting in a well distributed pressure along the perfusion chamber and the same happens with all the other combinations.

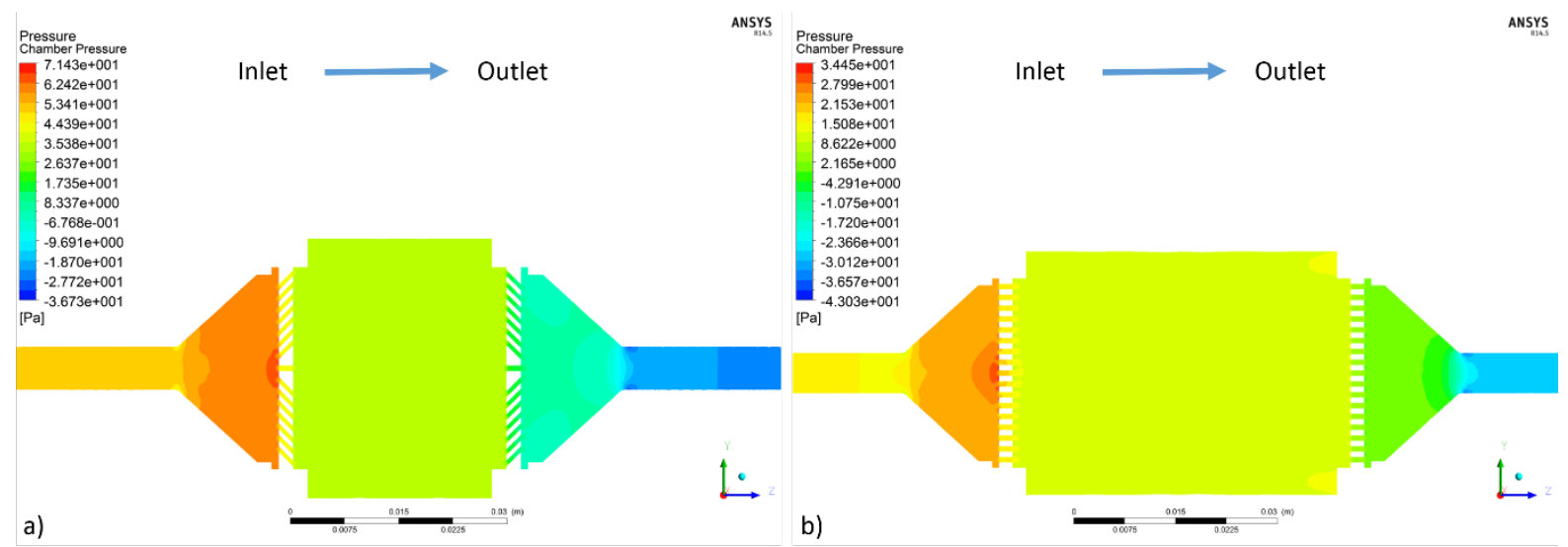

Figure $46 \mathrm{~V} 2$ pressure results without scaffold for a) the OF-CO and b) the PF-OO.

\section{Pressure results with scaffold}

Simulation results with scaffold within the perfusion chamber have a different behaviour than without scaffold. As is possible to observe in Figure 47, the behaviour within each membrane configuration is not steady in the same input velocity. For all the input velocities the highest combinations remains the same across the three input velocities, i.e., the combination with highest value is the IF-CO although the ones with the lowest value are two, for V1 and V2 the combination $P F-O C$ and for $\mathrm{V} 3$ the combination IF-OC, in spite of the value is approximately similar. The huge difference in the pressure values regarding the piston configurations $O C$ and $C O$ is related to the position of the inlet and outlet pistons. In the $O C$ configuration, the fluid after leaving the inlet membrane, has a work volume larger than the $C O$ configuration and also since the outlet membrane is in the "closed" (close to the scaffold) position allowing the fluid to exit immediately. While in the CO configuration, the inlet position is located near the scaffold, the fluid when leaves the inlet membrane bumps into the scaffold causing an accumulation of fluid in that small volume area increasing the pressure before it passes through the membrane. 

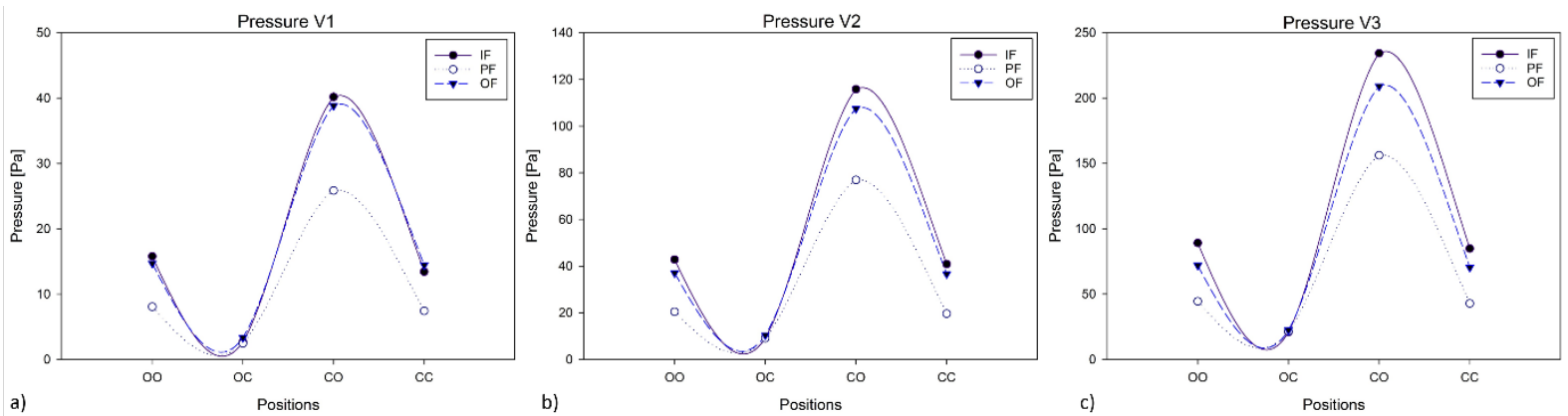

Figure 47 Pressure results for the three input velocities with scaffold.

The combination IF-CO achieved the highest value for all the input velocities in which V1 obtained 4,017 $\times 10^{1} \mathrm{~Pa}$, for V2 was $1,158 \times 10^{2} \mathrm{~Pa}$ (Figure 48a) and V3 achieved 2,342 $\times 10^{2} \mathrm{~Pa}$. As mentioned before, the combinations that obtained the lowest pressure values were the combination PF-OC with V1 achieving 2,694 Pa and V2 9,083 Pa (Figure 48b) and the combination IF-OC for V3 obtained 2,135 $\times 10^{1} \mathrm{~Pa}$. In Figure 48, it is possible to observe the pressure values for V2 (since the configuration of the pistons is the same for the combination $P F-O C$ and $I F-O C$ ), and also it is possible to realize that in the work volume (space between the inlet and outlet membranes) the pressure is homogeneous even around and inside the scaffold. One of the reasons is that the variation of pressure on the scaffold is so low that it is smaller than the scale used in this results.

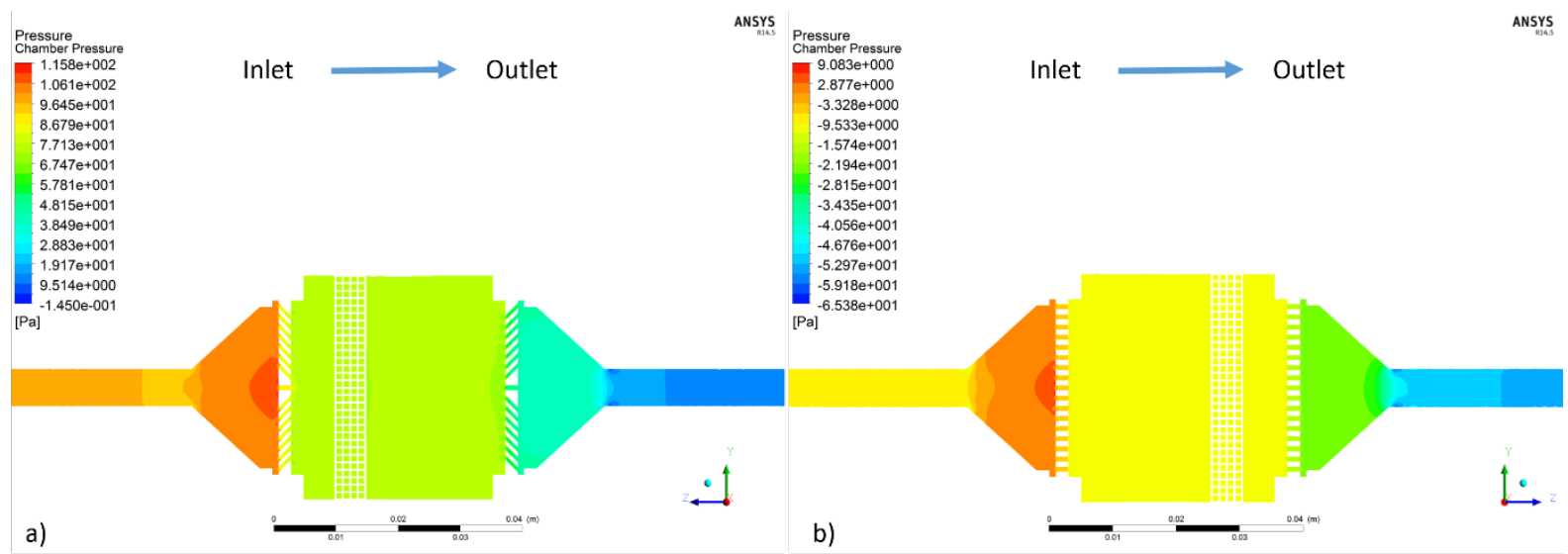

Figure $48 \mathrm{~V} 2$ pressure results with scaffold for a) the IF-CO and b) the PF-OC.

\section{iv. Scaffold Velocity}

For a better understanding on how the tissue culture will be carried out under the different velocities and piston/membrane combinations, it is necessary to see the impact of the flow at the scaffold surface. 
In Figure 49 it is possible to observe the results of the velocity on the scaffold being the configuration IF the one with the higher velocity in all three input velocities being the piston configuration $\mathrm{CO}$ the one with the highest value in all. Comparatively the lowest results were also obtained by the same combination in the three input velocities, namely PF-OC.
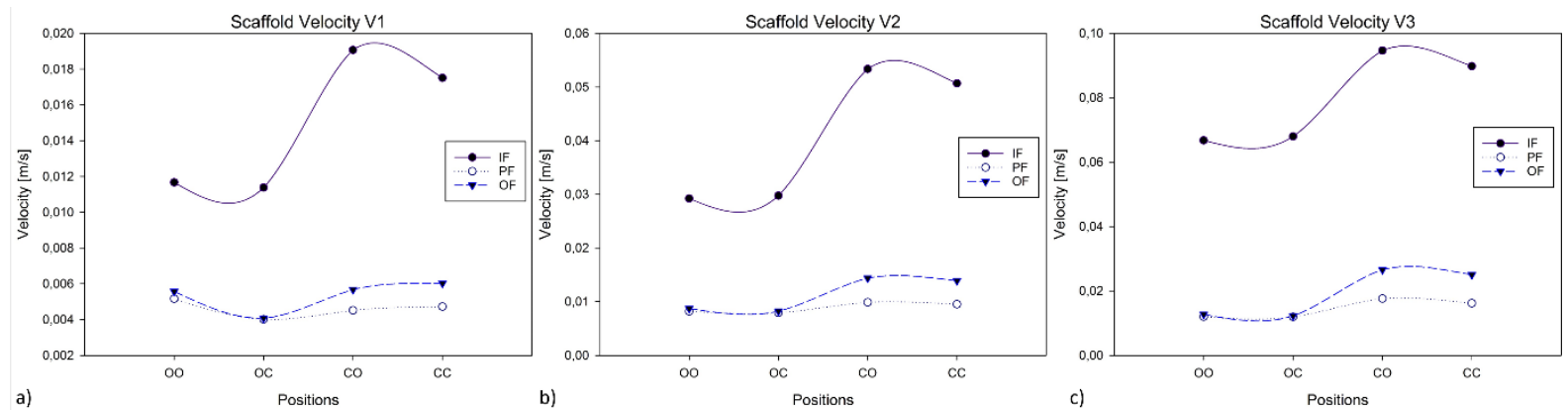

Figure 49 Scaffold velocity results for the three input velocities.

Comparing the profiles of the scaffold surface (Figure 50) it is possible to observe that the perfusion membranes plays a key role in the distribution of the velocity in the scaffold. The highest values were obtained by the $I F-C O$ combination where V1 achieved $1,907 \times 10^{-2} \mathrm{~m} / \mathrm{s}$, V2 $5,336 \times 10^{-2} \mathrm{~m} / \mathrm{s}$ and V3 $9,462 \times 10^{-2} \mathrm{~m} / \mathrm{s}$. But more importantly it is possible to observe that the higher values are located in the centre of the scaffold (Figure 50a) because of the orientation of the membrane pores while the $O F$ membrane redirects the fluid towards the periphery of the scaffold (Figure 50c) and the PF has more homogeneous distribution (Figure 50b).
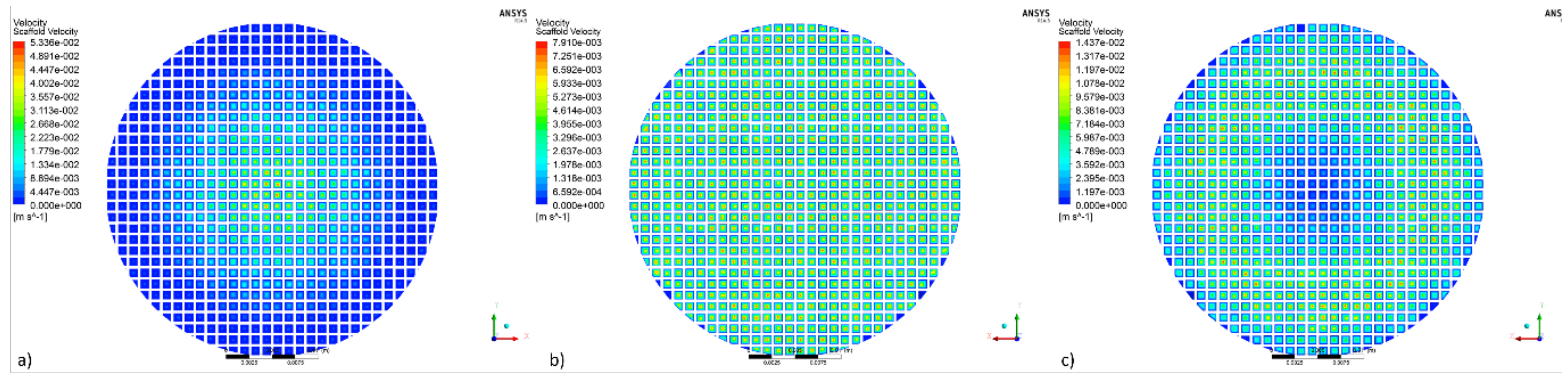

Figure $50 \mathrm{~V} 2$ scaffold velocity results for a) the IF-CO, b) the PF-OC and c) the OF-CO.

\section{v. Wall Shear Stress Results}

In Figure 51 it is illustrated the results of wall shear stress on the scaffold and, as in the scaffold velocity results, the IF-CO combination has the highest values of shear stress and PF-OC is the combination with the lowest shear stress. But in all the input velocities, the difference between the $P F-O C$ combination and the $O F-C O$ is almost insignificant. As it is possible to observe in the Figure 51, the values of the wall shear stress increase in all the membrane 
configurations (significantly in the IF configuration) when the inlet piston moves to the "close" position and this is due to the smaller volume available between the scaffold and the inlet membrane because there is less fluid, therefore the fluid that exits the membrane collides almost directly to the scaffold surface.
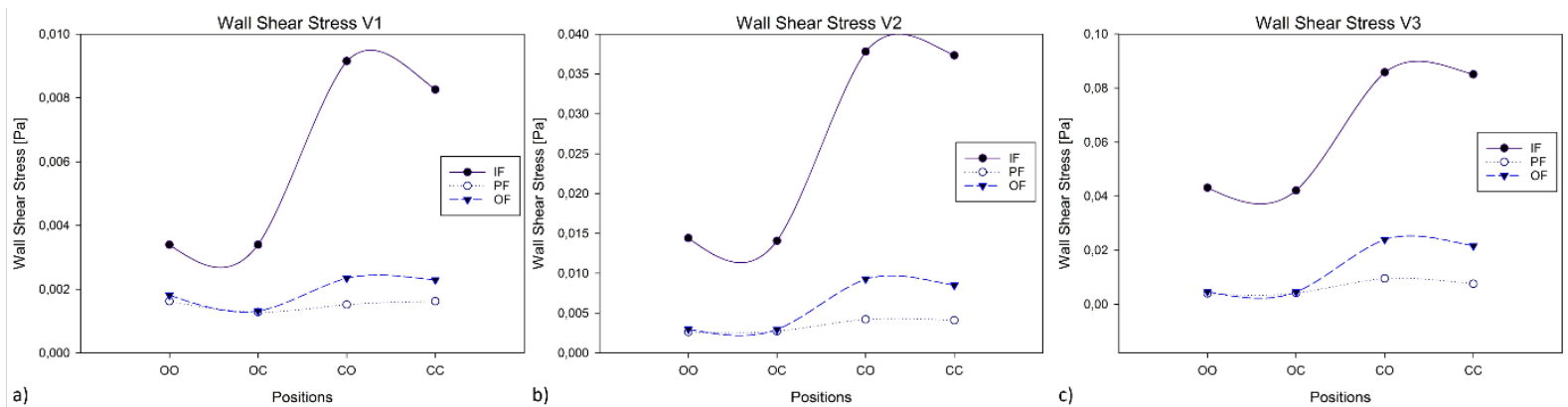

Figure 51 Scaffold velocity results for the three input velocities.

The wall shear stress evaluation is of most importance to the tissue culture because with this it is possible to prevent damage to the cells exceeding their stress limit and therefore creating conditions to a prosper tissue culture. In Figure 52 it is represented the results just for the V2 input velocity because the tendency is the same for V1 and V3 with lower and higher values respectively than V2. For IF-CO, the results for the three input velocities were V1 with 9,154 $\times 10^{-3} \mathrm{~Pa}$; V2 with 0,0378 Pa; and V3 with 0,0582 Pa, being the highest point the centre of the scaffold and lower at the periphery of the scaffold as it is possible to observe in Figure 52a. It is also important to refer that with the increase in the input velocity the stress value in the middle tends to be more focuses and less spread around the centre area of the scaffold. The results for $O F-C O$ are quite the opposite of the $I F$ configuration because since the perfusion membrane configuration redirects the fluid to the periphery of the scaffold, the centre of it has a low shear stress rate (Figure 52c).

The lowest results were achieved by the PF-OC with a velocity of V1 with a shear stress of $1,285 \times 10^{-3} \mathrm{~Pa}$; for V2 obtained $2,723 \times 10^{-3} \mathrm{~Pa}$; and for V3 was $4,16 \times 10^{-3} \mathrm{~Pa}$. As it is possible to observe in Figure 52b, the shear stress ratio is almost uniformly distributed throughout the surface of the scaffold due to the membrane configuration $P F$ directing the fluid perpendicular to the scaffold. 

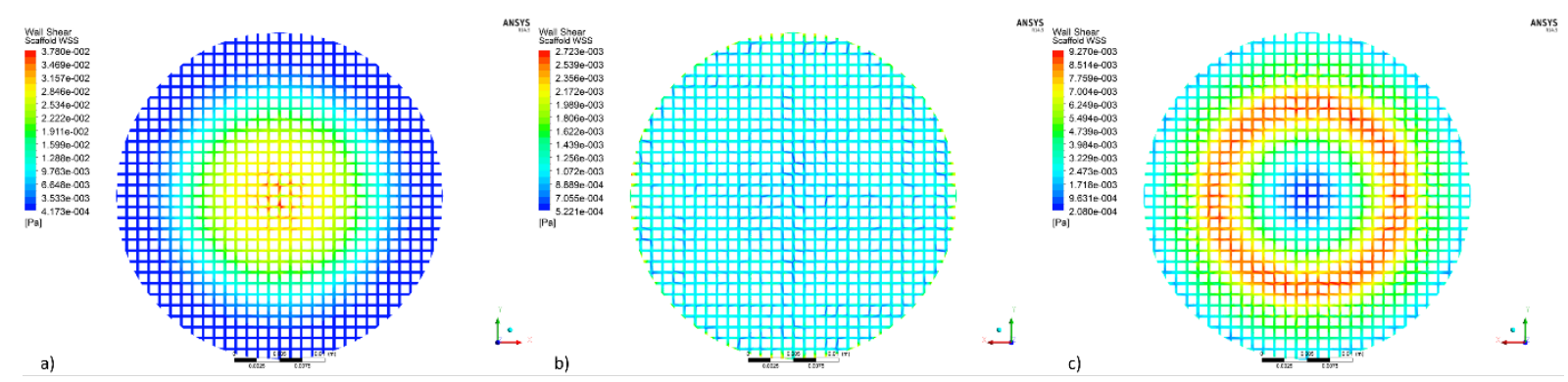

Figure $52 \mathrm{~V} 2$ wall shear stress results for a) the IF-CO, b) the PF-OC and c) the OF-CO. 


\section{Conclusions and future works}

In this chapter will be presented the conclusions of this work presenting the pros and cons of the work carried out under the perfusion bioreactor and future works in order to continue improving the tissue culture in bioreactors.

\subsection{Conclusions}

When comparing the results of the simulations with and without the presence of the scaffold it is easy to understand that the presence of the scaffold changes the fluid behaviour in many ways, causing in almost all the combinations the decrease of the velocity, pressure and turbulence. In terms of turbulence the only piston configuration that is higher with the presence of the scaffold is the $\mathrm{CO}$ for every membrane configuration due to the proximity of the piston to the scaffold.

From the results it's possible to conclude that the $O F$ membrane configuration is the one that allows having higher velocities within the chamber and in the scaffold area (Figure 53), due to the vortices created by the fluid being forced towards the wall of the chamber. In this case, the vortices located in the inner centre of the chamber with a clockwise rotation giving the fluid more velocity towards to the outer part of the scaffold. The scaffold has a low velocity in the middle section and a higher velocity in the periphery areas with this configuration. Also with this configuration, when the position of the pistons are in $O O$ and $O C$, the velocity is tendency lower than in the other two positions and this is due to the higher volume of fluid in the chamber before passing by the scaffold.

With the $P F$ configuration the fluid runs parallel to the chamber and perpendicular to the scaffold surface, having a lower fluid velocity value than the IF configuration when the input velocity is lower (V1) but when the input velocity increases (V2 and V3) the PF configuration has a higher fluid velocity that IF configuration. With the PF configuration the velocity within 
the chamber is higher when the pistons are in the $C O$ and $O C$ positions due to the proximity of the piston to the scaffold, when compared to the $O O$ or $C C$ positions, the fluid hits the scaffold more homogenously having a fluid velocity around the scaffold more constant.

In all the input velocities, the $I F$ configuration has lowest values than the $O F$ configuration due to the vortices created from the fluid flowing inwards to the centre of the chamber creating these vortices in the outer part of the chamber (close to the walls of the chamber). These vortices rotate counter-clockwise and lower the fluid velocity towards the scaffold redirecting the fluid to the middle part of the scaffold and reducing the fluid from running to the outer parts of the scaffold. With high input velocities, the vortex gets higher reducing proportionally the fluid velocity towards the scaffold (Figure 53).

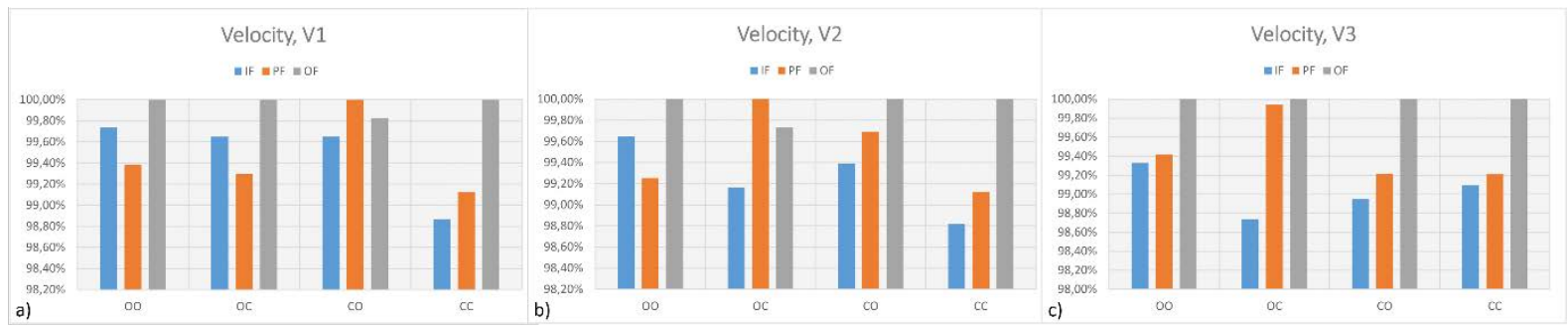

Figure 53 Velocity comparison in percentage between the different combinations with scaffold.

Regarding the turbulence values, the difference between each configuration is higher than the difference between velocity values reaching almost 50\% of each configuration.

The IF configuration has higher values (Figure 54) in all the input velocities and in all configurations due to the vortices created by the membrane configuration. Having higher vortices increases the turbulence value and lowers the velocity value for the $I F$ configuration due to the vortex being located in the outer part of the chamber.

The IF configuration combined with the $P F$ configuration are the ones with the lowest turbulence values, the last one due to the membrane configuration having the pores parallel to the fluid direction and forcing the fluid towards the scaffold surface with a more homogenous distribution of the fluid.

The $O F$ configuration presents the lowest turbulence values when compared to the IF configuration (Figure 54). In this case, the vortices created by the OF configuration are smaller and are located in the inner centre of the chamber helping the fluid to gain velocity and directing it towards the scaffold. 


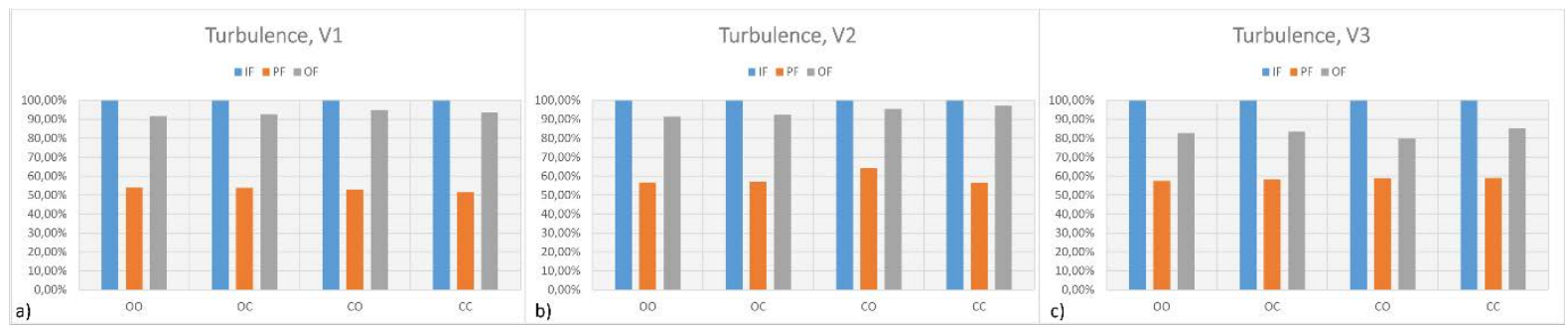

Figure 54 Turbulence comparison in percentage between the different combinations with scaffold.

Concerning the pressure within the chamber caused by the fluid flow, it is possible to observe in Figure 55 that the configuration $I F$ has higher values of pressure for the $O O$ and $C O$ configurations in all the velocities, plus in the V2 and V3 input velocities, the CC configuration have higher pressure values than the other piston configurations. The fact that the membrane redirects the fluid to the centre of the chamber is the cause of the high pressure within the chamber increasing the turbulence of the fluid and therefore also the pressure. There is just one combination that has the highest value in all the input velocities and that is the OF-OC. The main cause for this is the piston position $O C$ that has more volume for the fluid before the scaffold and then due to the "close" position of the outlet piston allows the fluid to rebound increasing the pressure within the chamber.

The $P F$ configuration due to the membrane configuration doesn't create much pressure than the other two configurations, having the lowest pressure value for all the input velocities.

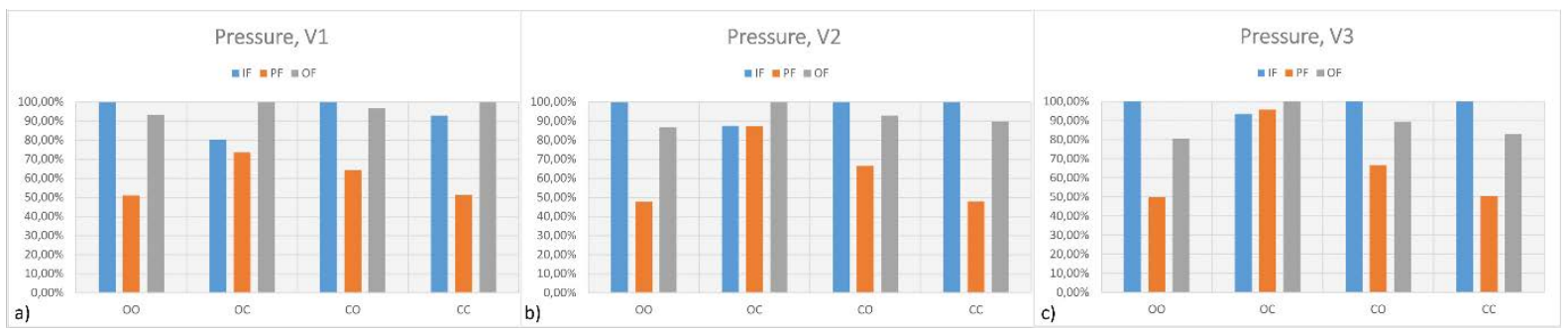

Figure 55 Pressure comparison in percentage between the different combinations with scaffold.

One of the most important reasons to perform this work is to understand the behaviour of the fluid towards the scaffold in order to have an optimum tissue culture. It is important to understand the fluid around the scaffold and in which terms it reaches the scaffold namely in terms of velocity and most importantly the shear stress in the scaffold.

Comparatively to the velocity in Figure 56, it is possible to observe that the membrane configuration IF has a greater impact in all the input velocities having more than $80 \%$ in some cases relatively to the other two configurations $P F$ and $O F$. As mentioned before the 
configuration of the membrane plays a key role in this case since it redirects the fluid towards the centre of the chamber thus to the centre of the scaffold. It is also possible to observe that the difference between the IF configuration and the other two grows as the input velocity increases, i.e., the V1 input velocity has a much smaller difference between them than the V2 and consequently the V3.

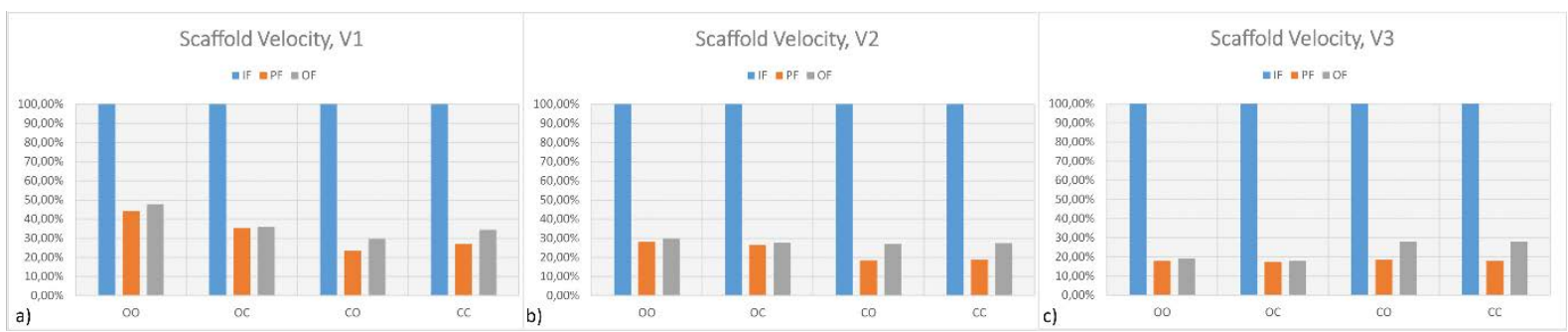

Figure 56 Scaffold velocity comparison in percentage between the different combinations.

When comparing the wall shear stress of each configuration it is possible to infer that the $I F$ configuration has a higher shear stress value than the other two configurations due to its membrane configuration. It has differences in some cases more than $90 \%$ for the $P F$ configuration and $80 \%$ for the $O F$, in all the V3 input velocities. As the input velocity increases, the difference between the $I F$ configuration and the $P F$ and $O F$ also increases.

The focus of the stress for the IF configuration is the centre of the scaffold where it reaches its high value while the OF configuration reaches its high value in the outer part of the scaffold and the $P F$ configuration presents a uniform distribution of the shear stress across the surface of the scaffold.

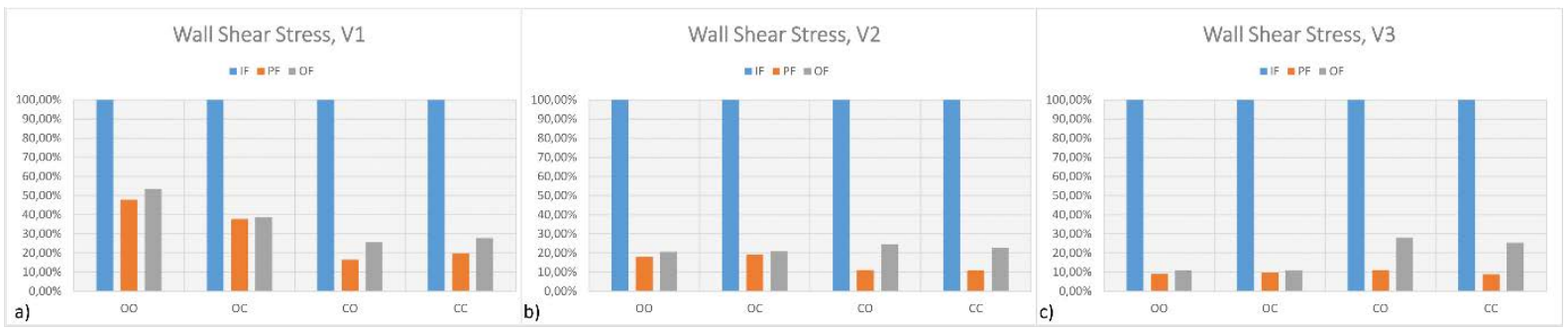

Figure $\mathbf{5 7}$ Wall shear stress comparison in percentage between the different combinations.

One of the major conclusions that was possible to observe after analysing the results and was one of the primary goals of this works, was the comparison of the results of the calculated shear stresses on the designed perfusion bioreactor on the surface of the scaffold and the actual shear stress values that the cells can withstand in order to obtain an optimum cell viability and therefore proliferation. 
In Figure 58 it is possible to observe the comparison between the shear stress results obtained and the limit/optimal shear stress values of the cells. In this work it was used three input velocities V1, V2 and V3 (0,1/0,2/0,3 m/s respectively) and with this velocities it is possible to observe in Figure 58 that it was created optimum stress values to culture hepatocytes since the value of the shear stress of the three input velocities ranges between $1,29 \times 10^{-3} \mathrm{~Pa}$ and $0,086 \mathrm{~Pa}$ and for the hepatocytes the optimal stress value for culture is 0,033 $\mathrm{Pa}$. But in order to create, for instance osteoblasts, the shear stress obtained with the three input velocities is too high damaging the cells. One of the possibilities to obtain the ideal culture stress is to lower the input velocity of the fluid (culture medium).

In the other hand there are cells with a much higher optimal stress value as it is the case of osteocytes, smooth muscle and heart valves tissue and for these cases the input velocity has to increase. Analysing the results obtained with the input velocities used it was estimated that with a input velocity ranging between $1,5 \mathrm{~m} / \mathrm{s}$ and $7 \mathrm{~m} / \mathrm{s}$ it is possible to obtain shear stress values between 0,5 $\mathrm{Pa}$ and 2,5 $\mathrm{Pa}$ to make it possible to culture for example the mentioned tissues.

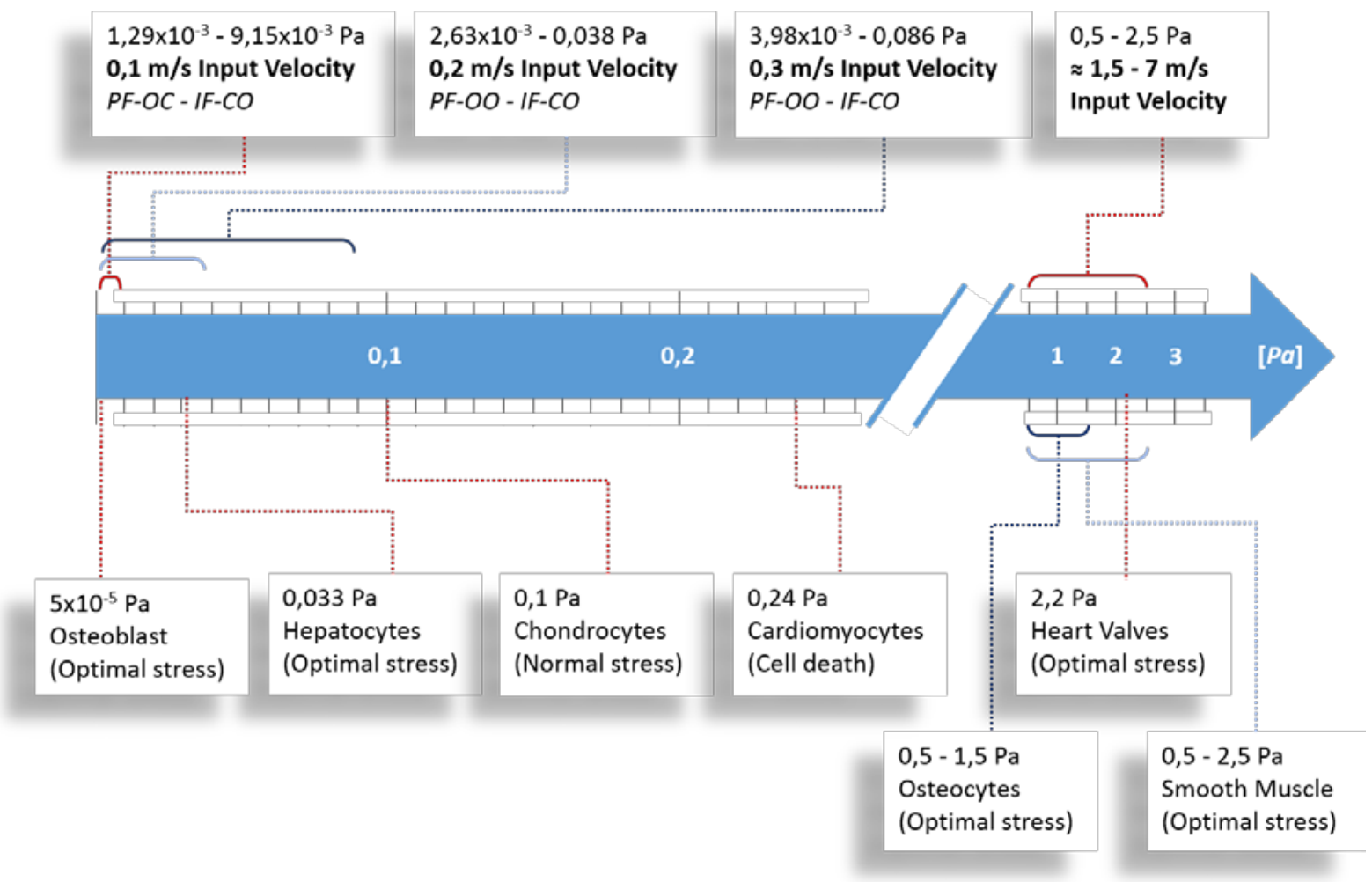

Figure $\mathbf{5 8}$ Shear stress results comparison with optimal/normal stress of the cells. 


\subsection{Future Works}

Possible future works following this research can be undertaken with experimental tests and numerical validation.

Concerning the experimental work;

- Scaffold enzymatic degradation on the designed perfusion bioreactor;

- Micro-CT images of the degraded scaffolds in order to obtain accurate 3D models;

- Mechanical analysis of the degraded scaffolds;

The numerical simulation of future work includes:

- Analysis of the pressure on the scaffold;

- Structural simulations of the scaffold as a result from the pressure values;

- Permeability analysis of the scaffolds;

- Models of cellular proliferation within this bioreactor;

Several questions have been answered throughout this work and created new doubts and new research opportunities to be carried out. 


\section{References}

Altman, G.H., Lu, H.H., Horan, R.L., Calabro, T., Ryder, D., Kaplan, D.L., Stark, P., Martin, I., Richmond, J.C. and Vunjak-Novakovic, G. (2002) "Advanced Bioreactor with Controlled Application of Multi-Dimensional Strain for Tissue Engineering", Journal of Biomechanical Engineering, 124(6):742-749.

Baldocchi, D. (2005) "Wind and Turbulence, Surface Boundary Layer: Theory and Principles" Lecture 16 - Part 1, University of California.

Bancroft, G.N., Sikavitsas, V.I., van den Dolder, J., Sheffield, T.L., Ambrose, C.G., Jansen, J.A. and Mikos, A.G. (2002) "Fluid flow increases mineralized matrix deposition in 3D perfusion culture of marrow stromal osteoblastos in a dose-dependent manner", PNAS 99(20), 12600-12605.

Bártolo, P.J., Almeida H. and Laoui, T. (2009a) "Rapid prototyping \& manufacturing for tissue engineering scaffolds", International Journal of Computer Applications in Technology, 36(1):1-9.

Bártolo, P.J., Almeida, H.A., Rezende, R.A., Laoui, T. and Bidanda, B. (2008) "Advanced Processes to Fabricate Scaffolds for Tissue Engineering", in: Virtual Prototyping \& BioManufacturing in Medical Applications; B. Bidanda and P.J. Bártolo (Eds.) Springer, New York, 151-174.

Bártolo, P.J., Chua, C.K., Almeida, H.A., Chou, S.M. and Lim, A.S.C. (2009b) "Biomanufacturing for Tissue Engineering: Present and Future Trends", Virtual and Physical Prototyping, 4(4):203-216.

Bártolo, P.J., Kruth, J.P., Silva, J., Levy, G., Malshe, A., Rajurkar, K., Mitsuishi, M., Ciurana, J. and Leu, M. (2012) "Biomedical production of implants by additive electro-chemical and physical processes", CIRP Annals - Manufacturing Technology, 61(2):635-655. 
Begley, C.M. and Kleis, S.J. (2000) "The Fluid Dynamic and Shear Environment in the NASA/JSC Rotating-Wall Perfused-Vessel Bioreactor", Biotechnology and Bioengineering, 70(1):32-40.

Bhumiratana, S. and Vunjak-Novakovic, G. (2012) "Concise Review: Personalized Human Bone Grafts for Reconstructing Head and Face", Stem Cells Translational Medicine, 1:64-69.

Bilgen, B., Sucosky, P., Neitzel, G.P. and Barabino, G.A. (2006) "Flow Characterization of a Wavy-Walled Bioreactor for Cartilage Tissue Engineering", Biotechnology and Bioengineering, 95(6):1009-1022.

Billiet, T., Vandenhaute, M., Schelfhout, J., Van Vlierberghe, S. and Dubruel, P. (2012) "A review of trends and limitations in hydrogel-rapid prototyping for tissue engineering", Biomaterials, 33(26):6020-6041.

Bliem, R., Konopitzky, K. and Katinger, H. (1991) "Industrial Animal Cell Reactor Systems: Aspects of Selections and Evaluation". Advances in Biochemical Engineering/Biotechnology, 44:1-26.

Boontheekul, T. and Mooney, D.J. (2003) "Protein-based signalling systems in tissue engineering", Current Opinion in Biotechnology, 14:559-565.

Brown, M.A., Iyer, R.K. and Radisic, M. (2008) "Pulsatile Perfusion Bioreactor for Cardiac Tissue Engineering", Biotechnology Progress, 24(4):907-920.

Bueno, E.M., Bilgen, B., Carrier, R.L. and Barabino, G.A. (2004) "Increased Rate of Chondrocyte Aggregation in a Wavy-Walled Bioreactor, Biotechnology and Bioengineering, 88(6):766-777.

Butler, M. (2004). "Growth and maintenance of cells in culture". In: Animal Cell Culture and Technology; M. Butler (Ed.). London and New York: Garland Science/BIOS Scientific Publishers, Taylor \& Francis Group. $2^{\mathrm{a}}$ Ed., 55-73.

C.I.T., Centre for Tissue Engineering of the University of Pavia, Italy. http://cit.unipv.it/cit/gallery/main.php?g2_itemld=28 (Accessed in 20/10/2014)

Cabrita, G.J.M., Ferreira, B.S., Silva, C.L., Gonçalves, L., Almeida-Porada, G. and Cabral, J.M.S. (2003) "Hematopoietic stem cells: from the bone to the bioreactor", Trends in Biotechnology, 21(5):233-240. 
Caplan, A.I. and Bruder, S.P. (2001) "Mesenchymal stem cells: building blocks for molecular medicine in the 21st century", Trends in Molecular Medicine, 7(6):259-64.

Cartmell, S., Porter, B., García, A. and Guldberg, R. (2003) "Effects of Medium Perfusion Rate on Cell-Seeded Three-Dimensional Bone Constructs in Vitro". Tissue Engineering, 9(6):1197-1203.

Celik, I.B. (1999) "Introductory Turbulence Modeling”, Lectures, West Virginia University

Chen, C.S., Mrksich, M., Huang, S., Whitesides, G.M. and Ingber, D.E. (1997) "Geometric control of cell life and death", Science, 276:1425-1428.

Chen, H.C. and Hu, Y.C. (2006) "Bioreactors for tissue engineering", Biotechnology Letters, 28(18):1415-1423.

Chen, H.C., Lee, H.P., Sung, M.L., Liao, C.J. and Hu, Y.C. "A novel rotating-shaft bioreactor for two-phase cultivation of tissue-engineered cartilage", Biotechnology Progress, 20(6):1802-1809

Cooper Jr., J.A., Li, W.J., Bailey, L.O., Hudson, S.D., Lin-Gibson, S., Anseth, K.S., Tuan, E.S. and Washburn, N.R. (2007) "Encapsulated Chondrocyte Response in a Pulsatile Flow Bioreactor", Acta Biomaterialia, 3(1):13-21.

Démarteau, O., Wendt, D., Braccini, A., Jakob, M., Schäfer, D., Heberer, M. and Martin, I. (2003) "Dynamic compression of cartilage constructs engineered from expanded human articular chondrocytes", Biochemical and Biophysical Research Communications, 310(2):580-588.

Derakhshandeh, B. Vlassopolous D. and Hatzikiriakos S.G. (2012) "Thixotropy, Yielding and ultrasonic Doppler velocimetry in pulp fibre suspensions", Rheologica Acta, 51(3):201214.

Douglas, J. F., Gasiorek, J. M., Swaffield, J.A. and Jack, L.B. (2005) "Fluid Mechanics", 5th Ed., Pearson Education Limited, Harlow, UK.

Eshraghi, S. and Das, S. (2010) "Mechanical and microstructuralproperties of polycaprolactonescaffolds with one-dimensional, two-dimensional, and threedimensional orthogonally oriented porous architectures produced by selective laser sintering", Acta Biomaterialia, 6(7):2467-2476.

Fuchs, J.R., Nasseri, B.A. and Vacanti, J.P. (2001) "Tissue engineering: a 21st century solution to surgical reconstruction", The Annals of Thoracic Surgery, 72, 577-581, 2001. 
Ghosh, S. and Kaplan, D.L. (2008) "In vitro 3D Human Tissue Models for Osteochondral Diseases" in: Advances in Tissue Engineering, J. Polak, S. Mantalaris and S.E. Harding (Eds.), Imperial College Press, London, 781-819.

Gibson, L.J. (2005) "Biomechanics of cellular solids", Journal of Biomechanics, 38:377-399.

Godara, P., McFarland, C. D. and Nordon, R. E. (2008) "Design of bioreactors for mesenchymal stem cell tissue engineering". Journal of Chemical Technology and Biotechnology, 83(4): 408-420.

Gòdia, F. and Solà, C. (1995) "Fluidized-Bed Bioreactors - Review", Biotechnology Progress, 11(5):479-497.

Gomes, M.E. and Reis, R.L. (2004) "Biodegradable polymers and composites in biomedical applications: from catgut to tissue engineering. Part 2 Systems for temporary replacement and advanced tissue regeneration", International Materials Review, 49:274285.

Gross, K.A. and Rodríguez-Lorenzo, L.M. (2004) "Biodegradable composite scaffolds with an interconnected spherical network for bone tissue engineering", Biomaterials, 25:49554962.

Guillotin, B. and Guillemot, F. (2011) "Cell patterning technologies for organotypic tissue fabrication", Trends in Biotechnology, 29(4):183-190.

Hirschel, M., Gangemi, J.D., McSharry, J. and Myers, C. (2011) "Novel Uses for Hollow Bioreactors", Genetic Engineering \& Biotechnology News, 31(12).

Hoesli, C.A., Luu, M. and Piret, J.M. (2009) "A Novel Alginate Hollow Fiber Bioreactor Process for Cellular Therapy Applications", Biotechnology Progress, 25(6):1740-1751.

Hutmacher, D.W. (2001) "Scaffold design and fabrication technologies for engineering tissues-state of the art and future perspectives", Journal of Biomaterials Science. Polymer Edition, 12(1):107-124.

Hutmacher, D.W., Teoh, S.H., Ranawake, M., Chong, W.S., Ting, K.S., Chua, K.C., Myint, T., Puah, C.M., Foo, T.T. and Schantz, J.T. (2006) "Bioreactor for growing cell or tissue cultures", US Patent 2006/0019388 A1.

Jaasma, M.J., Plunkett, N. A. and O'Brien, F.J. (2008) "Design and validation of a dynamic flow perfusion bioreactor for use with compliant tissue engineering scaffolds", Journal of Biotechnology, 133(4):490-496. 
Janssen, F.W., Oostra, J., van Oorschot, A. and van Blitterswijk, C.A. (2006) "A perfusion bioreactor system capable of producing clinically relevant volumes of tissue-engineered bone: in vivo bone formation showing proof of concept", Biomaterials, 27(3):315-323.

Jeong, J.H., Kima, S.W. and Park, T.G. (2007) "Molecular design of functional polymers for gene therapy", Progress in Polymer Science, 32(11):1239-1274.

Kim, B.S. and Mooney, D.J. (2001) "Development of biocompatible synthetic extracellular matrices for tissue engineering", Trends Biotechnology, 16:224-230.

Klement, B.J., Young, Q.M., George, B.J. \& Nokkaew, M. (2004) "Skeletal tissue growth, differentiation and mineralization in the NASA Rotating Wall Vessel", Bone, 34(3):487498.

Korossis, S.A., Bolland, F., Kearney, J.N.,Fisher, J. and Ingham E. (2005) "Bioreactors in Tissue Engineering", in: Topics in Tissue Engineering, N. Ashammakhi and R.L. Reis (Eds.), Vol. 2 (ebook).

Kreeger, P.K. and Shea, L.D. (2002) "Scaffolds for Directing Cellular Responses and Tissue Formation in Biomimetic Materials and Design", in: Biomimetic Materials and Design: Biointerfacial Strategies, Tissue Engineering and Targeted Drug Delivery; A.K. Dillow and A.M. Lowman (Eds.) Marcel Dekker, Inc, New York, 283-309.

Kreke, M.R., Huckle, W.R., Goldstein, A.S. (2005) "Fluid flow stimulates expression of osteopontin and bone sialoprotein by bone marrow stromal cells in a temporally dependent manner", Bone, 36:1047-1055.

Kumar, S., Wittmann, C. and Heinzle, E. (2004) "Minibioreactors - Review", Biotechnology Letters, 26(1):1-10.

Kuppan, P., Sethuraman, S. and Krishnan, U.M. (2012) "Tissue engineering interventions for esophageal disorders - Promises and challenges", Biotechnology Advances, 30(6):1481-92

Langer, R. (1997) “Tissue engineering: a new field and its challenges”, Pharmaceutical Result, $14: 840-841$

Langer, R. and Vacanti, J.P. (1993) “Tissue engineering”, Science, 260:920-926.

Leong, K.F., Cheah, C.M. and Chua, C.K. (2003) "Solid freeform fabrication of threedimensional scaffolds for engineering replacement tissues and organs", Biomaterials, 24:2363-2378. 
Leong, K.F., Chua, C.K., Sudarmadjia, N. and Yeong, W.Y. (2008) "Engineering functionally graded tissue engineering scaffolds", Journal of Mechanical Behaviour of Biomedical Materials, 1:140-152.

Liu, C.Z. and Czernuszka, J.T. (2006) "On the development of biodegradable scaffolds for tissue engineering: a perspective", Materials Science and Technology, 12:2479-2488.

Lyons, E. and Pandit, A. (2005) "Design of Bioreactors for Cardiovascular Applications", in: Topics in Tissue Engineering, N. Ashammakhi and R.L. Reis (Eds.), Vol. 2 (ebook).

Mahajan, H.P. (2005) "Evaluation of chitosan gelatine complex scaffolds for articular cartilage tissue engineering", MSc Thesis, Mississipi State University, USA.

Martin, I., Wendt, D. and Heberer, M. (2004) "The role of bioreactors in tissue engineering", Trends in Biotechnology, 22(2):80-86.

Martin, Y. and Vermette, P. (2005) "Bioreactors for tissue mass culture: Design, characterization, and recent advances". Biomaterials, 26(35):7481-7503.

Matsumoto, T. and Mooney, D.J. (2006) "Cell instructive polymers", Advances in Biochemical Engineering/Biotechnology, 102:113-137.

Minuth, W.W., Strehl, R. and Schumacher, K. (2005) "Microreactor Optimisation for Functional Tissue Engineering", In: Bioreactors for Tissue Engineering: Principles, Design and Operations; J. Chaudhrui and M. Al-Rubeai (Eds.). The Netherlands: Springer, 19-42.

Mistry, A.S. and Mikos A.G. (2005) "Tissue engineering strategies for bone regeneration", Advances in Biochemical Engineering/Biotechnology, 94:1-22.

Mooney, D.J., Cima, L.G., Langer, R., Johnson, L., Hansen, L.K., Ingber, D.E. and Vacanti, J.P. (1992) "Principles of tissue engineering and reconstruction using polymer-cell constructs", Materials Research Society Symposium Proceedings, 252:345.

Nguyen, D.T., Brotherton, J.D. and Chau, P.C. (2005) "Enhancing cell viability with pulsating flow in a hollow fiber bioartificial liver", Biotechnology Letters, 27(19):1511-1516.

Nguyen, Q.H. and Choi, S.B (2012) "Optimal Design Methodology of Magnetorheological Fluid Based Mechanisms", in: Smart Actuation and Sensing Systems - Recent Advances and Future Challenges, G. Berselli, R. Vertechy and G. Vassura (Eds.), InTech, 347-382.

Niklason, L.E., Gao, J., Abbott, W. M., Hirschi, K. K., Houser, S., Marini, R. and Langer, R. (1999) "Functional Arteries Grown in Vitro", Science, 284(5413):489-493. 
Norotte, C., Marga, F.S., Niklason, L.E. and Forgacs, G. (2009) "Scaffold-free vascular tissue engineering using bioprinting", Biomaterials, 30(30):5910-5917.

Orr, D.E. and Burg, K.J.L. (2008) "Design of a Modular Bioreactor to Incorporate Both Perfusion Flow and Hydrostatic Compression for Tissue Engineering Applications", Annals of Biomedical Engineering, 36(7):1228-1241.

Park, J., Li, Y., Barthiaume, F., Toner, M., Yarmush, M. and Tilles, A. W. (2008) "Radial Flow Hepatocyte Bioreactor Using Stacked Microfabricated Grooved Substrates". Biotechnology and Bioengineering, 99(2):455-467.

Pazzano, D., Mercier, K.A., Moran, J.M., Fong, S.S., DiBiasio, D.D., Rulfs, J.X., Kohles, S.S. and Bonassar, L.J. (2000) "Comparison of Chondrogensis in Static and Perfused Bioreactor Culture", Biotechnology Progress, 16(5):893-896.

Porter, B., Zauel, R., Stockman, H., Guldberg, R. and Fyhrie, D. (2005) "3-D computational modeling of media flow through scaffolds in a perfusion bioreactor", Journal of Biomechanics, 38(3):543-549.

Pörtner, R. (2009) "Characteristics of Mammalian Cells and Requirements for Cultivation" In: Cell and Tissue Reaction Engineering; R. Eibl, D. Eibl, R. Pörtner, G. Catapano and P. Czermark. Berlin Heidelberg: Springer, 13-47.

Pörtner, R. and Giese, C. (2007) "An Overview on Bioreactor Design, Prototyping and Process Control for Reproducible Three-Dimensional Tissue Culture", in: Drug Testing In Vitro: Breakthroughs and Trends in Cell Culture Technology, U. Marx and V. Sandig (Eds.), Wiley, Weinheim.

Pörtner, R., Nagel-Heyer, S., Goepfert, C., Adamietz, P. and Meenen, N.M. (2005) "Bioreactor Design for Tissue Engineering", Journal of Bioscience and Bioengineering, 100(3):235245.

Pozrikidis, C., (2009) "Fluid Dynamics: Theory, Computation and Numerical Simulation", 2nd Ed., Springer, New York, USA.

Radisic, M., Marsano, A., Maidhof, R., Wang, Y. and Vunjak-Novakovic, G. (2008) "Cardiac tissue engineering using perfusion bioreactor systems". Nature Protocols, 3(4):719-738.

Redondo, J.M. (2014) "Topics on Environmental and Physical Geodesy", Class Notes, Polytechnic University of Catalonia, BarcelonaTech. 
Reverchon, E. and Cardea, S. (2012) "Supercritical fluids in 3-D tissue engineering", The Journal of Supercritical Fluids, 69:97-107.

Risbud, M. (2001) "Tissue engineering: Implications in the treatment of organ and tissue defects", Biogerontology, 2:117-125.

Rose, F.R. and Oreffo, R.O. (2002) "Bone Tissue Engineering: Hope vs Hype", Biochemical and biophysical Research Communications, 292:1-7.

Rouwkema, J., Rivron, N.C. and van Blitterswijk, C.A. (2008) "Vascularization in tissue engineering", Trends in Biotechnology, 26(8):434-441.

Sanz-Herrera, J.A., Garcia-Aznar, J.M. and Doblaré, M. (2009) "On scaffold designing for bone regeneration: a computational multiscale approach", Acta Biomaterialia, 5:219-229.

Schinagl, R. M., Kurtis, M. S., Ellis, K. D., Chien, S. and Sah, R. L. (1999) "Effect of Seeding Duration on the Strength of Chondrocyte Adhesion to Articular Cartilage". Journal of Orthopaedic Research, 17(1):121-129.

Schulz, R.M. and Bader, A. (2007) "Cartilage tissue engineering and bioreactor systems for the cultivation and stimulation of chondrocytes", European Biophysics Journal, 36(4):539-568.

Serra, M., Brito, C., Leite, S.B., Gorjup, E., von Briesen, H., Carrondo, M.J.T. and Alves, P.M. (2009). "Stirred bioreactors for the expansion of adult pancreatic stem cells", Annals of Anatomy, 191(1):104-115.

Singh, H., Teoh, S.H., Low, H.T. and Hutmacher, D.W. (2005) "Flow modelling within a scaffold under the influence of uni-axial and bi-axial bioreactor rotation", Journal of Biotechnology, 119(2):181-196.

Skalak, R. and Fox, C.F. (1988) “Tissue Enginering”, Alan R. Liss, New York.

Tabata, Y. (2001) "Recent progress in tissue engineering", Drug Discovery Today, 6:483-487.

Tan, K.H., Chua, C.K., Leong, K.F., Cheah, C.M., Gui, W.S., Tan, W.S., Wiria, F.E. (2005) "Selective laser sintering of biocompatible polymers for applications in tissue engineering", BioMedical Materials and Engineering, 15:113-124.

Tan, P.S. and Teoh, S.H. (2007) "Effect of stiffness of polycaprolactone (PCL) membrane on cell proliferation". Materials Science and Engineering: C, 27:304-308. 
Tessmar, J.K. and Gopferich, A.M. (2007) "Matrices and scaffolds for protein delivery in tissue engineering", Advanced Drug Delivery Reviews, 59:274-291.

Truscello, S., Kerckhofs, G., Van Bael, S., Pyka, G., Schrooten, J. and Van Oosterwyck, H. (2012) "Prediction of permeability of regular scaffolds for skeletal tissue engineering: A combined computational and experimental study", Acta Biomaterialia, 8(4):1648-1658.

Vasanthan, K.S., Subramanian, A., Krishnan, U.M and Sethuraman, S. (2012) "Role of biomaterials, therapeutic molecules and cells for hepatic tissue engineering", Biotechnology Advances, 30(3):742-752.

Vickers D. and Thomas, C.K. (2013) "Some aspects of the turbulence kinetic energy and fluxes above and beneath a tall open pine forest canopy", Agriculture and Forest Meteorology, 181:143-51.

Vozzi, G., Flaim, C., Ahluwalia, A. and Bhatia, S. (2003) "Fabrication of PLGA scaffolds using soft lithography and microsyringe deposition", Biomaterials, 24:2533-2540.

Wang, D., Liu, W., Han, B. and Xu, R. (2005) "The Bioreactor: A Powerful Tool for Large-Scale Culture of Animal Cells", Current Pharmaceutical Biotechnology, 6(5):397-403.

Wendt, D., Marsano, A., Jakob, M., Heberer, M. and Martin, I. (2003) "Oscillating Perfusion of Cell Suspensions Through Three-Dimensional Scaffolds Enhances Cell Seeding Efficiency and Uniformity", Biotechnology and Bioengineering, 84(2):205-214.

Zhang, Z.Y., Teoh, S.H., Chong, W.S., Foo, T.T., Chng, Y.C., Choolani, M. and Chan, J. (2009) "A biaxial rotating bioreactor for the culture of fetal mesenchymal stem cells for bone tissue engineering", Biomaterials, 30(14):2694-2704.

Zienkiewicz, O.C., Taylor, R.L. and Nithiarasu, P., (2005) "The finite element method for fluid dynamics". Elsevier, 6th Edition. 108-115. 